U.S. Department

of Transportation

National Highway

Traffic Sofehy

Administration

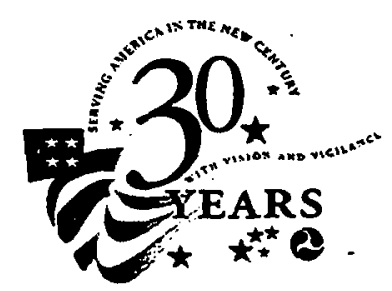

DOT HS 808676

July 1997

Technical Report

\title{
Characteristics and Conditions of Teenage Safety Belt Use
}


This publication is distributed by the U.S. Department of Transportation, National Highway Traffic Safety Administration, in the interest of information exchange. The opinions, findings and conclusions expressed in this publication are those of the author(s) and not necessarily those of the Department of Transportation or the National Highway Traffic Safety Administration. The United States Government assumes no liability for its contents or use thereof. If trade or manufacturer's name or products are mentioned, it is because they are considered essential to the object of the publication and should not be construed as an endorsement. The United States Government does not endorse products or manufacturers. 


\section{ACKNOWLEDGMENTS}

This study would not have been possible without the cooperation of many people who permitted the research team to survey at their facilities. We are grateful to each of the school administrators, restaurant owners, shopping center managers, church pastors, and others too numerous to mention by name, who willingly accommodated our data collection.

We gratefully acknowledge the participants of the study, the teens who took time to answer our questions as we interrupted their activities, and those who generously shared their opinions with us during the focus group sessions.

This study included many hours of labor intensive field work. The following individuals are credited with the successful acquisition of the data included in this study: Nada Trout, Shannon Frankel, Sandra Schoeneman, Alberto Castano-Pardo, Wanda Menges, Diana Wallace, and Stacey White. In addition, the authors acknowledge the contribution of Dr. Lindsay Griffin as focus group moderator and report reviewer.

The Information Technology and Exchange Center of TTI, headed by Susan Lancaster, lead the efforts in developing advertising campaigns targeting teenage part-time safety belt users and nonusers. The artwork for the campaigns was provided by Dick Westbrook of Houston, Texas. 
Tochaicel Report Decumentetion Poge

\begin{tabular}{|c|c|}
\hline $\begin{array}{l}\text { 1. Compono. } \\
\text { DOT HS } 808676\end{array}$ & 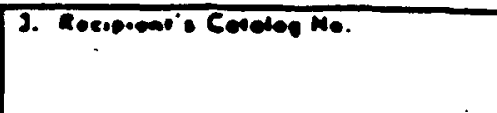 \\
\hline $\begin{array}{l}\text { Characteristics and Conditions of } \\
\text { Teenage Safety Belt Use }\end{array}$ & 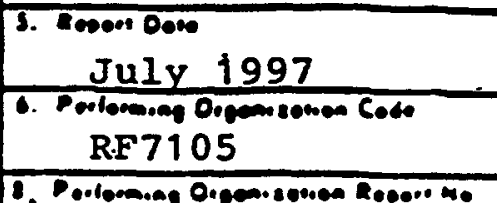 \\
\hline $\begin{array}{l}\text { 1. 4mo womack, Ratie N., Trout, Nada H., } \\
\text { Davies, Becky.J. }\end{array}$ & \\
\hline 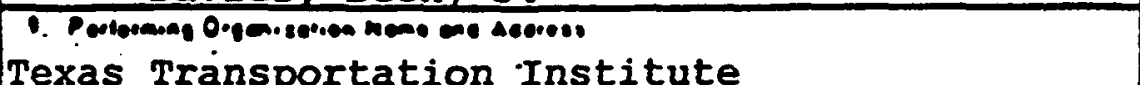 & 10. Tooe Uaou Mo (TRAis) \\
\hline $\begin{array}{l}\text { Texas A\&M University System } \\
\text { College Station, Texas 77843-3135 }\end{array}$ & $\begin{array}{l}\text { II Conevesi or Goent mo. } \\
\text { DTNH22-94-C-05010 }\end{array}$ \\
\hline 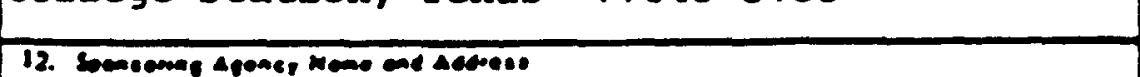 & 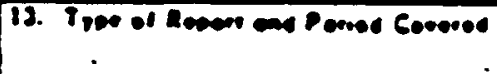 \\
\hline $\begin{array}{l}\text { U.S. Department of Transportation } \\
\text { National Highway.Traffic Safety Administration } \\
\text { Washington, D.C. } 20590\end{array}$ & 16. Iropenenop Aponer Code \\
\hline
\end{tabular}

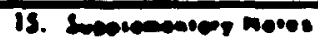

Technical Representative for NHTSA was Michael F. Smith.

10 Danoes

Safety belt use was observed for 7,384 vehicle occupants estimated as 15-19 years old in four states-Texas, Virginia, Idaho, and Mississippi. Age and other pertinent information was obtained from 2,330 teen occupants. Belt use ranged from 19.5 percent in Yazoo City, Mississippi to 57.6 percent in Charlottesville, Virginia. Teens more likely to be belted were: drivers, females, occupants of passenger cars, younger, had taken driver education, and lived in larger cities. Very few teens wore safety belts in the back seat. They were more likely to buckle up on the highway, and less likely to buckle up for recreational and short,-local trips. Teen passengers tended to make their restraint decision on a conditional basis more often than teen drivers.

Reasons most often given for lack of use included discomfort and lack of habit. Many teens, in focus group discussions, expressed doubts about the effectiveness of safety belts in a crash. For most teens in the discussion groups, parental influence seemed to be a greater influence on belt wearing behavior than peer pressure.

According to teens in the focus groups conducted in this study, effective approaches for improving belt use among teens should portray realistic consequences of not wearing safety belts. Habitual belt use can be promoted with parental influence at an early age, and with enforced primary use laws.

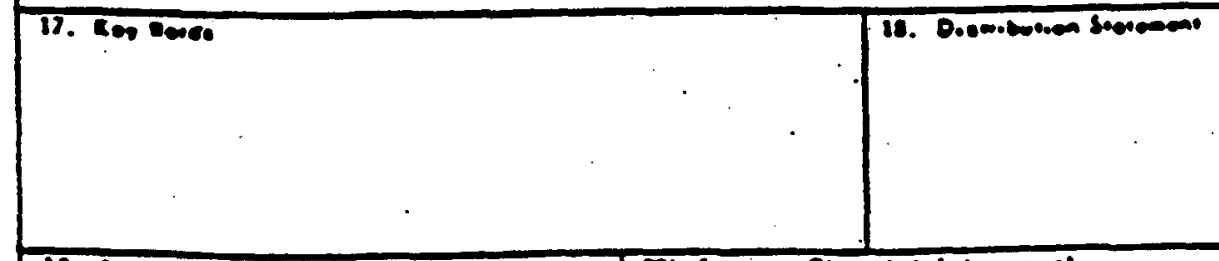

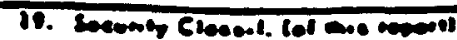

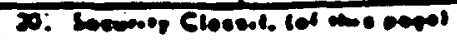

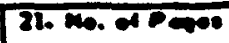

22 Pnes

Form DOT F 1700.7 B-721 Reproduction af form and coopleted pege is authorlsed 


\title{
CHARACTERISTICS AND CONDITIONS OF TEENAGE SAFETY BELT USE
}

\begin{abstract}
This study focused on achieving a better understanding of safety belt use patterns among 1519 year-old teenagers. A primary goal was to identify subgroups of teens who are part-time safety belt users, and to determine conditions in which belt use or non-use is made. Using this information, the study utilized focus groups to investigate methods to increase belt use among this age group, and evaluated the effectiveness of proposed alternatives for increasing use.

The study was conducted in one state with a primary safety belt law (Texas), and three states with secondary safety belt laws (Virginia, Idaho, and Mississippi). In each state, a metropolitan area and a small city or town were selected for inclusion in the study. Surveys of safety belt use were conducted in a variety of locations where teens were likely to be observed in different types of activities.
\end{abstract}

Safety belt use was determined for 28,326 occupants in 17,411 vehicles, 7,384 of whom were estimated as 15-19 years old. In addition, age and other pertinent information was obtained for 2,330 teen occupants in 1,453 vehicles.

Patterns of safety belt use for teens were found to be similar to those of the adult population at large, although the teenage usage rate was lower than the general usage rate in each area. Overall teen restraint use was estimated to be 57.6 percent in Charlottesville, Virginia, 56.8 percent in Houston, Texas, 44.0 percent in Navasota Texas, 42.7 percent in Boise, Idaho, 41.2 percent in Roanoke, Virginia, 31.8 percent in Mountain Home, Idaho, 26.4 percent in Jackson, Mississippi, and 19.5 percent in Yazoo City, Mississippi.

When position in the vehicle was taken into account, no statistically significant differences in driver restraint use between teens and older adults were found in Houston, Charlottesville, and Boise. Compared to older adults, significantly lower driver restraint use was observed for teens in Roanoke, Navasota, Mountain Home, Jackson, and Yazoo City.

Subgroups of teens who were more likely to use safety belts included drivers, females, occupants of passenger cars rather than pickups, younger and less experienced teen drivers. Additionally, those who had taken driver education were more likely to use safety belts, and those who were observed in the larger cities were more likely to be belted than those in smaller cities and towns.

Almost 60 percent of the teens interviewed said there were times or conditions in which they did not always wear their safety belt. . Very few said they wear them in the back seat. Teens were more likely to buckle up when driving on the highway, and less likely to buckle up for short trips in the city and when involved in recreational activities. Passengers were more likely than drivers to use safety belts on a conditional basis. 
Ten focus groups and one in-depth interview were held in the four study states to explore attitudes regarding safety belt use and approaches for influencing belt use behavior and attitudes. Teens who wore safety belts on a regular basis did so primarily because it was their habit. Although most of the full-time users believed in the safety benefit of wearing safety belts, they were not motivated entirely by an accurate perception of accident risk, or of crash dynamics. More commonly, they had used them from an early age, began wearing them in conjunction with learning to drive, or had been convinced by a first-hand accident experience or the experience of someone close to them. Habitual belt wearers often credited their parents for establishing their practice of using safety belts.

Focus groups to evaluate approaches for improving belt use among teens confirmed the appeal of realism, visual consequences and peer involved presentations when demonstrating the effectiveness of safety belt use. Focus group participants expressed a dislike for the use of animation, such as the Vince and Larry campaign, citing them as inappropriate conveyors of information that should be treated more seriously. The campaign alternative that was most appealing in most of the focus groups depicted death as a consequence for not wearing a safety belt. However, some regional variation was noted with regard to the appeal of various approaches, demonstrating the unlikelihood of a panacea advertising campaign for all teens.

Widespread endorsement of greater enforcement, higher fines, or parental steps to influence use was not found, although some of these factors did appear to be at work in the establishment of the belt wearing habit. An enforced, primary law was considered by the focus group participants to be a potentially highly effective approach for increasing consistent restraint use. 


\section{TABLE OF CONTENTS}

Chapter 1: Introduction ......................................................................................... Page 1

Chapter 2: Literature Review.................................................................................... Page 3

Chapter 3: ' Study Methodology.............................................................................. Page 9

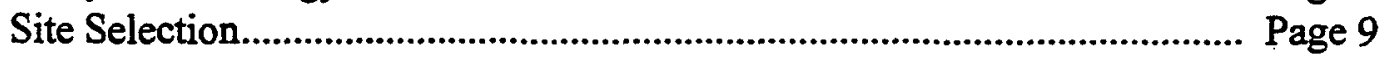

Data Collection-Observation Surveys.................................................... Page 12

Focus Group Method.................................................................................. Page 13

Chapter 4: . Observational Survey Results............................................................. Page 15

Safety Belt Use........................................................................................... Page 15

Verified Teenage Belt Use........................................................................ Page 19

Conditional and Situational Use................................................................. Page 26

Discussion Items........................................................................................ Page 28

Summary of Observational Survey Results................................................. Page 31

Chapter 5: Focus Group Discussions.................................................................... Page 33

Participant Selection and Recruitment ....................................................... Page 33

Results by Group .................................................................................... Page 35

Summary of Focus Group Results................................................................. Page 57

Chapter 6: Evaluation of Approaches to Increase Belt Use........................................ Page 60

Development of Approaches................................................................. Page 60

Evaluation of Approaches....................................................................... Page 66

Results of Safety Belt Campaigns Assessment........................................... Page 69

Message Delivery...................................................................................... Page 71

Results of Assessment of Other Approaches............................................. Page 71

Summary of Evaluation of Approaches to Increase

Safety Belt Use........................................................................... Page 73

Chapter 7: Conclusions and Recommendations....................................................... Page 74

Summary of Findings............................................................................ Page 74

Conclusions and Recommendations.............................................................. Page 76

Appendices: Appendix A--Observational Survey Instrument.......................................... Page 77

Appendix B-Individual Discussion Instrument........................................ Page 78

Appendix C-Assent/Consent Forms........................................................ Page 79

Appendix D-Dead at Seventeen ................................................................ Page 81

References: .......................................................................................................... Page 82 


\section{CHAPTER ONE}

\section{INTRODUCTION}

The ability to drive affords one a measure of freedom and independence that is highly valued in our automobile-oriented society. For teenagers in the United States, becoming an automobile driver is very often viewed as a rite of passage into adulthood. Tragically, this transition also leads to death for approximately 3,000 teenage drivers in the U.S. each year (USDOT, 1996). In fact, motor vehicle crashes are the leading cause of injury-related death for 15-19 year-olds in the U.S. This age group not only has the highest death rate for drivers, but also for their passengers, many of whom are also teenagers (USDOT, 1996).

Despite the availability of safety belts and the incontrovertible evidence of their injuryreducing effects, this highest risk age group is least likely to use them. The National Highway Traffic Safety Administration's (NHTSA) nationwide Motor Vehicle Occupant Safety Survey (Boyle,1995) found from telephone interviews that teenagers had the lowest rate of safety belt use. Observational surveys conducted by the Texas Transportation Institute (TTI) from 1985 to 1996 have shown that teenage drivers in Texas have been consistently the group least likely to use safety belts (Womack, 1996).

NHTSA commissioned the research described herein to determine why teenagers do not use safety belts more often and the best approaches to increase belt use for this group. Of specific interest were questions of "who, what, where, and why." In other words, who are the specific subgroups (if any) of teens who do not always use safety belts? What are the characteristics of teens who do and do not use safety belts? In what situations, or where do they not use them, and what are the reasons they give (the why) for their decisions?

To accomplish the above study objectives, teenagers in four states were observed in a variety of activities and situations involving motor vehicle travel. Demographic and other sociodemographic information was obtained from a sample of vehicle occupants. In addition, on-site discussions with 15-19 year-olds were conducted during which other conditions of belt use and nonuse were identified. These data provided the information needed to ascertain usage rates under varying conditions and to identify subgroups of part-time and non-users. Subsequently, focus groups were conducted in each of the four states to further investigate motivations and rationale for behavior and decision-making.

A final aim of this study was to provide recommendations for short and long-term strategies to increase teenage safety belt use. Additional focus groups were conducted in selected areas to elicit this target group's responses to a set of strategies and approaches developed from the information acquired through observation and data collection, and designed to increase safety beit use specifically among teens. 
This report documents the research performed to identify conditions of safety belt use for youth. Chapter Two is a summary of the literature review conducted in the early stages of the study. The research methodology is described in Chapter Three. Findings from each of the major tasks, the observational surveys, the individual discussions, and the focus groups, are described in Chapters 4-6. Chapter Seven summarizes the findings, conclusions, and provides study recommendations. 


\section{CHAPTER TWO}

\section{LITERATURE REVIEW}

In 1982, the Insurance Institute for Highway Safety declared that the major public health problem for teenagers in the United States was injuries in automobile crashes. Attesting to the continuing efforts to combat this problem, NHTSA, in 1994, proclaimed that traffic crashes are the number one killer of teenagers, and stressed that teens are involved in four times as many crashes as adults. Most studies of teenage automobile crashes focus on teenage drivers, yet the numbers of teenage deaths as passengers and as drivers has been about equal (Williams \& Karpf, 1983). There is a rise in the death rate of passengers which begins at age 13 , and these deaths are associated with motor vehicle crashes involving teenage drivers. In 1978, it was determined that 72 percent of the teen fatalities in automobile crashes occurred in vehicles driven by teenage drivers (Williams and Karpf, 1983). NHTSA reported in 1994 that nearly two out of three (63 percent) teenage passenger deaths occurred in vehicles driven by other teenagers (NHTSA, 1994). In emphasizing the significance of motor vehicle trauma as a public health priority, Sleet (1987) pointed out some disturbing probabilities: (1) that each person is likely to be involved in a crash every 10 years, and (2) that each of us has a 33 percent chance of suffering a disabling injury in a motor vehicle crash during a lifetime of driving. He added that the single most significant behavioral risk factor for sustaining an early death or disability is the failure to use safety belts.

It has been estimated that crash victims wearing a shoulder and lap harness are 56 percent less likely to suffer moderate or severe injury than are persons not wearing safety belts (Geller, Paterson, \& Talbott, 1982). Unfortunately, teenagers are not only the group at highest risk for traffic fatalities and injuries (Williams and Karpf, 1983), but also one of the groups with the lowest safety belt use rates (Williams, Wells \& Lund, 1983; Womack, 1994; Winnicki, 1995). Observational surveys conducted between 1985 and 1996 have shown that teenage drivers in Texas have been consistently the group least likely to wear safety belts (Womack, 1996).

Once the extent of a health problem such as teen motor vehicle death has been identified, the next step is to specify all behaviors that are related to the health problem. The strategies for motivating occupant protection have ranged from various engineering techniques and mass media campaigns to the enforcement of legal mandates requiring belt use. On January 1, 1985, New York became the first state to mandate safety belt use for front seat occupants (Preusser, Williams, \& Lund, 1987). Preusser et al. assessed the effect of New York's mandatory use law (MUL) on teenage drivers, and found that teens responded to the MUL with a substantial increase in belt use. However, both before and after enactment of the MUL, safety belt use by teens was lower than that of older drivers in the community in which the study was conducted. In Denmark, the use of safety belts has been mandatory since January 1976. A study conducted by Nordentoft, Kruse, Nielson, and Weeth (1978) demonstrated that 15 to 19-year olds responded to Denmark's safety belt law at only about half the rate of all older age groups. This group of researchers also reported that the initial positive effect of the MUL on traffic fatality reduction vanished during the second year after 
enactment even though the overall usage rates remained high. They attributed this outcome to the significant impact that high risk non-belt users have on traffic statistics (i.e., those persons who continue to refuse to wear safety belts are typically the ones who most need the protection they afford).

Any attempt to change human behavior must include a close look at the predisposing factors which likely perpetuate the behavior: that is, the knowledge, attitudes, and beliefs that individuals hold which either facilitate or block adoption of a health-positive behavior. Early observational and self-report studies claimed no relationship between driver belt use and age (Waller \& Barry, 1969; Robertson, O'Neill, and Wixom, 1972). However, Williams, et al. (1983) found that within five of six high schools and surrounding geographic areas where safety belt observations were conducted, voluntary belt use by other ages was more than double the student usage rate. Moreover, nonstudent belt use rates were more than five times as high at three of the locations. Their findings also revealed notable variation in overall belt use rates at the six locations, depending on the socioeconomic status of each of the study areas, with lower socioeconomic populations demonstrating lower safety belt usage rates. Williams et al. (1983) also pointed out the need for further research to determine the reasons why teenagers use safety belts less frequently within a variety of driving situations. As recently as 1993, Shinar conducted a study which extended and confirmed the findings of previous studies indicating consistent associations between belt use rates and demographic and socioeconomic variables. The principal finding of his study was that variability in belt use among sites is often associated with lower socioeconomic indicators and a high percentage of young people. This, he contends, often signals the presence of a potentially high risk population in need of safety measures specifically tailored to their needs.

NHTSA recently completed an evaluation of the effects of mandatory use laws on safety belt use, using the Fatal Accident Reporting System (FARS) data to examine fatalities and belt use nationally during the period since state laws have been enacted. This study confirmed many of the qualitative findings of earlier observational and telephone surveys. Lower belt use was found among occupants of pickups and vans, older vehicles, and occupants in the back seat. Lower usage was also found for occupants who had been drinking alcohol and for night-time fatalities. An increase in belt use was associated with age and for females. This study also confirmed "beyond any doubt that the enactment of a law is associated with increased safety belt use" (Winnicki, 1995, p.iii). Primary enforcement was found to be the most important aspect of use laws in affecting belt use rates. Additionally, higher usage rates were associated with higher fines.

In 1993, Schootman, Fuortes, Zwerling, Albanese, and Watson, conducted a study to determine the demographic factors associated with self-reported safety behaviors of adolescents. They found that teen safety belt usage was more prevalent in the front seat $(54 \%)$ than in the back seat $(15 \%)$ of a car, and that students from rural schools were even less likely to wear safety belts while riding in the front seat of a vehicle, an alarming conclusion since the injury rate on rural roads is typically wnuch higher than on urban roads. Unfortunately, the overwhelming majority of studies of safety belt user/non-user characteristics have targeted the adult population, with limited 
information available on younger drivers, who are often designated only as "college age" (Ferrari \& Carter, 1987).

More extensive research into the attitudinal factors involved in the non-use of safety belts has revealed that non-users typically make different decisions concerning other health-related behaviors and the consequences of those behaviors (Eiser \& Sutton, 1979). For example, Eiser and Sutton found that self-reported belt use was lower among smokers than non-smokers. A more revealing finding of their study was that non-belt users were more skeptical of the benefits of safety belt use than were belt users (i.e., only $52 \%$ of non-wearers believed that safety belts make driving safer compared with $92 \%$ of wearers). Loo (1984) studied 18 to 24 -year old drivers' attitudes toward compulsory belt use and the consistency of those attitudes with reported belt use. His research pointed out the need to focus on two types of non-users: those who disagree with mandatory use and never use belts (i.e., attitude and behavior are consistent); and those who agree with mandatory belt use but never use belts (i.e., attitude and behavior are inconsistent). He suggests that the latter group of non-users would be much more amenable to change. In a similar vein, Knapper, Cropley, and Moore (1976) maintained that the group most susceptible to change are those drivers who accept that safety belts work and evaluate their use favorably, but have never formed the habit of using them regularly.

NHTSA's Motor Vehicle Occupant Safety Survey (1995) compared teenagers 16-19 yearsold with those 21 and older as to the reasons they do use safety belts, and found that teen belt users were more likely than older users to agree with reasons posed for using them. That is, 98 percent of the teens surveyed used safety belts to avoid injury, while 94 percent of the older respondents used the same reasoning. This study found a major difference in motivation for wearing belts between teens and others to be the fear of sanctions, with teens being more inclined than others to say they wear safety belts to avoid a ticket. When asked to agree or disagree with statements concerning reasons for not wearing safety belts, teens were much more likely to be influenced by the other people in the vehicle. "Forgetting" and "being in a rush" were two primary reasons for not using safety belts that were more often cited by teens than by the older age groups.

An early literature survey conducted by Fhaner and Hane (1973a) confirmed consistent findings of a positive relationship between educational level and belt usage, and greater frequency of usage for highway than for city travel. They pointed out the lack of consistency in other individual variables, and suggested that the importance of situational variables has been underestimated. Later, Fhaner and Hane (1973b) focused on situations of safety belt use, noting that if situations could be shown to be a primary source of variation, there would be considerable value in analyzing the characteristics of high-use and low-use situations. However, the findings of their study indicated that the variation in safety belt use could be accounted for less by situational differences than by individual differences. It should be noted that their study was conducted very early in the history of the safety belt era (i.e., prior to the introduction of mandatory use laws and other efforts to promote safety belt wearing). Moreover, they suggested the use of a latent intermediate variable ("disposition for belt use") which, upon closer analysis, fluctuated along the continuum of situations within which drivers were most likely to use safety belts. 
More recently, Fockler and Cooper (1990) claimed that use of a "non-users" category was counterproductive to understanding the lack of safety belt usage in all driving situations. They felt that study of the situational use of safety belts should be undertaken to complement previous research on individual driver characteristics of belt users and non-users. They emphasized the reed for an "interpretive paradigm" wherein the actual situations of belt use or nonuse were identified and described from the driver's point of view. Their study found that, indeed, those persons observed not wearing safety belts also indicated that they do not behave consistently in all driving situations. Although they were able to delineate a few typical belt use and non-use situations, Fockler and Cooper concluded that more in-depth situational studies are needed in order to understand the socially accepted and shared perceptions of drivers in different situations. They also maintained that the important issue was how to increase the consistency of decision-making regarding safety belt use across a variety of different driving situations, and that successful promotion of safety belt use must be socially relevant to more drivers in more driving situations.

Ross, Greene, and House (1977) maintained that, due to the ambiguity of some social situations, there are often distortions in perceived consensus. This "false consensus effect" is an egocentric bias in interpreting social phenomena wherein we see our own behavioral choices and judgements as relatively common and appropriate to the circumstances (i.e., "everybody does it"). Adolescents, it is argued, may be particularly prone to egocentric attribution (Arnett, 1990; Dolcini et al., 1989; Enright, Shukla, \& Lapsley, 1980). The notion of adolescent egocentrism also includes the failure to differentiate between ideas that are unique to the individual and those that are more universally accepted. Such biases serve to exaggerate feelings of personal uniqueness, often leading adolescents to think that they are exempt from danger (Dolcini et al., 1989). This theory has been posited to account for the adolescent's predisposition to risk taking. Amett (1990) has argued that adolescents underestimate the probability that calamity will result from their risky behavior, thereby distorting the probability of a crash in their favor. This form of cognitive misjudgment has been cited as an explanation for the sense of immortality and invulnerability to harm often ascribed to the adolescent (Dolcini et al., 1989; Weinstein, 1980).

A great deal of traffic safety research and literature has been devoted to the risky behavior characteristic of the younger driver. Finn and Bragg (1986) found that young male drivers fail to perceive specific driving situations as being as risky as they are perceived by older drivers. Moreover, in spite of their limited driving experience, younger drivers are often more confident in their driving ability than older drivers (Matthews \& Moran, 1986). In general, people do not have accurate knowledge or perception of the risks they face (Lichtenstein et al., 1978; Shanteau, 1978), and the adolescent's dissociation between perceived and actual driving ability serves to enhance the tendency to view himself as immune from the effects of higher levels of risk. It has been argued that safety belts could increase one's feeling of safety and actually increase the amount of risk taking a driver is willing to engage in. However, contrary to this notion of danger compensation ( $O$ 'Neill, 1977; Peltzman, 1975), it has been shown that the use of vehicle safety devices such as safety belts do not necessarily encourage drivers to take greater risks. Rather, it is often the case that non-belt users are more likely to drive in ways that enhance the chances of being involved in a crash (Williams, et al., 1983). In empirical tests of these hypotheses, vonBuseck (1980) and Evans, 
Wasielewski, and vonBuseck (1982) all found that safety belt users did not follow other cars more closely, and Deutsch et al. (1980) determined that belt users are less likely to take the risk of running red lights than are non-belt usess,

Perceived driving safety (Svenson, Fischhoff, \& MacGregor, 1985) and probability of crash involvement (Slovic, Fischhoff, \& Lichtenstein, 1978) have both been closely tied to psychological investigations into the non-use of safety belts. Slovic et al., argued that the probability of death or injury on any single trip is likely too low to incite a motorist's concern for safety. The illusion of control (Langer \& Roth, 1975) combined with successive safe driving experiences may actually reinforce the driver for not wearing a safety belt, and lessen the chance that they will bother to buckle up on future trips. While Slovic et al. (1978) maintained that voluntary use of safety belts depended on motorists believing that their personal likelihood of being in a crash was high enough to justify wearing a belt, Svenson et al. (1985) found that safety belt use was only weakly related to their perceived effectiveness in preventing injury or fatality. Svenson et al. argue that providing more information about the effectiveness of safety belts is not as efficient as emphasizing other factors, such as comfort and adherence to the social norm, which cannot be outweighed by unrealistic optimism. Citing the positive correlation between a person's own reported belt use and estimation of others' use, they maintain that the ultimate success of safety belt promotion efforts lies in creation of a social norm, giving people the feeling that other drivers are using safety belts and it is all right to do so. Indeed, the image of the belted driver as either careful and responsible, or anxious and insecure (Fhaner \& Hane, 1974b) may contribute a great deal to one's attitude toward and use of safety belts.

The attitudes and behaviors of parents and peers in the use or non-use of safety belts can serve as potent reinforcers of the behavior. In a survey of high school students, Preusser, Williams, and Lund (1985) found that the process by which teens learn to drive and ultimately obtain a driver license is influenced to a large degree by the parents. Williams (1972) studied the factors associated with safety belt use in families, and noted a correlation between safety belt use of teens and parents. The modeling of safety belt use by parents is one of the best predictors of belt use by children (Lau, Quadrel, \& Hartman, 1990), and safety belt use is one of a constellation of health related behaviors highly influenced by parents and peers. Lau et al. maintained that modeling of behavior is the strongest socialization technique in the development of healthy lifestyles, and the most promising route for public health officials to adopt in the attempt to change those lifestyles.

Health education has recently been recognized as a promising preventive approach to changing individual health behaviors, and has been successfully directed at injury control and accident prevention. In addition to safety belt promotion, health education principles have been variously applied to automobile child restraint programs (Erikson and Gielsen, 1983); prevention of drinking and driving by young drivers (Basch, DeCicco, and Malfetti, 1989); and strategies to increase bicycle helmet wearing (Stevenson and Lennie, 1992). The focus group interview is one of the techniques that has been used to gather qualitative data concerning health related issues. By interacting with the group, researchers can probe more deeply into the "why" behind the behavior of interest, and encourage an exchange of ideas among group participants (Lederman, 1990). Basch 
(1987) claims that the focus group has been underutilized as a research technique in health education, and provides several examples of the successful use of focus groups with young people discussing such issues as teenage pregnancy and young driver behavior, including the use of safety belts. Basch et al. (1989) used the focus group technique to study the decision processes of young drivers with regard to drinking and driving. Although the majority of studies have used this technique with college age and adult populations, Stevenson and Lennie (1992) used the focus group approach with students from grade school through high school to research and develop strategies for increasing bicycle heimet wearing by this population. They were able to determine a number of beliefs and attitudes regarding helmet wearing, while "empowering" the groups of young people to develop the types of promotional strategies most likely to be accepted by young people. Emery et al. (1993) used the focus group.interview to identify salient issues in alcohol abuse by college students, and reported that this approach allowed them to assess the design of various message strategies, leading to programmatic changes at the health services level. The focus group setting is also useful in pretesting educational and other promotional materials prior to more widespread program adoption and evaluation, as a great deal may be learned from the ways in which health risks are perceived in different contexts by different individuals (Eiser and Harding, 1983).

Attempts to motivate the use of safety belts have gained a great deal of support from the behavioral sciences. Applied behavior analysis (Streff and Geller, 1986), behavior modeling (Cope, Johnson, and Grossnickle, 1990), and operant conditioning (Sleet and Geller, 1986) are but a few of the theory-driven attempts to promote the wearing of safety belts; and interventions based on social learning theory (Hawkins, 1992) emphasize the acquisition of such positive health habits during the crucial stage of adolescent development. Prior to the first legislation mandating the use of safety belts (1985), research was focused on the prediction of belt use (Jonah and Dawson, 1982; Jonah, 1984), and employed behavioral and social psychology models such as the "theory of reasoned action" (Budd, North, and Spencer, 1984; Wittenbraker, Gibbs, \& Kahle, 1983). Accordingly, the person's attitude toward the act, acknowledgment of the subjective norm regarding the behavior in question, and the person's motivation to comply were the best predictors of reported safety belt use.

Nelson and Moffit (1988) provided an overview of six theoretical frameworks that have been applied to efforts to increase safety belt use: theory of reasoned action; health belief model; fear arousal; operant conditioning; social learning theory; and diffusion theory. They suggested that it may be most desirable to combine theoretical approaches, keeping in mind that a theory is only as effective as its appropriate application. They emphasized the use of approaches that are simple to understand, easy to apply, appropriate for the setting, and previously demonstrated to be effective. In reviewing the effectiveness of various types of approaches for motivating safety belt use (for example, community awareness, educational, and incentive-based programs), Streff and Geller (1986) also stressed the need for a multifaceted attack on the problem. 


\section{CHAPTER THREE}

\section{STUDY METHODOLOGY}

This study focused on achieving a better understanding of the safety belt use patterns of teens. A primary goal was to identify subgroups of teens who are part-time belt users or non-users. Additionally, the study was performed to identify the conditions in which teens use safety belts. Teens were defined as 15-19 year-olds. A combination of observation surveys, individual discussions, and focus group discussions were the approaches used to collect data. Although sufficient data were necessary to provide reliable estimates for descriptive comparisons, the study was not intended to obtain a representative sample of the nation's 15-19 year-old population. Rather, sites were selected using specific criteria designed to highlight regional differences, Mandatory Use Law experience differences, and urban/rural differences.

\section{Site Selection}

The selection of sites for data collection was based on the intent to examine variables that might be associated with belt use. At a macro level, the existence and type of safety belt use law was a primary consideration. Sites were also selected to achieve regional variety, variety of licensure requirements, and a balance of urban and rural sites. The following four states and eight locations were selected for data collection:

Texas. Texas has a primary enforcement MUL (i.e, police may stop vehicles solely for belt law violations), and the fine for a safety belt citation in Texas is one of the three highest in the country (\$25-\$50). The minimum age for driver licensure with driver education is 16 , and the minimum age for licensure without driver education is 18 . In 1993 the statewide safety belt usage rate for front seat occupants was estimated to be 69 percent.

It is noteworthy that Texas has had an MUL with primary enforcement in place since September of 1985 . Therefore, the teenagers observed in this study have been subject to a primary MUL throughout their driving careers.

The two sites selected in Texas were:

Houston-a city of 1.6 million population in the coastal area of Texas. Houston has been a target city for safety belt observation in Texas since 1985. The data indicate that front seat occupant restraint use in Houston in 1994 was an estimated 69.2 percent.

Navasota-located approximately 70 miles northwest of Houston, Navasota has a population of 6,296. The nearest metropolitan area is the Bryan/College Station area 26 miles to the northwest. Occupant restraint use data were not available for Navasota. 
Virginia. Virginia has a secondary enforcement MUL (i.e., police must have some other reason to stop a vehicle before issuing a citation for safety belt nonuse), and the reported statewide usage rate in 1993 was 73 percent. Safety belt use by passengers through age 16 is the responsibility of the driver in Virginia, and the maximum fine for a first offense is \$25. Virginia's MUL was put into effect in January of 1988. The minimum age for licensure is 16 with driver education; applicants must be 19 years old to apply for a driver license without meeting the driver education requirement. The two sites selected in Virginia were:

Charlottesville-located in central Virginia, approximately 100 miles southwest of Washington, D.C. Charlottesville is the seat of both City and County governments, and is home to the University of Virginia. The population of the city is 40,512 and the Charlottesville SMSA which includes Albemarle, Fluvanna, and Greene Counties, is over 130,000 .

Roanoke--is located 168 miles west of the state capital of Richmond. The city's population is 96,397 and the 1990 SMSA Counties of Botetourt and Roanoke had a total population of approximately 224,000 .

Idaho. Idaho has a secondary enforcement MUL which went into effect in July of 1986 for drivers and front seat passengers in vehicles under 8,000 pounds. The fine for a safety belt violation is the lowest of any state in which a fine is assessed (\$5). The reported usage rate in 1993 was 59 percent. The minimum age for licensure is 15 with driver education (but driving is allowed during daylight hours only until age 16). In order to apply for a license without having taken driver education, applicants must be at least 17 years old. The two sites selected in Idaho were:

Boise--the capitol of Idaho and its largest city, with a population of 125,738. Boise is the location of Boise State University.

Mountain Home-located 45 miles southeast of Boise on Interstate 84, Mountain Home has a population of 8,900. Mountain Home is the site of a major air force base.

Mississippi. Mississippi was selected as a state with a secondary enforcement MUL, with a low level of compliance. The MUL in Mississippi was enacted in 1990 as a primary enforcement law with no penalties. It was amended in 1994 to include a $\$ 25$ fine and changed to a secondary enforcement law. In 1993 Mississippi's safety belt usage rate was estimated at 25 percent. In 1994 when this study began, teenagers in Mississippi were licensed at 15 with driver education, or without driver education they could obtain a 30-day permit that required a licensed adult in the front seat. After the 30-day learning period, the 15 year-old could be fully licensed. In September of 1995, the minimum age for full licensure changed to 16. The two sites selected in Mississippi were:

Jackson--the largest metropolitan area and capitol of Mississippi, with a population of 196,637. Jackson is the home of Jackson State University. 
Yazoo City--located 42 miles north of Jackson with a population of 12,427, Yazoo City is the county seat of Yazoo County.

To summarize, three of the eight sites selected were small towns under 15,000 population. These towns were intended to serve as settings for observations of the rural/small town environments in which teens drive. Four of the urban areas were between 90,000 and 300,000 population. They were selected as major urban areas of their states, and were intended to typify the urban driving environment for teens in Virginia, Idaho, and Mississippi. Houston, a major metropolitan area of over one million residents, was selected as one of the eight sites so that observations of teens in this type of urban driving environment could be made.

\section{Field Data Collection Locations}

A second layer of site selection was made within each community. These sites were selected to represent a variety of situations where teens could be observed. In each community the following observation sites were sought:

1. At least two high schools in the medium and larger urban areas. The literature indicates that lower socioeconomic status is correlated with lower safety belt use (Manheimer and Mellinger, 1964; Hunter, Stutts, Stewart, and Rodgman, 1988; Preusser, Blomberg, and Edwards, 1989; Wagenaar, Streff, Molnar, Businski, and Schultz, 1987; Shinar, 1993). To assure that the hypothesized relationship between teenage safety belt use and socioeconomic status was at least taken into account, high schools were selected to represent attendance zones of differing income levels whenever possible.

2. All high schools in the smaller towns. (Each smaller town had only one public high school.)

3. At least two fast food restaurants or similar establishments near each high school selected in the larger urban area, and one or more fast food restaurant(s) or similar establishment(s) in the smaller town.

4. At least two shopping centers in the larger urban area, and one or more shopping center(s) in the smaller town.

5. One or more high school event(s) such as a football game or other sports event, dance, or high school sponsored event in each survey city.

6. One or more popular recreational or "hangout" areas for teens in each survey city.

7. Four arterial intersections with high traffic volume in the medium and larger urban areas, and one arterial intersection with high traffic volume in the smaller town. 
Major arterial intersections were included for two reasons: 1) to provide an estimate of the safety belt use rate for the general population in the vicinity; and 2) to provide a condition in which teens might be observed as occupants in vehicles with other family members.

8. One university parking lot in cities where applicable.

9. One church in each small town, and one church in each area of the city where other observations were conducted in the larger cities.

The result was a variety of locations and situations across the targeted cities that included grocery stores, shopping malls, department stores, football games, volleyball games, soccer games, movies, video arcades, cruise routes, a haunted house, a concert; bars/nightclubs, many fast-food restaurants, service stations, convenience stores, a miniature golf course, a high school prom, church choir practice, prayer meetings, mass, and Sunday moming church services. In smaller and mediumsized cities, individuals were observed on multiple occasions engaging in a variety of activities.

\section{Data Collection-Observation Surveys}

Pilot observational surveys were conducted during the summer of 1995. Initially, researchers at other agencies who had conducted observational restraint use surveys on target populations were contacted to obtain copies of survey instruments. Using the materials gathered from this effort and the instruments in use by TTI for collecting restraint data, forms were developed for pilot testing. The instrument evolved to the form shown in Appendix A for collecting occupant restraint data.

The observational surveys took place from September through November 1995 in the four states given above. The sites tended to be clustered near high schools to capture the situations and activities participated in by high schoolers in the area. Observations at high school sites were made during arrival and departure times. Non high school commercial and event sites were observed at appropriate activity times, e.g., lunch time and immediately after school at fast food restaurants; date and hangout places on weekend nights; shopping centers on weekend days; etc. Prior permission was granted to conduct surveys on the premises of each survey location.

Arterial intersections were observed for two person-hours during an off-peak travel period and for two person-hours during a peak travel period. Data were collected for each occupant in vehicles stopped at the signalized intersection in the lane closest to the observer. Each observer collected data for a different direction of travel. Data at situational sites were collected by two observers at separate entrances or exits whenever possible. At these sites, data were recorded for any vehicle that had at least one teenage occupant anywhere in the vehicle. 
variables:

The observational survey instruments were designed to collect data for the following

Belt use (yes, no, and incorrect)

Gender

Age (estimated by observer)

Race/Ethnicity

Vehicle type

Number of vehicle occupants

Seat position of occupants

Time of day

Weather conditions

Survey teams also collected data to more fully describe conditions of belt use, reasons for non-use, and to isolate specific ages. Therefore, a segment of those observed at all sites other than arterial intersections were approached by a survey team member and asked to verify their age and discuss conditions under which they do not use safety beits. These individual discussions provided information regarding the following:

Beit use (yes, no, and incorrect)

Gender

Age (verified by occupant)

Race/Ethnicity

Vehicle type

Number of vehicle occupants

Seat position of occupants

Relationship of occupants to each other

Type of license of teen driver

Completion of driver education (yes, no, or in progress)

Frequency of belt use in eight different situations

Individual discussions were held with teen vehicle occupants in a random fashion, alternating selections of driver and passenger from any one vehicle. However, because the objective of the discussion procedure was to identify subgroups of non-users and part-time users, non-belted occupants were selected over belted occupants when a choice was made. The individual discussion guide is provided in Appendix B.

\section{Focus Group Method}

The next phase of the research involved conducting focus groups among teen subgroups defined during the observational surveys as non-users or part-time belt users. Groups were held in each of the study cities. The approach called for recruiting eight to ten participants for each group. 
In each city, at least one group was recruited from a high school location. Other groups were recruited from situational contexts in which low usage was observed.

The study staff approached primarily non-belted teens as they emerged from vehicles, explained the purpose of the focus group, which was scheduled to take place the next day at the same location, and gave them a set of permission forms (see Appendix C). The forms included a participant assent form describing the intent of the focus group, that videotaping would be done, and the expectations and compensation for the participants, a parental consent form, and an introductory letter. Teens were asked to bring completed forms with them to the focus group the following day. Each teen was compensated $\$ 10$ for their participation.

During the focus groups, the moderator led the teens through discussions of several topics. The discussions began on a general level on the topic of risk. After 15 to 20 minutes on this issue, the discussion was steered toward safety belt use. Once the specifics of safety belt use had been thoroughly discussed, the moderator did a bit more probing into the attitudes of the teens regarding issues related to safety belts. The final topic was a discussion of ways to encourage teens to wear safety belts more often. Each group was approximately $1 \frac{1}{2}$ to 2 hours long. When time permitted, the moderator added a post script to the group discussion as a form of evaluation. Participants were asked their general opinions of the activity, effects of the video camera, suggestions for improvement, and the suitability of the time, place, and compensation.

With the information gleaned from the 10 focus groups, and from the individual discussions conducted during the observational surveys, approaches for improving belt use for conditional and non-users were developed. These approaches were focus group tested in four locations-Yazoo City, Jackson, Houston, and Navasota. Students were recruited from high schools in Yazoo City, Houston, and Navasota, and from Jackson State University in Jackson. Safety belt use was observed for students recruited from school parking lots, but Yazoo City participants were selected by the Principal from student organizations in advance. 


\section{CHAPTER FOUR}

\section{OBSERVATIONAL SURVEY RESULTS}

Two types of data were collected using observational surveys. A set of observations was made at most sites to determine patterns of belt use for the general traffic, including teenagers. Data for a usable total of 28,326 occupants in 17,411 vehicles was obtained using this method. Of these occupants, 7,384 were estimated as 15-19 years old. A subset of vehicles $(1,453)$ with 3,010 occupants was sampled for more detailed information, such as age and other driving related information, as described in Chapter Three. Ages were verified for 2,330 teen occupants in this manner. The results were usually analyzed separately by state and city, given the variation in usage for each area.

\section{Safety Belt Use}

Table 4.1 gives the broadest view of restraint use for all of the traffic observations and compares the teenage usage rate with that of the population as a whole in each of the study areas. These data were collected from passing traffic (momentarily stopped), and therefore include all seating positions, and estimates of teen years. It is apparent from these data that, overall the teen belt use rate is lower for every location than the use rate for the general population observed.

Table 4.1. Safety Belt Use For General and Teen Population

\begin{tabular}{|c|c|c|c|c|c|}
\hline Location & $\begin{array}{l}\text { Total } \\
\mathbf{R} \\
\%\end{array}$ & $\begin{array}{l}\text { pulation } \\
\text { ained } \\
\mathbf{N}\end{array}$ & $\begin{array}{l}\text { T } \\
\text { Res } \\
\%\end{array}$ & $\begin{array}{l}\text { is } \\
\text { ined } \\
\cdot \mathbf{N}\end{array}$ & $\begin{array}{l}\text { \%-age Point } \\
\text { Difference }\end{array}$ \\
\hline $\begin{array}{l}\frac{\text { Texas }}{\text { Houston }} \\
\text { Navasota }\end{array}$ & $\begin{array}{l}70.5 \\
53.1\end{array}$ & $\begin{array}{l}4213 \\
1872\end{array}$ & $\begin{array}{l}56.8 \\
44.0\end{array}$ & $\begin{array}{l}854 \\
316\end{array}$ & $\begin{array}{r}-13.6 \\
-9.1\end{array}$ \\
\hline $\begin{array}{l}\text { Virginia } \\
\text { Charlottesville } \\
\text { Roanoke }\end{array}$ & $\begin{array}{l}64.5 \\
55.1\end{array}$ & $\begin{array}{l}5102 \\
3424\end{array}$ & $\begin{array}{l}57.6 \\
41.2\end{array}$ & $\begin{array}{r}1323 \\
818\end{array}$ & $\begin{array}{r}-6.9 \\
-13.9\end{array}$ \\
\hline $\begin{array}{l}\frac{\text { Idaho }}{\text { Boise }} \\
\text { Mountain Home }\end{array}$ & $\begin{array}{l}46.8 \\
43.1\end{array}$ & $\begin{array}{l}6473 \\
1375\end{array}$ & $\begin{array}{l}42.7 \\
31.8\end{array}$ & $\begin{array}{r}2346 \\
381\end{array}$ & $\begin{array}{r}-4.1 \\
-11.3\end{array}$ \\
\hline $\begin{array}{l}\text { Mississippi } \\
\text { Jackson } \\
\text { Yazoo City }\end{array}$ & $\begin{array}{l}33.0 \\
28.3\end{array}$ & $\begin{array}{l}3367 \\
2377\end{array}$ & $\begin{array}{l}26.4 \\
19.5\end{array}$ & $\begin{array}{l}800 \\
514\end{array}$ & $\begin{array}{l}-6.6 \\
-8.8\end{array}$ \\
\hline
\end{tabular}


Since each state in the study has Mandatory Use Laws (MUL's) that cover only front seats, it is appropriate to examine restraint use for the front seat only. A z-test using $\mathrm{p} \leq .05$ as a basis for statistically significant differences was used for the analysis. Table 4.2 shows that in Houston, Charlottesville, and Boise there was no statistical difference in driver restraint use between teens and older drivers; and in Charlottesville, Boise, Jackson, and Yazoo City, there was no statistical difference between teen passengers and older passengers. Teen front seat passengers were less likely than teen drivers to use safety belts in Houston and Boise, as were their adult counterparts. No statistically significant difference in teen driver and teen front seat passenger use was found in Navasota, Charlottesville, Roanoke, Mountain Home and Yazoo City. However, passengers 20 and older were significantly less likely than drivers to be belted in Virginia and Mississippi.

Table 4.2. Front Seat Restraint Use for Teens

Compared to Occupants 20 and Older

\begin{tabular}{|c|c|c|c|c|c|c|}
\hline \multirow{2}{*}{ Location } & \multicolumn{2}{|c|}{ Drivers Restrained } & & \multicolumn{3}{|c|}{ Passengers Restrained } \\
\hline & \begin{tabular}{cc}
\multicolumn{2}{c}{ Teens } \\
$\%$ & (N)
\end{tabular} & $\begin{array}{cc}2 & 20 \text { Years } \\
\% & \text { (N) }\end{array}$ & $\begin{array}{l}z \text {-test } \\
\text { value }\end{array}$ & \begin{tabular}{ll}
\multicolumn{2}{c}{ Teens } \\
$\%$ & (N)
\end{tabular} & $\begin{array}{l}\begin{array}{l}22 \\
\% \text { Years } \\
\%\end{array} \quad \text { (N) }\end{array}$ & $\begin{array}{l}z \text {-test } \\
\text { value }\end{array}$ \\
\hline $\begin{array}{l}\text { Texas } \\
\text { Houston } \\
\text { Navasota } \\
\text { z-test value }\end{array}$ & $\begin{array}{ll}78.6 & (608) \\
48.4 & (159) \\
& 7.03\end{array}$ & $\begin{array}{cc}78.5 & (2447) \\
56.9 & (1050) \\
12.42\end{array}$ & $\begin{array}{l}N S \\
2.00\end{array}$ & $\begin{array}{c}61.9(197) \\
43.4 \quad(136) \\
3.38\end{array}$ & $\begin{array}{cc}69.9 & (594) \\
54.7 & (318) \\
4.51\end{array}$ & $\begin{array}{l}2.03 \\
2.22\end{array}$ \\
\hline $\begin{array}{l}\text { Virginia } \\
\text { Charlottesville } \\
\text { Roanoke } \\
\text { z-test value }\end{array}$ & $\begin{array}{cc}68.2 & (613) \\
50.8 & (392) \\
5.53\end{array}$ & $\begin{array}{cc}70.3 & (2680) \\
64.1 & (1826) \\
4.34\end{array}$ & $\begin{array}{l}N S \\
4.81\end{array}$ & $\begin{array}{cc}63.5 & (477) \\
43.8 & (297) \\
5.43\end{array}$ & $\begin{array}{cc}62.4 & (745) \\
52.3 & (482) \\
3.50\end{array}$ & $\begin{array}{l}N S \\
2.32\end{array}$ \\
\hline $\begin{array}{l}\text { Idaho } \\
\text { Boise } \\
\text { Mtn. Home } \\
\text { z-test value }\end{array}$ & $\begin{array}{cc}50.0 & (1270) \\
37.0 & (219) \\
3.66\end{array}$ & $\begin{array}{cc}52.2 & (2884) \\
46.4 & (694) \\
2.49 & \end{array}$ & $\begin{array}{l}\text { NS } \\
2.75\end{array}$ & $\begin{array}{c}43.1 \cdot(782) \\
29.0(131) \\
3.25\end{array}$ & $\begin{array}{c}46.3 \quad(643) \\
52.1 \quad(192) \\
N S\end{array}$ & $\begin{array}{l}N S \\
4.31\end{array}$ \\
\hline $\begin{array}{l}\text { Mississippi } \\
\text { Jackson } \\
\text { Yazoo City } \\
\text { z-test value }\end{array}$ & $\begin{array}{ll}28.7 & (408) \\
21.2 & (222) \\
& 2.11\end{array}$ & $\begin{array}{cc}39.6 & (1806) \\
34.6 & (1227) \\
2.81\end{array}$ & $\begin{array}{r}4.33 \\
4.38\end{array}$ & $\begin{array}{cc}30.3 & (280) \\
21.5 & (200) \\
2.20\end{array}$ & $\begin{array}{c}28.6 \quad(402) \\
24.6 \quad(313) \\
\text { NS }\end{array}$ & $\begin{array}{l}N S \\
N S\end{array}$ \\
\hline
\end{tabular}

Another pattern illustrated in Table 4.2 is the difference in use between larger and smaller cities. In almost every case, restraint use in the major city was significantly higher than in the 
smaller town. One exception was Mountain Home's numerically higher usage rate than Boise's for passengers 20 and older. (The difference was not statistically significant.) Also, the difference between passenger restraint use for those 20 years-old and older in Jackson and in Yazoo city was not statistically significant. These major urban/small town differences in belt use were greater for teens than for older occupants.

While drivers and front seat outboard passengers are reported in Table 4.2, it is also important to note that the observed back seat belt use for teens was 10.9 percent $(\mathbb{N}=963)$. The back seat belt use rate for older passengers was 18.4 percent.

Additionally, Table 4.2 illustrates differences in safety belt use among the four states selected for the study. Belt use percentages for the observations were as expected, given the type of law in each state. That is, Texas, with a primary law, had the highest belt use; followed by Virginia, with a secondary law and previously reported high usage rates; followed by Idaho, with a secondary law and moderate usage rates; and followed by Mississippi, with a secondary law and previously reported low usage rates. The pattern of use for the general population, based on type of law, was mirrored by the teen population surveyed.

Tables $4.3,4.4$, and 4.5 provide more information about patterns of belt use in each location for the variables gender, ethnicity, and vehicle type. It is apparent from Table 4.3 that the expected relationship between gender and belt use holds true among teens. That is, males were significantly less likely than females to use safety belts in six of the eight locations. This relationship was not found, however, in the highest use and lowest use locations (Houston and Yazoo City, respectively).

Table 4.4 shows the percent belt use for each ethnic group identified in the observational surveys. In Texas, belt use did not appear to be related to ethnicity. There was not enough ethnic diversity to make any statements regarding Idaho. However, in Virginia and Mississippi, Anglo occupants were much more likely to be belted than Black occupants; and the Hispanic/American Indian, and Other categories had insufficient frequencies to make any statistical comparisons.

The relationship between vehicle type and belt use among teens is shown in Table 4.5. Statistically significant differences were found in Texas, Boise, and Yazoo City between car occupant and pickup occupant belt use. The differences found in Virginia, Mountain Home, and Jackson were not statistically significant. Similar differences were observed between car occupants and sport utility vehicle (SUV) occupants where large enough frequencies of SUV's were observed. 
Table 4.3. Occupant Restraint Use by Gender for Teens

\begin{tabular}{|c|c|c|c|c|c|}
\hline \multirow[t]{2}{*}{ Location } & \multicolumn{4}{|c|}{ Teens Restrained } & \multirow{2}{*}{$\begin{array}{l}\text { Z-test } \\
\text { of signi- } \\
\text { ficance }\end{array}$} \\
\hline & $\%$ & $\begin{array}{l}\text { les } \\
(\mathbb{N})\end{array}$ & & les & \\
\hline $\begin{array}{l}\frac{\text { Texas }}{\text { Houston }} \\
\text { Navasota }\end{array}$ & $\begin{array}{l}69.9 \\
33.3\end{array}$ & $\begin{array}{l}(471) \\
(174)\end{array}$ & $\begin{array}{l}72.5 \\
57.0\end{array}$ & $\begin{array}{l}(382) \\
(142)\end{array}$ & $\begin{array}{l}\text { NS } \\
z=4.3\end{array}$ \\
\hline $\begin{array}{l}\text { Virginia } \\
\text { Charlottesville } \\
\text { Roanoke }\end{array}$ & $\begin{array}{l}50.9 \\
35.7\end{array}$ & $\begin{array}{l}(638) \\
(415)\end{array}$ & $\begin{array}{l}63.8 \\
46.6\end{array}$ & $\begin{array}{l}(682) \\
(403)\end{array}$ & $\begin{array}{l}z=4.8 \\
z=3.2\end{array}$ \\
\hline $\begin{array}{l}\frac{\text { Idaho }}{\text { Boise }} \\
\text { Mtn. Home }\end{array}$ & $\begin{array}{l}34.7 \\
26.5\end{array}$ & $\begin{array}{r}(1158) \\
(196)\end{array}$ & $\begin{array}{l}50.5 \\
36.5\end{array}$ & $\begin{array}{r}(1188) \\
(189)\end{array}$ & $\begin{array}{l}z=7.8 \\
z=2.1\end{array}$ \\
\hline $\begin{array}{l}\text { Mississippi } \\
\text { Jackson } \\
\text { Yazoo City }\end{array}$ & $\begin{array}{l}14.6 \\
19.3\end{array}$ & $\begin{array}{l}(391) \\
(274)\end{array}$ & $\begin{array}{l}38.2 \\
20.0\end{array}$ & $\begin{array}{l}(403) \\
(235)\end{array}$ & $\begin{array}{l}z=7.8 \\
\text { NS }\end{array}$ \\
\hline
\end{tabular}

Table 4.4. Occupant Restraint Use by Race/Ethnicity for Teens

\begin{tabular}{|c|c|c|c|c|c|c|c|c|}
\hline Location & \multicolumn{2}{|c|}{ Anglo } & \multicolumn{2}{|c|}{ Black } & \multicolumn{2}{|c|}{ Hispanic/Am. Ind. } & \multicolumn{2}{|c|}{ Other } \\
\hline $\begin{array}{l}\text { Texas } \\
\text { Houston } \\
\text { Navasota }\end{array}$ & $\begin{array}{l}70.1 \\
42.9\end{array}$ & $\begin{array}{l}(365) \\
(191)\end{array}$ & $\begin{array}{l}70.1 \\
42.5\end{array}$ & $\begin{array}{r}(184) \\
(40)\end{array}$ & $\begin{array}{l}71.9 \\
47.6\end{array}$ & $\begin{array}{r}(253) \\
(84)\end{array}$ & $\begin{array}{l}76.1 \\
00.0\end{array}$ & $\begin{array}{r}(46) \\
(1)\end{array}$ \\
\hline $\begin{array}{l}\text { Virginia } \\
\text { Charlottesville } \\
\text { Roanoke }\end{array}$ & $\begin{array}{l}60.5^{\mathrm{a}} \\
46.1^{\mathrm{b}}\end{array}$ & $\begin{array}{r}(1119) \\
(624)\end{array}$ & $\begin{array}{l}36.3^{\mathrm{a}} \\
24.8^{\mathrm{b}}\end{array}$ & $\begin{array}{l}\text { (168) } \\
(169)\end{array}$ & $\begin{array}{l}44.4 \\
11.1\end{array}$ & $\begin{array}{r}(18) \\
(9)\end{array}$ & $\begin{array}{c}100.0 \\
45.4\end{array}$ & $\begin{array}{l}\text { (12) } \\
\text { (11) }\end{array}$ \\
\hline $\begin{array}{l}\frac{\text { Idaho }}{\text { Boise }} \\
\text { Mtn. Home }\end{array}$ & $\begin{array}{l}44.2 \\
32.3\end{array}$ & $\begin{array}{r}(2153) \\
(350)\end{array}$ & $\begin{array}{l}18.7 \\
12.5\end{array}$ & $\begin{array}{r}(16) \\
(8)\end{array}$ & $\begin{array}{l}25.8 \\
22.7\end{array}$ & $\begin{array}{l}(89) \\
(22)\end{array}$ & $\begin{array}{l}50.0 \\
50.0\end{array}$ & $\begin{array}{r}(26) \\
(4)\end{array}$ \\
\hline $\begin{array}{l}\text { Mississippi } \\
\text { Jackson } \\
\text { Yazoo Cit }{ }_{y}\end{array}$ & $\begin{array}{l}48.9^{\mathrm{c}} \\
28.0^{\mathrm{d}}\end{array}$ & $\begin{array}{r}(90) \\
(157) \\
\end{array}$ & $\begin{array}{l}24.4^{c} \\
16.0^{d}\end{array}$ & $\begin{array}{l}(680) \\
(338)\end{array}$ & $\begin{array}{l}00.0 \\
50.0\end{array}$ & $\begin{array}{l}(2) \\
(2)\end{array}$ & $\begin{array}{l}00.0 \\
00.0\end{array}$ & $\begin{array}{l}(0) \\
(0)\end{array}$ \\
\hline $\begin{array}{l}z=6.07, p<.01 \\
z=5.5, p<.01\end{array}$ & & $\begin{array}{l}c_{z}=4.44, \\
d_{z}=2.93,\end{array}$ & $\begin{array}{l}<.01 \\
<.01\end{array}$ & & & & & \\
\hline
\end{tabular}


Table 4.5. Occupant Restraint Use by Vehicle Type for Teens

\begin{tabular}{|c|c|c|c|c|c|c|c|}
\hline Location & \multicolumn{2}{|c|}{ Car } & \multicolumn{2}{|c|}{ Pickup } & $\begin{array}{l}z \text {-test } \\
\text { value }\end{array}$ & \multicolumn{2}{|c|}{ SUV* } \\
\hline $\begin{array}{l}\frac{\text { Texas }}{\text { Houston }} \\
\text { Navasota }\end{array}$ & $\begin{array}{l}73.7 \\
57.7\end{array}$ & $\begin{array}{l}(653) \\
(182)\end{array}$ & $\begin{array}{l}62.2 \\
22.0\end{array}$ & $\begin{array}{l}(119) \\
(109)\end{array}$ & $\begin{array}{l}2.41 \\
6.61\end{array}$ & $\begin{array}{l}62.6 \\
40.0\end{array}$ & $\begin{array}{r}.(83) \\
(25)\end{array}$ \\
\hline $\begin{array}{l}\text { Virginia } \\
\text { Charlottesville } \\
\text { Roanoke }\end{array}$ & $\begin{array}{l}57.9 \\
40.8\end{array}$ & $\begin{array}{r}(1106) \\
(718)\end{array}$ & $\begin{array}{l}49.5 \\
35.8\end{array}$ & $\begin{array}{l}(91) \\
(53)\end{array}$ & $\begin{array}{l}N S \\
N S\end{array}$ & $\begin{array}{l}61.9 \\
50.0\end{array}$ & $\begin{array}{r}(113) \\
(46)\end{array}$ \\
\hline $\begin{array}{l}\frac{\text { Idaho }}{\text { Boise }} \\
\text { Mtn. Home }\end{array}$ & $\begin{array}{l}46.2 \\
32.1\end{array}$ & $\begin{array}{r}(1733) \\
(246)\end{array}$ & $\begin{array}{l}33.6 \\
30.0\end{array}$ & $\begin{array}{l}(435) \\
(110)\end{array}$ & $\begin{array}{l}4.92 \\
N S\end{array}$ & $\begin{array}{l}30.4 \\
50.0 .\end{array}$ & $\begin{array}{r}(168) \\
(7)\end{array}$ \\
\hline $\begin{array}{l}\text { Mississippi } \\
\text { Jackson } \\
\text { Yazoo City }\end{array}$ & $\begin{array}{l}26.3 \\
20.0\end{array}$ & $\begin{array}{l}(706) \\
(384)\end{array}$ & $\begin{array}{r}16.0 \\
9.5\end{array}$ & $\begin{array}{l}(50) \\
(74)\end{array}$ & $\begin{array}{l}N S \\
2.64\end{array}$ & $\begin{array}{l}45.7 \\
35.5\end{array}$ & $\begin{array}{r}(35) \\
\text { (31) }\end{array}$ \\
\hline
\end{tabular}

${ }^{*}$ Sport Utility Vehicle

\section{Verified Teenage Belt Use}

The preceding tables give an indication of patterns of safety belt use among occupants believed to be 15-19 years-old who were observed in traffic surveys. The subset of observations that were made for stopped vehicles provided a more accurate assessment of age distinctions and other attributes of occupants. Belt use was identified for 2,264 teens 1519 years-old. Although a portion of these teens were the same as those observed in the above survey data, the overlap was not complete. Table 4.6 shows restraint use for all teens observed in the traffic survey in which age was estimated and in the subset of vehicles in which ages were verified by the occupants. The differences between the two data sets were not significant in Houston, Charlottesville, Jackson and Yazoo City. Belt use was significantly higher for the teens of known age in Roanoke, Boise, and Mountain Home, and significantly lower in Navasota. These differences can be explained partly by the differences in the types of sites where the more detailed information was obtained. For example, high school parking lots were the most common sites for age information to be given; whereas unverified ages were more likely to be recorded at cruise and major event sites. Belt use by site type is discussed later in this chapter. Table 4.7 compares belt use using estimates of age with belt use using verified ages for each age year. The estimates used in Tables 4.1 through 4.5 are comparable for each age up to 19 to the extent that one could surmise that the patterns reported for the teen group are reasonable estimates. 
Table 4.6. Safety Belt Use For Teen Population (Estimated Compared to Verified Ages)

\begin{tabular}{||l|rr|rr|r||}
\hline Location & \multicolumn{2}{|c|}{$\begin{array}{c}\text { Teens } \\
\text { Restrained } \\
\text { (Verified Age) } \\
\%\end{array}$} & \multicolumn{2}{|c|}{$\begin{array}{c}\text { Teens } \\
\text { Restrained } \\
\text { (Est. Age) } \\
\%\end{array}$} & $\begin{array}{c}\text { Percentage } \\
\text { Point } \\
\text { Difference }\end{array}$ \\
\hline Texas & & & & & \\
\hline Houston & 62.7 & 306 & 56.8 & 854 & -5.9 \\
Navasota & 28.0 & 164 & 44.0 & 316 & +16.0 \\
\hline Virginia & & & & & \\
\hline Charlottesville & 61.8 & 301 & 57.6 & 1323 & -4.2 \\
Roanoke & 57.7 & 260 & 41.2 & 818 & -16.5 \\
\hline Idaho & & & & & \\
\hline Boise & 49.7 & 495 & 42.7 & 2346 & -7.0 \\
Mountain Home & 42.2 & 142 & 31.8 & 381 & -10.4 \\
\hline Mississippi & & & & & \\
\hline Jackson & 28.8 & 371 & 26.4 & 800 & -2.4 \\
Yazoo City & 16.4 & 225 & 19.5 & 514 & +3.1 \\
\hline
\end{tabular}

4.7. Belt use By Age:

Estimated Compared to Verified Ages

\begin{tabular}{|c|cc|cc||}
\hline \multirow{2}{*}{ Age } & \multicolumn{2}{|c|}{$\begin{array}{c}\text { Restraint Use } \\
\text { Verified Age }\end{array}$} & \multicolumn{2}{c|}{$\begin{array}{c}\text { Restraint Use } \\
\text { Estimated Age }\end{array}$} \\
\cline { 2 - 6 } & $\%$ & $\mathbf{N}$ & $\%$ & $\mathbf{N}$ \\
\hline 15 & 43.80 & 395 & 42.86 & 847 \\
\hline 16 & 48.92 & 646 & 46.12 & 2296 \\
\hline 17 & 46.23 & 664 & 48.20 & 2089 \\
\hline 18 & 41.88 & 351 & 42.19 & 1159 \\
\hline 19 & 38.94 & 208 & 48.67 & 528 \\
\hline
\end{tabular}


Figure 4.1 shows safety belt use for each age across all sites. This graph indicates that, overall, 16 year-olds had the highest belt use and 19 year-olds had the lowest. While belt use tended to decrease with age beginning at age 16 , the differences for the group were not significant when compared using a Chi-square test.

Figure 4.1 Teen Safety Belt Use By Age

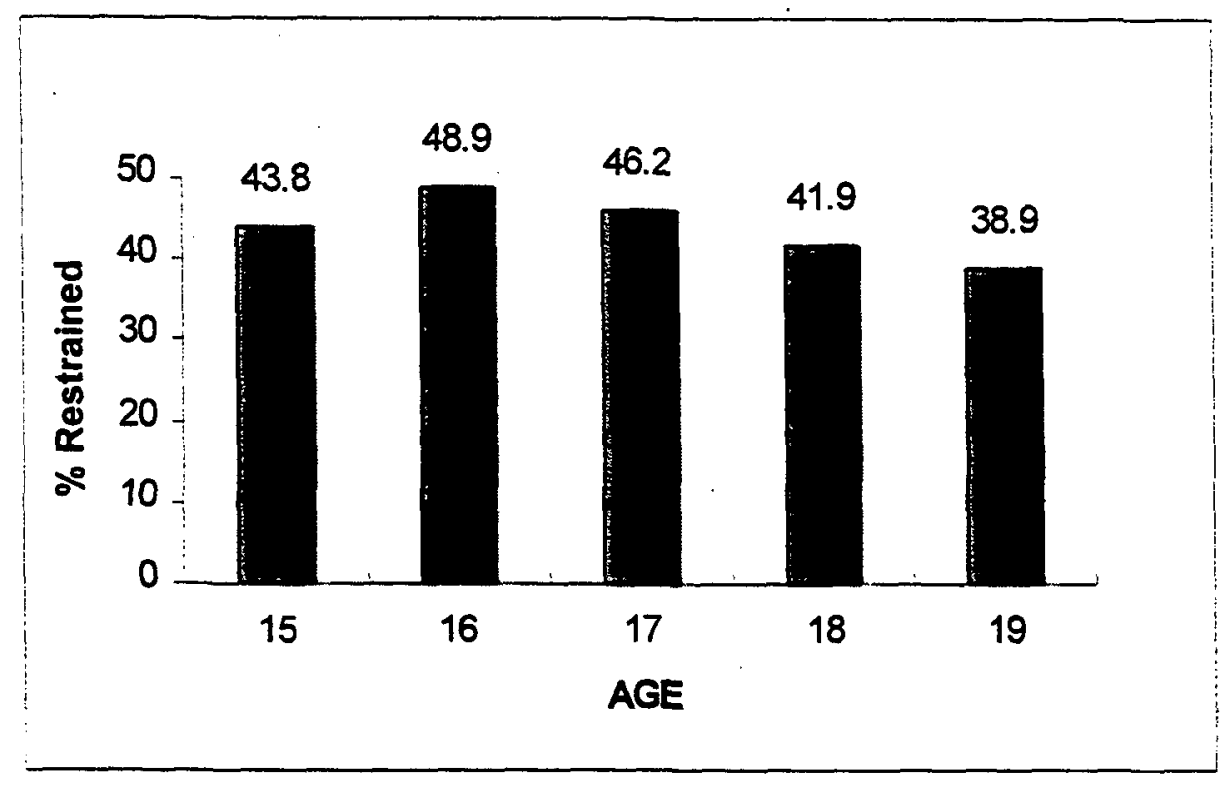

Table 4.8 gives belt use for each age observed and verified in the survey for each site. The sample sizes tended to be smaller in the upper ages (18 and 19) because many of the observations were made at high schools in the fall where the majority of teens encountered were 15-17 years old. Fifteen year-olds were also observed less frequently simply because fewer of them drive in each state.

Chi-square tests of significance revealed differences in belt use by age in two of the eight locations, Mountain Home and Jackson. In each of these sites, 17 and 18 year-olds had much lower belt usage rates. No statistically significant differences were found within the $15-19$ age group in the remaining six locations. 
Table 4.8. Occupant Restraint Use by Age

\begin{tabular}{|c|c|c|c|c|c|c|c|c|c|c|}
\hline \multirow[t]{2}{*}{ Location } & \multicolumn{2}{|c|}{15} & \multicolumn{2}{|c|}{16} & \multicolumn{2}{|c|}{17} & \multicolumn{2}{|c|}{18} & \multicolumn{2}{|c|}{19} \\
\hline & $\%$ & (N) & $\%$ & (N) & $\%$ & (N). & $\%$ & (N) & $\%$ & (N) \\
\hline Texas & & & & & & & & & & \\
\hline Houston & 56.6 & (53) & 69.4 & (72) & 65.2 & (92) & 56.3 & (64) & 64.4 & (25) \\
\hline Navasota & 32.0 & (25) & 27.9 & (61) & 22.5 & (40) & 32.1 & (28) & 30.0 & (10) \\
\hline Virginia & & & & & & & & & & \\
\hline Charlottesville & 46.0 & $(50)$ & 64.8 & (91) & 65.5 & (116) & 65.6 & (32) & 58.3 & (12) \\
\hline Roanoke & 34.1 & (38) & 62.5 & (80) & 56.0 & (75) & 74.4 & (39) & 57.1 & (28) \\
\hline Idaho & & & & & & & & & & \\
\hline Boise & 48.5 & (103) & 52.0 & (150) & 53.3 & (135) & 50.9 & (57) & 34.0 & (50) \\
\hline Mtn. Home* & 57.6 & (33) & 54.8 & (42) & 26.3 & (38) & 23.5 & (17) & 33.3 & (12) \\
\hline Mississippi & & & & & & & & & & \\
\hline Jackson** & 37.7 & (53) & 35.7 & (84) & 26.4 & (110) & 16.9 & (77) & 31.9 & (47) \\
\hline Yazoo City & 25.0 & (40) & 13.6 & (66) & 15.5 & $(58)$ & 16.2 & (37) & 12.5 & (24) \\
\hline
\end{tabular}

${ }^{*} X^{2}=12.7, \mathrm{p}=.013$

$* * X^{2}=9.9, \mathrm{p}=.042$

Figure 4.2 shows overall male and female belt use for each age. At age 15 safety belt use was virtually the same for males and females. For each progressive age up to 19 the gap between male and female belt use grew larger. However, the differences were significant only for the 17 and 18 year-old males and females $(z=2.859, p<.01$, and $z=2.921, p<.01$ respectively).

Differences in male and female safety belt use at each age were more pronounced for the driver. Figure 4.3 illustrates that male driver belt use was inversely related to age, and female driver belt use was higher than males at each age except 15 . The sample size for verified 15 year-olds was small for both genders (male $n=31$, female $n=39$ ). 
Figure 4.2 Overall Restraint Use By Gender By Age

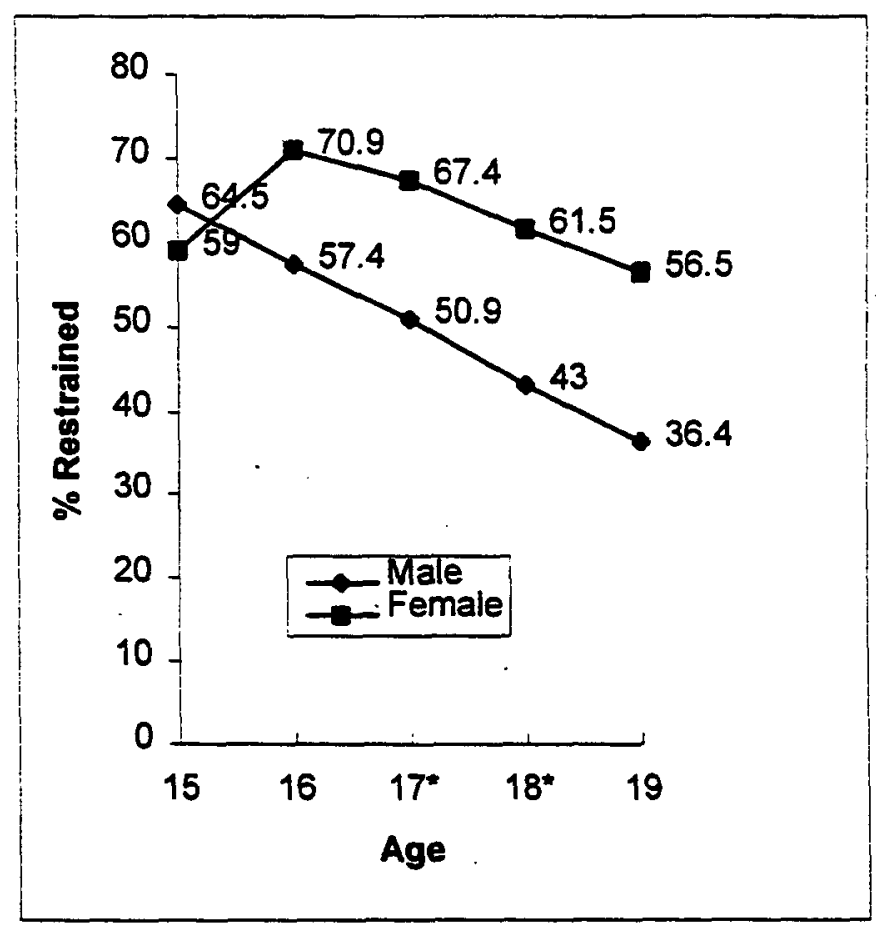

*Statistically significant differences between males and females.

Figure 4.3. Driver Restraint Use By Gender and Age

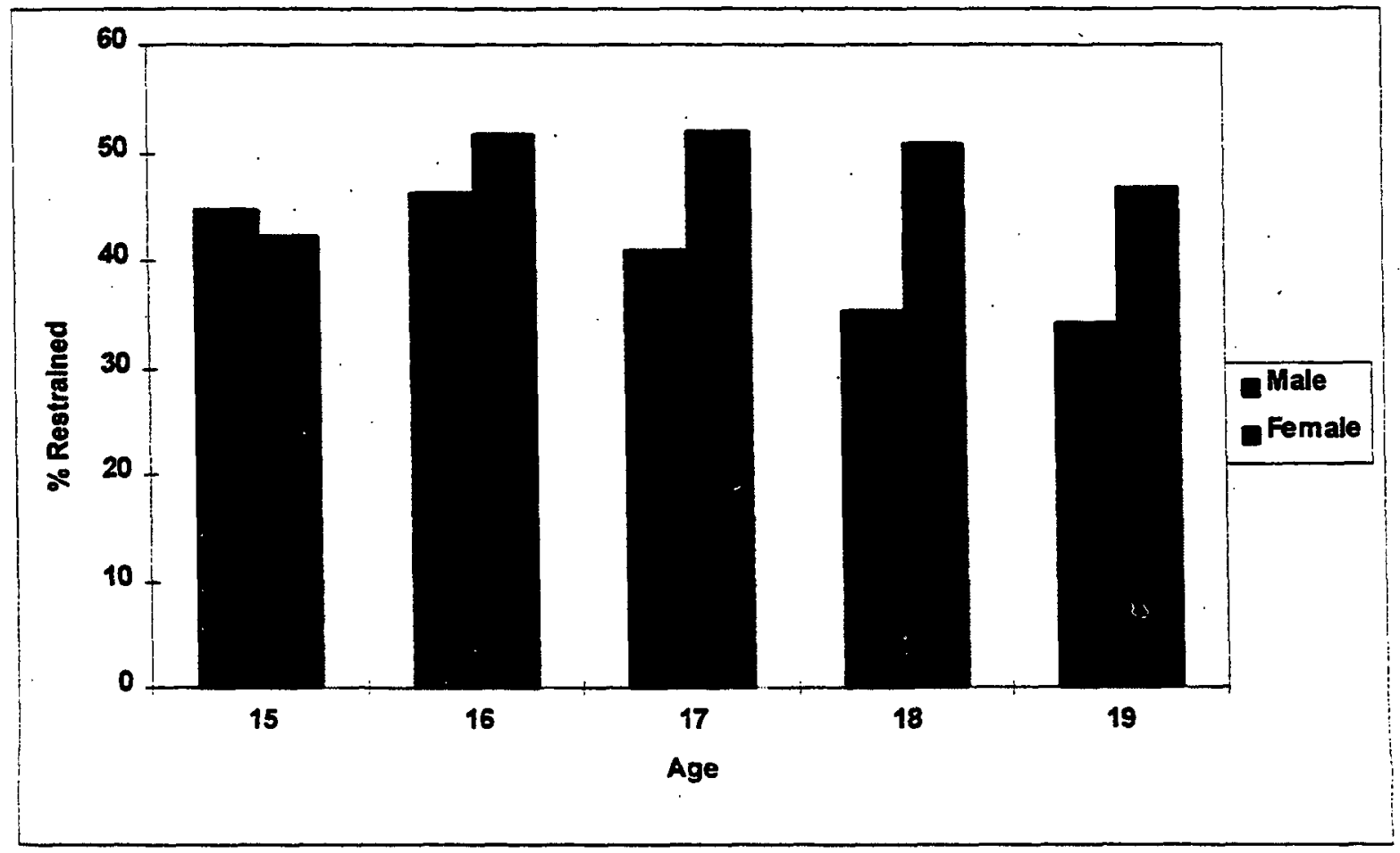


Type of license was found to influence safety belt use among teens, particularly those driving. The analysis is somewhat weakened by the small samples of 15 year-old licensed drivers and older-aged drivers without licenses or with beginner licenses. Even so, a pattern was detected indicating that new drivers or learning drivers were more prone toward belt use. As seen in Table 4.9, those with learner's permits or conditional licenses were the most prevalent belt users, and those with no license were least prevalent belt users. Only nine teens without a license were observed driving vehicles. Three of the nine were belted. At the other end of the continuum, 16 of the 18 drivers who were 15 years-old and held a learner's permit or conditional license were belted.

Table 4.9. Teen Occupant Restraint Use By Type of License

\begin{tabular}{|c|c|c|c|c|c|c|}
\hline \multicolumn{7}{|c|}{ ALL OBSERVATIONS } \\
\hline License Type & 15 & 16 & 17 & 18 & 19 & Total \\
\hline & $\% \quad(\mathrm{~N})$ & $\% \quad$ (N) & $\% \quad(N)$ & $\% \quad(\mathrm{~N})$ & $\% \quad(\mathrm{~N})$ & $(\mathbf{N})$ \\
\hline No License & $45.3(95)$ & $32.6 \quad(43)$ & $19.2(26)$ & 15.4 (13) & 0 & $35.2 \quad(182)$ \\
\hline Beginner License & $74.4 \quad(43)$ & $60.9 \quad(23)$ & $30.8 \quad(13)$ & $50.0 \quad(6)$ & 50.0 & 61.5 \\
\hline Operator License & $38.0(50)$ & $61.7 \cdot(326)$ & $56.1 \quad(360)$ & $50.3(191)$ & $42.9(126)$ & $54.5(1053)$ \\
\hline \multicolumn{7}{|c|}{ DRIVERS OBSERVED } \\
\hline No License & 100 & 100 & 20.0 & (1) & (1) & 33.3 \\
\hline Beginner License & 88.9 (18) & 66.7 & 66.7 & $50.0 \quad(2)$ & 66.7 & 76.3 \\
\hline Operator License & $46.2 \quad(26)$ & $68.4 \quad(247)$ & $65.8 \quad(263)$ & $56.1(139)$ & 43.3 & (793) \\
\hline
\end{tabular}

In cities other than Boise and Mountain Home, teens were asked if they had taken driver education. (This question was added subsequent to data collection in Idaho.) Of the 612 teens asked in Texas and Virginia, 93 had not taken driver education. Of the 354 teens asked in Mississippi, 184 had not taken driver education. Table 4.10 compares restraint use for those with and without driver education for each location, and across all locations. Those with driver education also included teens who were in the midst of taking driver education at the time of the observation.

Due to licensing requirements in Texas and Virginia, few teen drivers were interviewed who were not in the process of or had already completed driver education. For all three states, the impact of driver education on safety belt use was positive for teens. As shown in Table 4.10 the differences at the site level between those who did and those who did not have driver education ranged from 4.4 percentage points to almost 44 percentage points. Greater restraint use for driver educated teens 
was found at every age level (Table 4.11). However, it should be mentioned again that a majority of the teens surveyed who had not taken driver education were in Mississippi, where restraint use in general was lower.

Table 4.10. Teen Restraint Use by Driver Education

\begin{tabular}{|c|c|c|c|c|}
\hline Location & \multicolumn{2}{|c|}{$\begin{array}{l}\text { \% Restrained } \\
\text { With Driver } \\
\text { Education }\end{array}$} & \multicolumn{2}{|c|}{$\begin{array}{l}\text { \% Restrained } \\
\text { Without } \\
\text { Driver Education }\end{array}$} \\
\hline $\begin{array}{l}\frac{\text { Texas }}{\text { Houston }(N=165)} \\
\text { Navasota }(N=108)\end{array}$ & $\begin{array}{l}74.6 \\
32.0\end{array}$ & $\begin{array}{r}(N) \\
126 \\
75\end{array}$ & $\begin{array}{l}66.7 \\
21.2\end{array}$ & $\begin{array}{l}(\mathrm{N}) \\
39 \\
33\end{array}$ \\
\hline $\begin{array}{l}\text { Virginia } \\
\text { Charlottesville }(N=176) \\
\text { Roanoke }(N=163)\end{array}$ & $\begin{array}{l}72.7 \\
73.9\end{array}$ & $\begin{array}{l}165 \\
153\end{array}$ & $\begin{array}{l}54.5 \\
30.0\end{array}$ & $\begin{array}{l}11 \\
10\end{array}$ \\
\hline $\begin{array}{l}\text { Mississippi } \\
\text { Jackson }(\mathrm{N}=220) \\
\text { Yazoo City }(\mathrm{N}=134)\end{array}$ & $\begin{array}{l}40.9 \\
23.3\end{array}$ & $\begin{array}{r}110 \\
60\end{array}$ & $\begin{array}{l}25.5 \\
18.9\end{array}$ & $\begin{array}{r}110 \\
74\end{array}$ \\
\hline ALL (N=966) & 59.5 & 689 & 30.3 & 277 \\
\hline
\end{tabular}

Table 4.11. Teen Restraint Use by Driver Education and Age

\begin{tabular}{||c|cc|cc||}
\hline Age & \multicolumn{2}{|c|}{$\begin{array}{c}\text { \% Restrained With } \\
\text { Driver Education }\end{array}$} & $\begin{array}{c}\text { \% Restrained Without } \\
\text { Driver Education }\end{array}$ \\
\hline 15 & 68.6 & $(\mathrm{~N})$ & & $(\mathrm{N})$ \\
71 & 34.7 & 75 \\
\hline 16 & 64.3 & 213 & 25.0 & 64 \\
\hline 17 & 61.2 & 224 & 27.8 & 72 \\
\hline 18 & 51.6 & 126 & 34.2 & 38 \\
\hline 19 & 50.7 & 67 & 30.4 & 23 \\
\hline
\end{tabular}




\section{Conditional and Situational Use}

As evidenced in the review of literature, prior studies have documented characteristics of safety belt non-users to a large degree, and many of the findings for the observational surveys reported in this study follow fairly predictable patterns. This study was also designed to examine the conditions in which teens may choose not to use safety belts, and the situations that teens routinely find themselves in that may be related to less frequent safety belt use. The study was to determine if there are subsets of part-time users whose restraint behaviors are influenced by other people, events, or situations.

One variable hypothesized to have an effect on teen belt use was the other occupants of the vehicle, and specifically their relationship to the teen. When ages were verified with teen occupants, they were also asked if the other occupants were friends, family members, a date, or some other relationship to them. In 833 cases in which belt use was identified and age was verified, there was more than one person in the vehicle. Fifty-seven percent of the time, the multiple occupants were friends. Thirty-seven percent of the time, the other occupants were family members. And five percent of the time, the occupants were dates. (Note that many of the sites were date-type locations and many of the teens observed were in male/female pairs. However, most identified themselves as friends rather than dates.) Table 4.12 shows that belt use was about the same regardless of the relationship of the teen to other occupant(s). However, females were significantly more likely to wear safety belts when with friends than were males.

For teen drivers, there was no difference between belt use when driving alone versus when accompanied by others. The usage rate for teens driving alone in the vehicle was 58.1, and the rate for teens driving with others in the vehicle was 55.9 (z-test not significant).

Table 4.12. Teen Restraint Use By Occupant Relationship

\begin{tabular}{|c|c|c|c|c|c|c|c|c|c|}
\hline Restrained & \multicolumn{2}{|c|}{$\begin{array}{rr}\text { Alone } \\
\% & \text { (N) }\end{array}$} & & (N) & $\begin{array}{l}\text { Relative } \\
\% \quad \text { (N) }\end{array}$ & & (N) & \multicolumn{2}{|c|}{$\begin{array}{l}\text { Total Driving } \\
\text { W/Others } \\
\begin{array}{ll}\% & \text { (N) }\end{array}\end{array}$} \\
\hline $\begin{array}{l}\text { 15-19 Year- } \\
\text { Old Males }\end{array}$ & 50.0 & (424) & 39.4 & (264) & 43.5 (145) & 66.7 & (21) & 50.5 & (188) \\
\hline $\begin{array}{l}\text { 15-19 Year- } \\
\text { Old Females }\end{array}$ & 67.7 & $(362)$ & 50.2 & (209) & 47.6 (164) & 54.5 & (22) & 62.7 & $(150)$ \\
\hline Z-test Value & \multicolumn{2}{|c|}{5.12} & \multicolumn{2}{|c|}{2.36} & $N S$ & \multicolumn{2}{|c|}{$N A$} & \multicolumn{2}{|c|}{2.27} \\
\hline $\begin{array}{l}\text { Total } \\
\text { Restrained } \\
\end{array}$ & 58.1 & $(786)$ & 44.2 & (473) & (309) & 60.5 & (43) & 55.9 & (338) \\
\hline
\end{tabular}


As described in the methodology chapter, a variety of sites were selected to maximize the opportunity for observing teens in different contexts. For the analysis of situational restraint use, sites were grouped into five categories--high school, recreation, shopping, intersection and church. High school sites were surveyed during arrival and departure times, with contact for age verification made during the morning observations. When appropriate, observations were also made at lunch periods and for students leaving early for work study or with senior privileges. Recreation sites included the fast-food locations, cruising routes, sporting events, movies, and hang-out places. In situations where there was sufficient volume of teenage traffic, observations were made of the general traffic in conjunction with the verification of ages of teens observed in stopped vehicles. Otherwise, the survey was focused on individual discussions with teens in the recreational context. Shopping sites included both general traffic surveys and individual discussions, and included shopping malls, commercial strip centers, service stations, and grocery stores. Church sites included general traffic observation (depending on the activity) and individual discussions with teens. Church activities ranged from Sunday morning services to a weekend church-sponsored concert. Intersection sites consisted of collecting data from traffic momentarily stopped at major intersections. Very few ages were verified at the intersection sites.

Table 4.13 shows restraint use for each site category for each study location. Although the fewest data points were collected at church sites, greater belt use was observed for those where larger sample sizes were obtained than for other sites in the same cities. Across all sites, and usually within each city, higher usage was observed at the arterial intersection sites. This was not the case in Mississippi. There is some speculation as to why teens observed in general traffic may have shown greater belt usage than teens in other situations. One is over-estimation of restraint use in this type of survey, and Table 4.6 bears this out to a degree. Another is the higher frequency of occupants observed in front seat positions for the general traffic observation than for the other teen related activities in which they were observed.

In Boise, teens observed at high schools were more likely to be belted than those involved in some form of recreational activity. In the other seven cities the difference between teen use of safety belts in recreational situations and high school trips was not statistically significant.

In Jackson, restraint use among teens was fairly consistent across situations (the one exception being church which had a very low $\mathrm{N}$ of 28 but a high usage rate of 75 percent). Other sites showed a bit more fluctuation across situations. However, significant differences between high school, recreational, and shopping trips were observed only for Yazoo City as a higher than expected use was observed for shopping trips.

Across all sites, recreational and shopping trip restraint use were not different enough to be significant. However, restraint use was higher for church trips than all others, followed by arterial intersection observed restraint use, followed by trips to and from school. Restraint use for each of these situational conditions was greater than recreational and shopping conditions when all sites were combined. 
Table 4.13. Teenage Situational Restraint Use

\begin{tabular}{|c|c|c|c|c|c|}
\hline \multirow{2}{*}{ Location } & \multicolumn{5}{|c|}{ Situation } \\
\hline & High School & Recreation & Shopping & Intersection & Church \\
\hline $\begin{array}{l}\text { Houston } \\
\text { Navasota }\end{array}$ & $\begin{array}{ll}66.0 & (197) \\
44.1 & (204)\end{array}$ & $\begin{array}{ll}58.9 & (112) \\
51.6 & (122)\end{array}$ & $\begin{array}{c}64.5 \quad(138) \\
*\end{array}$ & $\begin{array}{ll}74.8 & (539) \\
40.4 & (47)\end{array}$ & $68.7 *(96)$ \\
\hline $\begin{array}{l}\text { Charlottesville } \\
\text { Roanoke }\end{array}$ & $\begin{array}{ll}57.4 & (909) \\
39.7 & (411)\end{array}$ & $\begin{array}{ll}56.2 & (422) \\
46.7 & (315)\end{array}$ & $\begin{array}{rr}48.4 & (62) \\
40.3 & (154)\end{array}$ & $\begin{array}{rr}70.0 & (80) \\
55.6 & (115)\end{array}$ & $\begin{array}{lr}64.2 & (151) \\
45.2 & (42)\end{array}$ \\
\hline $\begin{array}{l}\text { Boise } \\
\text { Mountain Home }\end{array}$ & $\begin{array}{ll}47.7 & (1701) \\
29.8 & (292)\end{array}$ & $\begin{array}{ll}32.2 & (659) \\
35.8 & (106)\end{array}$ & $\begin{array}{ll}41.3 & (242) \\
51.7 & (29)\end{array}$ & $\begin{array}{lr}51.1 & (180) \\
38.3 & (94)\end{array}$ & * \\
\hline $\begin{array}{l}\text { Jackson } \\
\text { Yazoo City }\end{array}$ & $\begin{array}{ll}26.0 & (550) \\
16.2 & (308)\end{array}$ & $\begin{array}{ll}25.4 & (205) \\
18.1 & (199)\end{array}$ & $\begin{array}{ll}26.7 & (206) \\
26.0 & (150)\end{array}$ & $\begin{array}{lr}25.8 & (182) \\
11.8 & (68)\end{array}$ & $?_{*}^{75.0}$ (28) \\
\hline All Sites & $43.0 \quad(3664)$ & 36.9 (1311) & $39.4 \quad(799)$ & $55.5 \quad(1305)$ & $64.7 \quad(278)$ \\
\hline
\end{tabular}

*Sample size under 25 .

\section{Discussion Items}

In addition to what was observed, teens were asked several questions about their restraint behavior. A large proportion of these conversations occurred in school parking lots. However, substantial numbers of teens were engaged in conversations in the parking lots of shopping centers, restaurants, and other recreational sites.

Random occupants were asked about the frequency with which they use safety belts in a variety of conditions: as a driver, a passenger, on the highway, in town, on trips to and from school, to and from work, when they are just having fun with friends, and on dates. They were also asked to give their reasons for use or non-use in these various conditions.

A portion of teens reported that their restraint use behavior was consistent across all situations. Just over 38 percent said they always buckled up no matter what the situation. Only 2.2 percent said they never buckled up regardless of the situation. The "always" responses were given more often in Houston and Charlottesville, and the "never" responses were more prevalent in Yazoo City and Jackson. Table 4.14 shows the consistent users and non-users for each study site. Teens who said they always buckled up gave reasons such as habit, the law, and "something I have grown up doing." Those who said they never wore safety belts tended to think they were unnecessary or to not think about them at all. 
Table 4.14. Belt Use By Teens: Self Reported Always and Never Use

\begin{tabular}{|l|c|c|c|}
\hline \multicolumn{1}{|c|}{ Location } & \% Always Use & \% Never Use & \# Interviewed \\
\hline Boise & 39.7 & 1.9 & 312 \\
\hline Charlottesville & 54.8 & 0.0 & 186 \\
\hline Houston & 59.5 & 0.5 & 173 \\
\hline Jackson & 22.5 & 4.0 & 227 \\
\hline Mountain Home & 32.1 & 1.2 & 81 \\
\hline Navasota & 23.9 & 0.8 & 117 \\
\hline Roanoke & 54.4 & 2.4 & 169 \\
\hline Yazoo City & 10.6 & 6.4 & 142 \\
\hline Total & 38.5 & 2.2 & 1407 \\
\hline \hline
\end{tabular}

Figure 4.4 illustrates self reported belt use for each of the conditions presented to the random sample of teen occupants. The situation in which teens, regardless of age, reported they wore safety belts most often was when on the highway. Over 85 percent of the 1,355 teens interviewed said they either always or most of the time wore their safety belt on the highway. Only seven percent said they rarely or never wore their belt on the highway. And 7.5 percent said they were part time safety belt users on the highway. The reasons given for wearing safety belts on the highway tended to center around the need for protection at higher speeds and the fear of a crash on the highway. Several teens also mentioned a greater likelihood of getting a ticket for not wearing a safety belt on the highway. Those who said they chose not to wear safety belts on the highway most often mentioned they were uncomfortable, and they like to lie down or sleep on trips.

The situations in which teens regardless of age, reported they wore safety belts least often was in the city and during recreational driving or riding. Approximately 69 percent of the teens interviewed reported they always or almost always wore their safety belts in the city, around town, and when they were just out for fun. Eighteen percent of those interviewed said they rarely or never wore safety belts when they were involved in recreational activities. The reasons they gave for choosing not to buckle up on these occasions included not thinking about it, not going very far, being uncomfortable, and not having a safety belt available or in working order. Only three people mentioned not wearing a safety belt when they were out with friends because of a perception of "not beirg cool." 
Figure 4.4 Self Reported Situational Belt Use

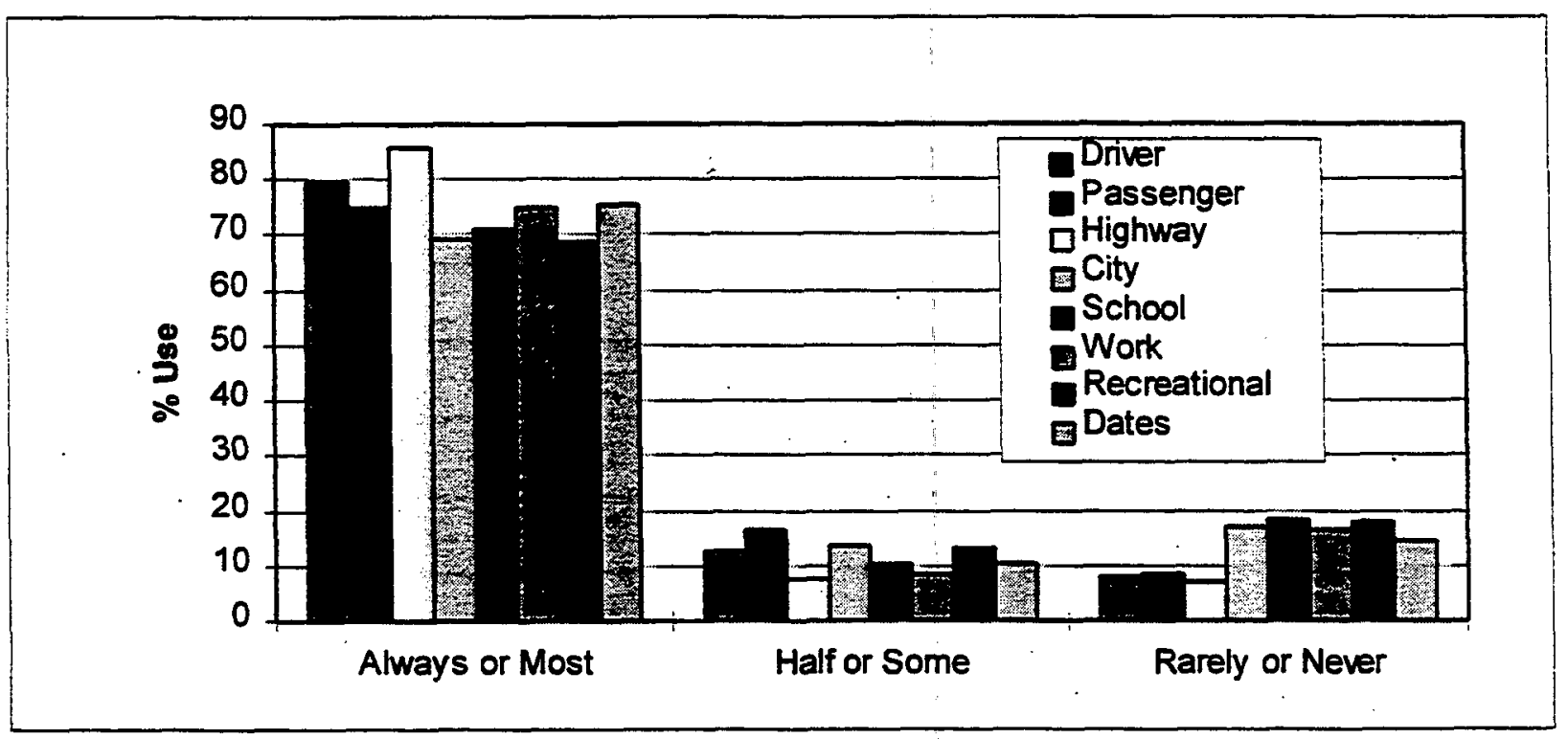

Seventeen percent of the teens interviewed said they very rarely or never buckled up when they were in a vehicle on city streets or in town. The most common reasons for lack of use were that they were only going a short distance, they did not feel safety belts were necessary in town, and they forget to put them on in town.

Approximately 13 percent said they wore their safety belts some of the time or about half the time in the city and for recreational trips. Those who buckled up during recreational situations gave the usual responses for why, such as out of habit and having automatic belts. However, a common response given for wearing belts under these conditions was that they did not trust their friends' driving. Additionally, eleven part-time belt wearers indicated they made their decision based on who was driving and how much they trusted the driver.

The highest percentage of part-time use was for the situation of being a passenger. Two major decision factors emerged in conversations with teens regarding their belt wearing behavior as passengers. Who they were riding with was a more important determinant for safety belt use than where they were going or what they were doing. This was most often expressed as "I don't trust my friends' driving," or "I trust my own driving more than someone else's." The other major factor was where in the car they were a passenger. Many reported they did not wear safety belts when they were a passenger in the back seat. Even those who reported they "always wore their safety belts" often said "except in the back seat" when asked if there were any exceptions. 


\section{Summary of Observational Survey Results}

Observational surveys were conducted in Texas, Virginia, Idaho, and Mississippi. Over 17,000 vehicles were observed, and restraint data were recorded for 28,326 occupants, 7,384 of whom were estimated as 15-19 years old. Ages and other pertinent information was obtained from 2,330 teen occupants in 1,453 vehicles.

Restraint use for teens followed a similar pattern as has been demonstrated for the general population of adult vehicle occupants in previous surveys. Specifically, higher belt use was found in the larger cities versus smaller cities within the same state. Usage rates, overall, for each state approximated usage rates reported in statewide surveys, and the teen usage rate tended to be lower. The lowest teen usage rates were observed in Mississippi (23.7 percent), the state selected for this study as a secondary law state with low usage rates in previously reported state surveys. The highest usage rates were observed in Texas ( 53.3 percent), the state selected for this study as a primary law state. And Virginia and Idaho results were relatively comparable to previously reported state usage rates.

Differences between teen usage rates and the usage rate for older occupants were not as disparate when location in the vehicle was taken into account. There were no significant differences in usage rates for front seat teen drivers and front seat older drivers in Houston, Charlottesville, and Boise.

Overall, belt use was higher among females than males. This gap widened with each age year after 15. Anglos were more apt to wear safety belts in Virginia and Mississippi. However, a relationship between ethnicity and belt use was not found in Texas, and the sample in Idaho was primarily Anglo.

Pickup drivers and passengers were less likely to wear safety belts in Texas, Idaho, and Yazoo City. These were also locations where higher numbers of pickups were observed.

The objective of this study was to go beyond estimating belt usage rates for teens. The primary purpose for conducting the study was to identify conditions for belt use among this group. Therefore, in addition to observing general demographic and vehicular characteristics, data were also collected from teens regarding their age, driver training, license type, their relationship to others in the vehicle, and their report of belt wearing patterns in situations other than the one in which they were observed.

Belt use by age was determined by asking a subset of teens their age: Results indicated that belt use was lowest for 19 year-olds and highest for 16 year-olds, and the difference was almost 10 percentage points. 
There was some indication that beginning drivers were more prone toward belt use. Over 76 percent of the drivers observed who had beginner permits were belted, compared to 59.5 percent of the teen drivers observed with operator licenses.

A major influence on safety belt use was driver education. In each of the study sites, those who had taken driver education were more likely to be belted.

The rate of safety belt use was about the same regardless of the relationship of teens observed to other occupants in the vehicle. Females were more likely to wear safety belts in the presence of friends than were males. The audience effect was not strong. No significant difference in belt use was observed between teens driving alone and teens accompanied by others.

For all sites combined, teenage restraint use was highest for church trips (64.7 percent). Teens observed in traffic at arterial intersections were restrained 55.5 percent of the time. Observations of teens going to or from high school revealed a range in use from 16.2 percent in Yazoo City to 66 percent in Houston, with an average across all sites of 43 percent. Teens engaged in shopping and recreational activities were restrained approximately 39 and 37 percent of the time, respectively.

During conversations with teens, 38.5 percent reported they always buckled up, no matter what the situation. Almost 60 percent admitted there were times or conditions in which they did not always wear their safety belt. The highest percentage of teens ( 85.5 percent) said they wore safety belts alwavs or most of the time on the highway. The lowest percentages of teens $(69.5$ percent and 68.9 percent) said they wore their belts in the city or during recreational activities. Passengers were most apt to use safety belts on a conditional basis, depending on who was driving and where they were riding in the vehicle. 


\section{CHAPTER FTVE}

\section{FOCUS GROUP DISCUSSIONS}

After observing and analyzing patterns of safety belt use in the eight study communities, the next step was to convene focus groups in each community. The purpose of conducting focus groups was to gain a better understanding of the reasons for restraint use or non-use or conditional use, and to explore the decision making process with this population subgroup.

\section{Participant Selection and Recruitment}

The goal in each community was to conduct focus groups comprised of 8 to 10 individuals. Since the primary issue of interest was reasons for restraint non-use or part-time use, locations were targeted where larger frequencies of non-users were observed in the observational surveys. However, as a matter of convenience, schools were also selected as recruiting sites and sites to conduct the group sessions. Given the site observational usage rates, the following group compositions and locations were planned:

\begin{tabular}{|c|c|c|c|}
\hline Location & $\underline{\text { Age }}$ & Gender & $\underline{\text { Site }}$ \\
\hline Boise & $\begin{array}{l}15 \\
19\end{array}$ & $\begin{array}{l}M \& F \\
M\end{array}$ & $\begin{array}{l}\text { high school } \\
\text { restaurant/arcade center }\end{array}$ \\
\hline Mountain Home & $17-19$ & $M \& F$ & $\begin{array}{l}\text { high school and convenience } \\
\text { store }\end{array}$ \\
\hline Houston & $\begin{array}{l}15 \\
18-19\end{array}$ & $\begin{array}{l}M \& F \\
M \& F\end{array}$ & $\begin{array}{l}\text { high school } \\
\text { cruise route }\end{array}$ \\
\hline Navasota & $16-17$ & $M \& F$ & high school or cruise route \\
\hline Jackson & $\begin{array}{l}17-19 \\
15-16\end{array}$ & $\begin{array}{l}\mathbf{M} \\
\mathbf{M}\end{array}$ & $\begin{array}{l}\text { nightclub } \\
\text { high school }\end{array}$ \\
\hline Yazoo City & $16-19$ & $\mathrm{~F}$ & high school or fast food chain \\
\hline Charlottesville & $\begin{array}{l}15 \\
15\end{array}$ & $\begin{array}{l}\mathrm{M} \\
\mathrm{F}\end{array}$ & $\begin{array}{l}\text { high school or movie theater } \\
\text { high school or movie theater }\end{array}$ \\
\hline Roanoke & $\begin{array}{l}15 \\
15\end{array}$ & $\begin{array}{l}\mathrm{M} \\
\mathrm{F}\end{array}$ & $\begin{array}{l}\text { high school } \\
\text { high school }\end{array}$ \\
\hline
\end{tabular}


The procedure for recruiting was to approach teens as they got out of vehicles; after first identifying their safety belt use. In most cases, teens were targeted who had not been wearing their safety belt. A very brief explanation of the focus group (usually to be held the next day) was given, followed by asking their age. If they met the age criteria, further information about the focus group was given, including mention of compensation, and the teen was asked to participate. If they agreed and were under 18, they were given a consent form to be completed by a guardian and turned in at the focus group on the following day. This procedure worked very well at the high school sites. However, at recreational sites the procedure proved more difficult for targeting the appropriate age and gender criteria while also securing a commitment of time away from the activity.in which they were engaged. Therefore, some adaptations were made in the field to attempt to recruit the target age and gender independent of location. For example, 18 and 19 year-old males in Jackson were not recruited from the nightclub where they had been observed in the previous survey, but instead were recruited from a male dormitory parking lot at Jackson State University. Also, the cruise site in Houston was abandoned in favor of a high school located one block off of the main cruise street. Therefore, the composition and locations of the focus groups held were as follows:

\section{Location}

Boise Group I

Mountain Home

Group I

Houston Group I

$$
\begin{aligned}
& \text { 7--15 year-old females } \\
& 4--16 \text { year-old females } \\
& 1--15 \text { year-old male }
\end{aligned}
$$

Houston Group II

Navasota

Group I

Jackson Group I
3--18 year-old males

3--18 year-old females

\section{Composition of Focus Group}

1--15 year-old female

2--16 year-old females

$1--15$ year-old male

2--16 year-old males

6--17 year-old females

1-17 year-old male

1-18 year-old male

2--16 year-old females

4--16 year-old males

2-17 year-old females

3--18 year-old males

6--19 year-old males
Site of Focus Group

high school

high school

high school

high school adjacent to cruise route

high school

Jackson State University 


\begin{tabular}{|c|c|c|}
\hline Jackson Group II & $\begin{array}{l}1--15 \text { year-old male } \\
6-16 \text { year-old males } \\
1--17 \text { year-old male }\end{array}$ & high school \\
\hline $\begin{array}{l}\text { Yazoo City } \\
\text { Group I }\end{array}$ & $\begin{array}{l}2-16 \text { year-old females } \\
3--17 \text { year-old females } \\
3--18 \text { year-old females }\end{array}$ & high school \\
\hline $\begin{array}{l}\text { Charlottesville } \\
\text { Group I }\end{array}$ & $\begin{array}{l}4-15 \text { year-old females } \\
4-16 \text { year-old females }\end{array}$ & high school \\
\hline $\begin{array}{l}\text { Charlottesville } \\
\text { Group II }\end{array}$ & $1--15$ year-old male & high school \\
\hline $\begin{array}{l}\text { Roanoke } \\
\text { Group I }\end{array}$ & $\begin{array}{l}2-15 \text { year-old females } \\
1--16 \text { year-old female } \\
3-15 \text { year-old males } \\
4-16 \text { year-old males }\end{array}$ & $\begin{array}{l}\text { restaurant for group, } \\
\text { recruited at high school }\end{array}$ \\
\hline
\end{tabular}

In addition to the groups above, a pilot group was conducted at the high school in Navasota, comprised of two 15 year-old females and two 16 year-old males.

Despite the fact that participants were recruited the day before the scheduled session, and that on the evening prior to the session, each participant was reminded by telephone there were a number of no-shows. Whenever possible, participants were over-recruited. In some cases, however, the opportunity for recruitment and the travel schedule necessitated some reduction in the number of participants, and even the total number of groups held.

Mention should also be made of the resulting composition of groups based on the emphasis on recruiting at schools. None of the participants were non-students. Additionally, because most of the groups were held immediately after school or during early evening hours on a weekday, students involved in extracurricular activities, and those with after school jobs were not very likely. to be available.

\section{Results By Group}

Boise Group: The group in Boise was comprised of six participants, three males and three females, who were 15 and 16 years old. Five of the participants were Anglo, and one was American Indian. As they were recruited, four of the participants were observed not wearing their safety belts. Belt use for two was not ascertained. Three participants had driver licenses, and three did not. 
Risk. Several of the participants in the Boise group had experienced accidents, so they considered themselves to be fairly cautious drivers. They did not consider Boise to be a very safe environment for driving. Mention was made that people run red lights a lot in Boise. Members of this group commented they thought, in general, their parents are safer and more skillful drivers because they have more driving experience and know the law better.

Although the members of this group did not acknowledge a great deal of risk-taking of their own, they reported riding with others who took driving risks on a frequent basis. These activities included speeding, taking curves too fast, and "piling-in lots of kids" in the car. The drivers in this group also admitted they exceeded the speed limit on freeways every day, usually by five to ten m.p.h.. On the "open road" or the Interstate they said they commonly drove $85 \mathrm{~m}$.p.h. Two drivers said they feel safe on the Interstate driving 100 m.p.h..

None of the participants said they ever drink and drive. Five of the six said they did ride with others who had been drinking, and this did not concern them greatly. In these situations, they claimed they had usually been drinking also, so their judgment was impaired.

Safety Belt Use. Safety belt use in this group ranged from "not much" to "feel naked without it." Those who were not inclined to wear their safety belts gave reasons such as: "I just don't worry about being in an accident;" "they're uncomfortable;" and "I just don't ever think about it."

Those who wore safety belts said they felt safer with them on. One participant commented, "you never know when something's gonna happen." Another said he wore his because he usually drove a small car and he felt he needed it.

Part-time use was reported in a few situations, such as when four-wheeling, when riding with parents, or when riding with others whom they judged not to be safe.

When asked if they believed safety belts save lives, those who said yes related accounts of friends or relatives who had survived crashes by virtue of being belted. One participant said she believed safety belts save lives in collisions, but she did not think she would be in one. The remaining participants thought safety belts were effective only sometimes, and gave anecdotal evidence to make their points.

Attitudes Toward the MUL. Members of this group were not certain of the requirements of the Idaho law. Several described the law as a primary one. They were not sure if it applied to riders in the back seat. They correctly identified the fine as $\$ 5$.

Half the group had the opinion that "people should be able to choose for themselves whether or not to wear safety belts." The other half supported the law and thought it should be enforced more than it was. 
No one in the group had ever received a safety belt citation. One participant had been in a collision after which a safety belt citation was issued to someone else in the car. No one else had any knowledge of anyone being cited for a safety belt violation in Boise. A discussion evolved during this focus group concerning the absence of safety belts on buses (inner city and school). The group felt belts were especially warranted on school buses, and particularly since the law required them in cars.

Approaches for Increasing Use. As mentioned previously, several members of this group were in favor of increasing enforcement of the safety belt law in Idaho, and believed this would encourage belt use. Someone also suggested increasing the fine.

One participant suggested the use of incentives to increase belt wearing behavior among teens. She said, "pay them to wear it." Someone else suggested fast-food coupons.

Several types of educational approaches were suggested by the moderator for comment. The group thought the ideas of posters and traffic safety experts speaking at assemblies were laughable. They agreed that a celebrity testimonial would be better received by their peers.

Participants described films as boring because they were "just cases, not real people." They indicated that a "real person" is necessary to deliver the message to evoke a response that "it could happen to me." Optimally, the "real person" would be someone in their age group who was a "paraplegic who survived because of a seatbelt."

The participants were asked if they recalled any safety belt commercials or campaigns. One male described in detail an "egg commercial." All the members of the group had seen it. Their reactions to it were: it was funny, weird, stupid, and made them laugh. No one said it affected their safety belt wearing behavior or would affect other teens' behavior. The group also recalled the crash dummy commercials. Each member of the group characterized these commercials as either stupid or funny. They all agreed they did not pay much attention to them, and did not feel they were effective. When asked what they thought would be an effective commercial, the group said it would need to depict real, live accidents that were somewhat gory.

Mountain Home: The group in Mountain Home was recruited by the principal of the school: The group had 11 participants, nine 17 year-olds and two 18 year-olds, nine females and two males. The ethnic composition was eight Anglos, two American Indian, and one Black. Safety belt use was not observed for any of the participants in this group, as they were recruited prior to the arrival of the focus group leaders in Mountain Home.

Risk. The teens in this group were of the opinion that Mountain Home, in general, was a safe place to drive. Many in the group were new.drivers, and as such they described themselves as somewhat nervous about their driving. They did not feel that being skillful necessarily prevented collisions. They did not see themselves as overly-cautious, and believed that driving should be fun and 
enjoyable. One member of the group, Billy (fictitious names are used in this report), considered himself a dangerous driver.

The types of dangerous driving they said they had done in the past included running a stop sign, being tired while driving, passing when they shouldn't, and being distracted by the radio. They described others in their age group who drive dangerously because they "think they're invincible."

When asked if anyone in the group ever speeds, the group gave a resounding yes. They claimed this to be a common practice by everyone, mostly on highways. Billy said he typically drove $100 \mathrm{~m} . \mathrm{p.h}$. to Boise.

When asked if anyone in the group ever drinks and drives, the group gave a resounding "no way." One person, Billy, said he had. The others said they always designated a driver, took the keys, or walked.

Safety Belt Use. Only one person in this group said he (Billy) did not wear his safety belt. He gave two reasons for not wearing it: 1) he did not see the need for it, and 2) he just did not like to wear it. However, Billy later said he requested that passengers in his vehicle buckle up because he was willing to take risks himself but did not want to put others at risk.

With the exception of one half-time user, the other members of the group reported they always wore their safety belts. The half-time user said the 50 percent of the time she wore it was when she was in a car with automatic belts, when she was with her Mother, and when she was on the highway.

About half of the group who always wore their safety belts said they had been influenced by their parents to wear them as children. One member of the group, Carl, had been involved in a serious crash and subsequently began wearing his safety belt. Several other members of the group said they had been convinced to wear safety belts after Carl's accident. Judy, who lived on a farm, said she even wore her belt the few feet when she had to get in and out to "get the gate." Another influence on belt use for this group was the mandatory requirement for safety belt use on the military base in Mountain Home.

Everyone in the group except Jennifer, the half-time user, believed in the effectiveness of safety belts in saving lives and reducing injuries. Jennifer said yes and no to this question and gave two example anecdotes of fatalities under both conditions of use.

Without prompting, and as an aside, the females in this group described a propensity to wear their safety belts incorrectly--under their arm, or behind their back. The reason given was for comfort and better fit.

Attitudes Toward the MUL. This group supported the Idaho mandatory use law. However, they were uncertain of its requirements and the fine. $\$ 50$ was the only amount mentioned. They did not 
feel the law needed to be enforced more because they were of the opinion that people should wear their safety belts for safety reasons, not because they were required by law to do so.

One person in the group had received a safety belt citation. According to her, the safety belt violation was her only offense and the reason she was stopped (although Idaho's law is a secondary one). Only one person had ever heard of anyone else being cited.

Approaches. The consensus among this group for the best way to encourage belt use among teens was to vigorously promote the benefits of using them. They agreed they thought teens would be most influenced by a live survivor. Several preferred statistical information to "a big bloody mess." Billy, the non-user, said taking his license away would convince him. He also said a $\$ 500$ fine would change his behavior, but "not until after he got caught."

The educational campaigns the group recalled were the egg commercials and the crash dummies. In both cases, they thought they were more funny than effective.

Houston Group I: This group was comprised of twelve students, 11 females and one male. Seven of the females and the male were fifteen years old. Four females were 16 years old. Four of the participants were Black and the remainder were Anglo. Eleven of the 12 were observed not wearing their safety belts when they were recruited. All 12 were passengers when observed. The one belted passenger was riding in the front seat. $A$ third of the group had taken driver education.

Risk. Many of the participants in this group were new drivers. They shared the opinion that they felt like they were in some ways better drivers than more experienced drivers because they were more cautious. They were less inclined to take risks because they did not want to make mistakes. However, they believed older drivers have a tendency to get comfortable and careless with their driving if they have not had an accident.

The flaws in their driving they mentioned were centered around not paying attention; e.g., listening to music, talking to friends, eating, and putting on makeup. They described many examples of friends, family, and themselves speeding and not paying enough attention to the point they felt they were in danger. They expressed confidence in their friends who.speed because they thought they knew what they were doing. They were not as confident in the driving ability of older adults, as described below:

Participant B: $\quad$...I'm used to teenagers and I'm not scared. But, like my Mom, she scares me when she drives....Teenagers know what they're doing and grownups don't.

Participant C: $\quad$ Around your own age, you're more comfortable with them. Your parents, they've been driving for years, but you know they're getting old and their eyes are kind of wearing out. And they're careless. 
Safety Belt Use. Most of the participants of this group were consistent safety belt users in the front seat. They considered themselves conditional users because they tended not to wear them in the back seat. The two who said they did not wear their safety belts all the time said they were uncomfortable and they just forget. Almost all the participants always wore their safety belt when they were with their parents, although they said their parents did not always wear their belts.

The members of this group wore their safety belts as an established habit. They did not indicate decision-making based on circumstances, situations, or peers. As one of the participants phrased it:

Participant G: To me, I don't even think about it. You know. I don't think, am I going to put my seatbelt on, where are we going? Who's driving? Am I going to get in a wreck? I just put it on. I guess because ever since I was little my Mom always said put your seat belt on. I used to hate having to make her tell me that, so I always just did it. I don't know why.

For the most part, this group recognized the life-saving and injury-reducing benefits of safety belts. However, they were not completely confident in their mechanical reliability.

Attitudes and Awareness of MUL. This group was very aware of the mandatory use law in Texas. They rode with others who had been given citations, and had family members who had been given safety belt citations. They mentioned that the sight of a policeman was enough to remind them or the occupants of their car to put their safety belt on. The following excerpt is an example of enforcement effects:

Participant D: $\quad$ My Mom...when we're driving...we'll see someone else pulled over and she'll say, do you have your seatbelt on?

Participant H: Boy, my Mom, she got a ticket once for not wearing her seatbelt. I had worn mine...and we were just going to the mall. It was just down the street. We just kept driving and driving, and that policeman kept looking at her, and she said, maybe he's looking at my vehicle. My sticker's not overdue or anything. And he turns the siren on and she pulls over, and she said, oh my God I forgot my seatbelt. I said, oh, yes you did. And so he came to the car and he said, ma'am, could I ask you a question? Why is it that your daughter is wearing her seatbelt and you don't? And she was mad and said, well, just give me my ticket, sir.

The participants in this group were in favor of the law in Texas. Eleven of the 12 thought it should be enforced more. The twelfth thought the current level of enforcement was appropriate. The group, in general, had an inflated notion of the amount of the fine for a safety belt violation. Estimates ranged from $\$ 50$ to $\$ 200$, and $\$ 83$ was an amount quoted by several. 
Approaches. During the discussion on approaches for increasing safety belt use, the group recommended that people stopped for not wearing seat belts should be required to attend a class in which movies similar to those they had seen in driver education class would be shown. These movies would graphically show the consequences of not wearing safety belts in collisions. The group emphasized the importance of reality based approaches that show consequences. One suggested that teens be taken to morgues and shown crash fatalities who had not been belted. They believed lecturing people or charging them a fine does not do enough to make them think that it could happen to them. This group was also particularly concerned that parents teach their children to wear safety belts, and that they serve as role models for this behavior. However, they thought educational efforts targeting their parents' age group were more or less wasted efforts because "it's too late for them."

Campaigns that they recalled as being particularly effective were anti-drinking and driving campaigns featuring videotape footage of real people who were later killed by drunk drivers. They mentioned the crash dummies as an example of commercials they did not think were effective. One participant said she had been afraid of them as a child. Others said they used to think they were cool, but not any more. They felt like the comical aspect of the cartoon characters took away from their effectiveness because "they're having crashes....and they always get back together."

When asked what would encourage them personally to wear their belts more consistently, their response was to be given more reminders in the vehicle. They recommended reminder notices on the dashboard, illuminated display reminders, voice reminders, pictures of their families with a reminder to buckle up nearby displayed in the car, and reminders from others in the car.

Houston Group II: Participants in Houston Group II were 18 year-old high school seniors. The group was comprised of four Anglos and two Hispanics, three males and three females. Belt use was determined as yes for two of the participants, and was not determined for the other four. They had all taken driver education.

Risk One participant cited night time as a time when risk is greater. All agreed that the risk is due to other drivers, not themselves. One mentioned the greater likelihood of drunk drivers at night. Another participant cited rush hour as a time when risk is greater. These urban drivers felt more comfortable on freeways than on major arterials, citing weaving traffic, high volume, and erratic stop and go traffic as bothersome and șometimes dangerous on major arterials.

Participants did not feel that their driver education had provided adequate training for being a good driver. Some felt that being a good driver required a great deal of practice. One female participant said: "some people are made to drive, some aren't. I think I was." One participant claimed to have slept throughout his driver education classes, and passed the test because it was "common sense." Several others claimed they did not get enough driving time in driver education, nor enough freeway experience during the behind-the-wheel portion. 
All agreed they drive dangerously at times. The types of dangerous moves mentioned included: cutting people off, weaving, driving too fast (especially with the radio on), driving too slow, and not paying attention. They said most of the time these behaviors were not prompted by the presence of someone else in the car. As one female said, "I don't think I ever try to show off when I'm with other people." However, they all admitted they rode as passengers with others whose driving they considered dangerous. They felt more at risk in these situations because as Ben pointed out: "When you're in the car with someone else...they think that they are in control. But you don't feel safe because you can't control it." Participants all voiced agreement with Ben's statement.

These high school seniors believed "old people" are the dangerous drivers on the road. The following excerpt accentuates this point:

Bob: $\quad$ And then old people.

Alicia: They drive me crazy.

Suzanne: You should retake driver's ed when you get older.

Bob: $\quad$ They drive too slow. They disrupt everyone else.

Alicia: They should tell you what $\mathbf{4 5}$ miles an hour is, if they go that speed.

Suzanne: I swear, when you hit, like 40 or something, you should have to retake driver's ed.

The group was very attuned to the dangers of drinking and driving. Several admitted they had done it in the past, but that was when they were younger and "not mature enough to be responsible." They strongly believed in designating a driver, taking the keys, or refusing to ride with someone who had been drinking.

Safety Belt Use. Most of the participants in this group were avid safety belt users. Only one person said she did not wear her safety belt all the time, and one said she always wore her safety belt while driving, but not while riding with her mom. The following excerpt is an example of the attitude that prevailed in this group:
Alicia: . I don't wear my seatbelt.
Richard: You don't? Why?
Alicia: I don't know.
Richard: You're stupid. You're in a jeep.

Several participants mentioned being ticketed in the past for not wearing a safety belt. One described the experience as "pretty embarrassing." In each case, participants said they were pulled over for the safety belt violation, and were not violating any other laws.

Several participants mentioned that their parents did not wear safety belts. The group's rationale for this behavior was that "they're not used to it." They believed their parent's age group was less likely to wear safety belts than their own peers. 
Aside from the two mentioned previously who admitted not wearing their safety belts, the participants were fairly consistent users. The conditions mentioned in which they would choose not to use a safety belt were when in the back seat, or in a large pickup. Both of these conditions are not covered by the Texas mandatory use law. Furthermore, the group did not feel there was any stigma attached to wearing a safety belt when they were with other teens.

Attitudes. This group voiced the opinion that safety belts could hurt you in an accident, but all preferred being hurt by the belt to being thrown out the windshield.

Two factors emerged as primary reasons the group had for using safety belts. They had either learned to use them at a very early age, or they had learned to use them in driver education class. Once they had developed the habit, they said they "felt safer." The following is an example of the heightened awareness of safety belt use for this group:

Teen A: When we started driving it was the law to wear it. When our parents started driving it was not the law to wear it. So, they are not primed for it at all. So when you start out with it, it's a habit.

Moderator: So, you wear your seatbelt because it's a habit for you, not because you're afraid you're going to be in a wreck?

Teen A: Well, you also feel safer. If you're driving down the street and you don't have your safety belt on, you feel like you're sliding around.

Teen B: $\quad$ Society has made it a bigger deal--made us more aware. Because if they weren't so wear your seatbelt, wear your seatbelt, I don't think that we would wear our seatbelts.

No one in the group disagreed with the Texas safety belt law. One participant voiced the opinion that people should wear safety belts for safety purposes, not because it's the law. They strongly agreed that the law was being enforced in Houston. One male participant related the following story regarding his experience when he was given a safety belt citation:

...when I got mine, the guy said tell your friends all the people in our unit are looking for people without their seatbelts. Warn all your friends. Tell your friends beware!

This group believed that teenagers were targeted by law enforcement agencies, not only for safety belt violations, but for traffic violations in general. They believed males were targeted more than females.

The amount of the fine for a safety belt violation was not viewed as excessive. The inconvenience of making a trip to the courthouse was described as a bigger hassle than the fine. Additionally, the experience of being stopped by an officer was described as more frightening and disturbing than the monetary punishment. 
Approaches. When asked for suggestions to encourage other teenagers to wear their safety belts in all types of conditions, the group referred to effective presentations they had seen in school, and films they had seen in driver education classes. The compelling component in each was the presentation of consequences.

The group said PSA's on the radio would need to be funny to grab their attention. The group said they did not pay attention to print media.

When asked if there were any public service announcements they disliked or that rubbed them the wrong way, they responded, "the crash dummy ones."

The most effective television PSA's they recalled were the anti-drinking and driving campaigns that depicted "real people" on video who had later been killed by drunk drivers. They felt that effective safety belt campaigns should also depict "real people" and show consequences.

Navasota Group: $\quad$ Four 16 year-old males, two 16 year-old females, and two 17 year-old females were in the Navasota focus group. Four of the participants were Black and four were Anglo. Six of the eight participants were not wearing safety belts when they were recruited.

Risk. The Navasota group cited speeding as the riskiest behavior they routinely do behind the wheel. Some of the drivers in the group were not licensed, so they were especially cautious when they drove to avoid being detected. They generally felt Navasota was a fairly safe place to drive.

No one in this group said they ever drink and drive, and they said it simply was not an issue for them. However, they occasionally ride with others who do.

Safety Belt Use. There were some part-time users in this group, and some in the group who usually wore their safety belts in the front seat, but not in the back seat. They wore their safety belts in the back seat when someone was driving crazy.

Those who wore their safety belts said they did so because they feel safer with them and because it was their habit. Part-time users were less likely to wear them for short distances and when "just in Navasota." They weren't inclined to think about being involved in a crash or about getting stopped for not wearing one.

This group was not convinced of the benefits of safety belts. They recounted stories of fatalities of belt wearers. They had little confidence in the mechanical operation of the shoulder hamess, and believed there was a fifty-fifty chance it would not engage when it should.

Attitudes Toward the MUL. No one in the group disagreed with the Texas MUL. They did not believe it was heavily enforced within the city limits of Navasota, but they felt they were more likely as teens to be stopped for a safety belt violation than were older adults. They had personally heard 
of relatively few citations. The group was not sure of the fine for a safety belt violation. A range of $\$ 75$ to $\$ 200$ was given. They thought $\$ 25$ or $\$ 30$ would be a more appropriate fine.

Approaches. Part-time users suggested more reminders (by other vehicle occupants) as a way to encourage teens to buckle up more. In terms of safety belt campaigns, the group said they did not pay attention to print media (with the exception of "the camel"). Posters, billboards, signs, etc., just become "part of the scenery." They thought speakers in assemblies who had been hurt not wearing a seatbelt, but survived to tell of the benefits of seat belts would be effective. However, participants pointed out that there is a segment of the population who will not be convinced until they are actually involved in a crash. Other approaches to increasing belt use included "pulling people over every time they are seen without a seatbelt," and witnessing an accident first-hand.

Jackson Group I: Group I in Jackson was conducted in the Student Union Building at Jackson State University. The nine 18 and 19 year-old participants were recruited from the parking lot of a freshman dormitory on campus. Most of the participants were recruited as they walked to and from the dorm and classroom buildings. Therefore the opportunity for observing safety belt use was minimal. All the participants in this group were Black. Four of the participants had taken driver education and five had not.

Risk. The participants in this group considered themselves to be at fairly high risk of being in an accident in Jackson. They commented on the frequency of accidents in Jackson daily, and the large number of poor drivers (especially older drivers). They saw themselves as relatively skillful drivers, although they admitted to driving dangerously at times. Their examples of dangerous driving behaviors included swerving from side to side, cutting people off, failing to give a turn signal, and driving without their license in the car. Several in the group described joy riding as an activity they did. This was done to "scare people" and to "show out for females." The only behavior mentioned that made them uncomfortable when riding with other teen drivers was speeding.

All of the participants in this group said they speed regularly when they drive (both in town and on the highway). Several said they speed "every time" they drive, "always," and "every day." The reason they said they speed was because they were in a hurry. They usually went at least five miles over the limit in town and 15 to 20 miles over the limit on the highway.

No one in the group said they ever drink and drive. They sometimes rode with others who had been drinking, but not if they were drunk. One participant commented that some people drive very well or better when they are drunk. They were more likely to ride with friends who had been drinking than with family members. Their approach to handling situations with drunk friends was to take the keys and drive for them.

Safety Belt Use. Only two members of the group wore their safety belts regularly, one always. The one individual who always wore his safety belt began in another state when he began driving. He said it was a habit that he did not even think about any more. Only one other participant mentioned 
ever wearing a safety belt, and he said the only time he did was when he was with his parents. Later in the discussion, most of the participants said they wore seatbelts on dates when their dates requested it. In particular, they mentioned wearing safety belts on prom night, primarily due to heightened awareness of safety concurrent with the prom event. One or two participants mentioned they sometimes wore their belts on the highway, due to the higher speed limit. They reported they might feel more inclined to wear them in a small car, but they did not feel they were necessary in a car with airbags.

Reasons given for non-use included: they're not cool; you feel like you're strapped down; they're uncomfortable; and they're inconvenient on short rides.

The participants in this group voiced the opinion that safety belts have a fifty-fifty chance of being beneficial in a crash. They had confidence in the mechanical integrity of the safety belt system, but thought the type of crash would determine a belt's effectiveness. When asked in what type of accidents belts would help, the answer was "just a bump" and collisions from the side.

Attitudes Toward the MUL. The nine males in this group did not disagree with the Mississippi mandatory use law. They said they very much agreed with it. They also said the police should enforce it more. No one in the group had ever received a safety belt citation, or knew anyone in Mississippi who had. Comments were made such as: "it's the law but they don't enforce it;" and "the police don't care." The group thought the fine in Mississippi was \$15, but they also thought the police could "charge whatever they want to." They did not think the fine should be higher to be more effective. More effective penalties they suggested were taking licenses away and requiring driver education for those cited.

Approaches. When asked for suggestions that might convince other teens to wear safety belts more, Charles answered, "I don't think there's anything you can say that will make someone wear their belt." And Antoan added, "they might wear it that day." Others suggested enforcing the law more and emphasizing it at age 16 when drivers are licensed. Others believed that people "have to experience a crucial accident" to be convinced.

This group was the only group to have positive comments about "the dummy commercials." Their comments were as follows:

Bobby: They should have more of the dummy commercials.

Charles: Yeah, I think they work.

Tarence: Little kids understand them. They speak to them. I.like 'em.

Andy: I think they're entertaining.

Moderator: What about for you? Do the dummies speak to you?

Antonio: They speak to us, but we don't listen.

The final question for this group was what might convince you, personally, to wear your safety belt more. The most common response was to have the experience themselves of being in an accident. 
A couple of individuals said more tickets would convince them. As a follow-up question, the moderator asked one of the participants in the group: "you had an accident but you don't wear your seat belt all the time now. What would convince you to wear it more?" His response was: "I don't really know. I wear it some since the accident. But here lately I don't. If my mother or girlfriend tell me, I'll wear it."

Jackson Group II: Group II in Jackson was conducted at a high school and was comprised of eight 15,16, and 17 year-old Black males, none of whom wore safety belts when recruited. Although they all drove, four of the eight were not licensed drivers. Two members of this group had completed a driver education course. One took the course, but did not complete it.

Risk. This group did not believe that driving or being in traffic in Jackson was any sort of risk. They all said they felt safe when they drove. One male said the only thing he feared was the police. He indicated this was because he drove without a license. When asked what they thought their chances were of being in an accident, the responses were 1 in 100 most commonly, and 1 in 75 . They felt like paying attention was the key to avoiding collisions.

Dangerous actions they reported they had done included not thinking about their driving, eating while driving, and talking to girls while driving. Two participants said they did not speed. In fact, one said he often drove below the speed limit. Again, the reason for this type of caution was because they drove without a license, according to the participants. The remaining six claimed to speed on a regular basis by at least 10 miles over the limit, and especially on the highway by 10 to 20 miles over the speed limit.

With the exception of one participant, this group said they did not drink and drive. Randy said he did occasionally drive after drinking, but "not that much and not that often." He also said he had never driven while intoxicated. The other members of the group said they would not even ride with others who were intoxicated or headed in that direction. Their response to the question, "what do you do in those situations," was "just don't get into the car."

Safety Belt Use. Only one person in this group was a regular safety belt user. The majority did not ever wear safety belts, unless the safety belts were automatic, or they rode with parents, or there was some other special condition that prompted their use, such as prom night. The moderator began this segment by asking, "are there times when you don't wear your safety belt?" After grins and laughter, Franklin responded with: "Never, except when they're automatic. I'm not a seat belt person. I wore one one time." His neighbor agreed: "I wore one one time--on prom night."

The major reason for non-use was because they are uncomfortable. When discussing this aspect of safety belts, the following exchange took place:

Lonnie I don't like it.
Moderator: 
Lonnie: I never tried it.

[Laughter]

Moderator: Have the rest of you tried it?

Participants: Yes. I tried it. It made me feel like a geek. You can't lean back with them

(various) on. I believe they're dangerous. You can kill yourself with one. In an accident, it's gonna choke you. I wouldn't wear one. Seat belts are bad. I think you have a better chance without it. I believe in airbags. I believe they can help you if you're behind them. The seat belt moves with you. You're gonna move into it in an accident. It's gonna kill you. You're gonna be messed up.

All the participants agreed safety belts were uncomfortable. Several thought they were dangerous. Several also thought they were inconvenient, making it difficult to eat and do other things in the car.

The one participant who regularly wore his safety belt did so because he felt safer with it. The others admitted there were times they would wear it, primarily when traveling out of state. "You never know how strict their laws might be."

One participant said he sometimes wore his safety belt at night because "nobody can see me then." Others said they might put their safety belt on at night on weekends because that was when people would be more wild.

The two conditions mentioned most frequently in which safety belts were worn were on prom night and when riding with parents. Members of this group who readily admitted they did not wear safety belts on many other occasions said they also asked their dates to wear them on prom night. They described it as "a night to be careful. People do a lot of crazy stuff on prom night." One participant mentioned he wore his safety belt on prom night, even though he did not have a date. The propensity toward caution on prom night did not extend to other dates. Only one participant said he wore his safety belt on dates. Another participant claimed he "was just trying to be cool."

This group, for the most part, did not have any confidence in the ability of safety belts to offer protection in a crash. They believed them to have a high likelihood of failure. Although they thought there were times safety belts could save someone's life, they mentioned "they're always havin' to cut somebody outta their seat belt."

This group believed rear-end collisions, and in some cases side collisions, were the primary types of collisions in which belts might be helpful . They saw no purpose in them for frontal collisions, and emphasized the likelihood of being choked by the shoulder harness.

The participants in this group expressed a degree of fatalism not found as strongly in other groups. They expressed the belief that in an accident, there was a fifty-fifty chance of being killed, so their decision was to "ride without it." Several times members of the group mentioned that "if it's your time to go, you're gonna go anyway, seat belt or no." 
This degree of fatalism may have been sparked to some extent by two crashes that had occurred recently in Jackson and were brought up during the session by several participants. In one crash, the only survivor was wearing a safety belt, and the others were thrown from the vehicle. In the second crash, the car was crushed and the fatal occupant was belted, while others were thrown from the vehicle.

Attitudes Toward the Law. The Mississippi mandatory use law did not have much, if any, effect on this group. They were aware that it existed, but said it was not enforced. No one had ever been cited for not wearing a safety belt, or knew anyone who had, although several had been ticketed and/or stopped for other violations (while not wearing safety belts). They thought their chances of being given a safety belt citation were "one in a million." They did not see any point in raising the fine, since they did not believe it would be enforced.

Approaches. The group offered several suggestions for increasing safety belt use: 1) make automatic lap belts instead of automatic shoulder harnesses; 2) have sports heroes endorse the behavior; and 3) make them more comfortable and more customized. In the words of Fredrick: "make designer belts--something you'd like to show off, like Nike seat belts. Let everybody know you got on your Nike seat belt."

With regard to PSA's, they said they didn't listen to commercials on the radio. They were more inclined to watch TV commercials. They recommended that messages be from "real people." They said they need to be straightforward and gruesome. "Show the pros and cons of wearing it and not wearing it." They mentioned they found the anti-drinking and driving messages effective because they were based on reality. They mentioned the crash dummies as a bad approach because they are too abstract, they are aimed at children, and send the message that you can walk around as if nothing happened after being in a wreck.

When asked what would convince them, personally, to wear their safety belt more often, the common response was to see someone they knew get killed without one.

Yazoo City Group: The Yazoo City group was comprised of eight 16-18 year-old females at Yazoo City high school, six of whom were Black and two of whom were Anglo. Two participants were recruited while wearing safety belts. One's use was not determined, and the remaining five were not belted. Half of the group had taken driver education.

Risk. The females in this group felt like they were safe drivers, but did not trust the actions of others. Several had accident experiences which heightened their insecurity on the road. They expressed the sentiment that older drivers are more a problem than teens, and that they should stop driving or be tested annually after a certain age. One participant said, "I don't think about having accidents. All I worry about is the police because I don't have a license and most of the time my friends I'm with don't have a license." 
This group was not as likely to speed as other groups suggested. They all admitted to speeding, usually by about five miles over the limit. They claimed "the Yazoo City cops don' $t$ have radar guns and everybody knows it." Most of the group did not drive in a careless manner to impress others.

No one in the group said they did or would drink and drive. They were opposed to riding with others who had been drinking. In the case of peers, they would make someone else drive, or not get in the car. In cases when several said they had ridden with someone who had been drinking, they were adults, usually family members, and they felt they had no choice. For example, one girl described a situation in which she was driven home from a babysitting job by the employer who had been drinking, and she had limited options on how to get home.

Safety Belt Use. The moderator asked, "are there times when you don't wear your safety belt?" All the participants giggled. Several said the only way they would wear one would be for a road block. Two members of the group said they never wear safety belts. One participant described being stopped every Saturday morning for a road block. After 4 verbal warnings, she was given a safety belt citation. She later said she still does not wear her safety belt except on holidays when traffic is heavy, on the highway, and on weekend nights when she feels it is more dangerous to be without it. She takes another route on Saturday mornings.

Part-time safety belt wearers gave the following situations for use: when it's an automatic shoulder hamess; when my mom's watching me leave the house; when I'm going to Jackson; and when I'm in somebody's new car and they might not have insurance.

A variety of reasons for non-use were given. One participant said she was usually finishing dressing when she was getting in the car, focusing on where she was going, not on a seat belt. Another participant said she worried that if someone tried to get in the car with her she wouldn't be able to get out quickly if she had a seatbelt on. Several said the cars they rode in usually either did not have seatbelts or they were too difficult to dig out of the seat. As one girl said, "in my Daddy's truck, his are so old I'd be afraid to use 'em. When you pull it down, dust flies off of it." Others said they were afraid of being trapped in them in an accident. One participant said she wore hers 50 to 75 percent of the time, but when she makes stops she forgets to put it back on. She said, "that's what happened yesterday. I had my seatbelt on when I left the house. Then I stopped at the Handy-Mart on the way to school and didn't put it back on, and look what happened. There you were at the school to see me without it." The group agreed that the primary reasons for non-use were that they were uncomfortable and they just don't think about it when they get in the car and go.

A major exception to this pattem of non-use was prom night. They all intended to wear their safety belts to the upcoming prom. They credited this decision to the week long emphasis on being safe on prom night.

This group did not have much confidence in the effectiveness of safety belts in crashes. They were suspicious of car manufacturers, and most expressed doubt that the mechanism would work properly when needed. The type of collision did not factor into their conclusions that safety belts are not 
dependable. This group also had members with fatalistic outlooks--those who commented "if it's your time to go, you're gonna go anyway.

Attitudes Toward the MUL. Participants in this group were aware of the Mississippi mandatory use law. Seven of the eight were in favor of it. The one participant opposed to the law was the driver who had been ticketed previously. They did not think increased enforcement was an effective approach, but favored more warnings for first time offenses. They did not believe the law was strictly enforced.

Approaches. The approach this group favored most for increasing belt use was a plethora of reminders. They suggested constant in-vehicle reminders such as buzzers, lights, voice reminders, and key chains with reminder slogans. One participant recommended an interlock system. At a personal level, the three approaches mentioned to influence their own belt use were: 1) "somebody close to me getting killed;" 2) "my mom telling me all the time;" and 3) "somebody reminding me."

Charlottesville Group I: Group I in Charlottesville was made up of four 15 year-old females and four 16 year-old females. Two of the members were Black and six were Anglo. Belt use was determined for three of the participants, two without safety belts and one with a safety belt. Belt use was not determined for the remaining participants.

Risk. The consensus among this group of females was that you cannot control what others do, no matter how skillful. Therefore, careful driving is not a deterrent to accidents. None of the participants mentioned any dangerous driving behavior of their own. However, they did say they rode with others who drove dangerously. The dangerous activity they mentioned was not paying attention, particularly when "messing with the radio." One participant said she sometimes takes her anger out on the car. Comments were made that even though they were occasionally in situations with friends who drove dangerously, they nevertheless felt safe because they believed their friends to be good drivers with quick reflexes.

Speeding was not a prevalent behavior among this group. Although several mentioned they sometimes would speed, it was not by much and usually unintentional.

None of the participants in this group said they drink and drive. Most said they did not drink. They all said they would not ride with others who had been drinking.

Safety Belt Use. Safety belt use was mixed among this group. Usage ran from "always, except in the back seat," to "sometimes," "half the time," and "never." They were more likely to use them in a small car than a large car. Several participants said they wore their safety belts when they "had a feeling something was going to happen." They were not able to identify anything specific that precipitated the feeling. Parental influence was mixed--some parents required safety belt use and others did not. Several mentioned they were more apt to use safety belts during bad weather. None of the participants wore their safety belts in the back seat. 
Non-use was primarily attributed to discomfort, and simply not thinking about it. Two participants said they felt safety belts were not necessary. The group repeatedly returned to the belief that sometimes it is better not to wear a safety belt to be able to get out of a vehicle after a collision or if you run off the road, and that safety belts actually do more harm than good at times.

Peer influence did not appear to be a major factor in situational use. The participants had friends who used safety belts and those who did not. One mentioned that some friends thought it looked stupid. One part-time user said she told hér friends after such a comment, "I think I look better in a seat belt than a body bag."

In what kind of accidents would safety belts be of help? The majority of the group thought belts would be most helpful in collisions from the rear. Only one mentioned frontal collisions where safety belts would be beneficial. And no one thought belts would be helpful in side collisions. On balance, the group was equally divided as to whether or not safety belts would be beneficial or harmful in the event of a crash.

When asked if they thought safety belts prevented injuries, the group responded with "no." They went on to say belts sometimes cause injuries, and only some of the time prevent injuries. One participant firmly believed there was a fifty-fifty chance the safety belt would activate.

Attitudes Toward the MUL. This group was basically unaware of the Virginia mandatory use law. There was some knowledge that a law existed, but no knowledge of the type or penalties associated with it. Mention was made of the requirements of the child restraint law. They did not believe the law was enforced, and one participant stated, "half the time police officers don't wear 'em." No one in the group had ever received a safety belt citation or had been in the car with anyone who had. One participant knew of someone who had received a safety belt citation, but was in another state.

The group did think that a mandatory use law was fair and justified. They said more people would wear safety belts if the law were enforced. As Jennifer said: "It's not being enforced. I'm not gonna put [my seat belt] on because I know I'm not gonna get pulled over if I'm not doing anything wrong."

The group was asked, "if the law were enforced, would you be more inclined to wear your seat belt?" The answer was no--not until they actually got caught. The participants all believed the law in Virginia should be enforced more, and that they would wear their safety belts more if it were. enforced. They unanimously agreed that they would be more likely to use safety belts if the fine was raised.

When asked how they would write the Virginia mandatory use law if given the opportunity, the members of this group were much more punitive than their state governmental body. They agreed that a graduated penalty was appropriate, with the first offense resulting in a warning, and subsequent offenses resulting in progressively higher fines, and leading to license suspension and ultimately vehicle impoundment. As one individual said, "if I have to pay $\$ 500$, I'm gonna wear 
that safety belt." And another said, "if you don't have a car, you don't have to worry about not wearing a belt."

Approaches. The group was probed for other ideas and suggestions for encouraging teens to use safety belts consistently. Their comments indicated they did not believe education would work. When asked why, one participant said, "everybody has a mind of their own." This group felt strongly that expert speakers at assemblies would not be effective, that such a speaker would be "just talk." They said they would not pay attention to posters or billboards, and they would change channels or ignore television commercials. They thought messages from survivors with whom they could relate would have some effect, but only in the short term. They believed most other teens would have what they considered the common response of "that won't happen to me." They suggested more depictions of bodies and consequences would have more influence.

The group was asked to share their opinions of current safety campaigns, and to note if there were any approaches that did not appeal to them. Testimonials from safety belt users were cited as annoying because of the implication "look at me, I'm perfect." The following excerpt reveals the attitude of the group toward a major campaign:

Angela: The ones about sex are OK, but all the other ones are kinda stupid. [Laughter]

Moderator: Well, let's just stick with traffic safety campaigns here.

Jessica: The dummy ones are stupid.

Sarah: They're dumb. It's like they're making light of a bad subject.

Anne: $\quad$ They need to come up with a new mascot because those guys are getting old and people ignore them.

Trish: They were cool at first. They're just dumb now.

As a final question, the group was asked, "what would convince you to wear a seat belt all the time?" Because their responses were so indicative of the difficulties of influencing the behavior of this segment of the population with educational and informational campaigns, they are quoted below:

Leslie: If one of my friends had an accident not wearing it, and was paralyzed.

Karen: If it was somebody I knew.

Trish: If it was a close friend or a relative.

Anne: If something happened to one of my best friends, or someone in my family, or to me even.

Moderator: What about you Jessica, you never wear it. What would cause you to change your mind?

Jessica: If one of my friends said you wear it or you get out and walk.

Jennifer: I've lost family members to car accidents. I've lost friends, too. And I don't want to lose no one that way. More than likely I would put mine on half the time. It makes me uncomfortable, you know. If I'm running down the road, it starts to irritate me. 
Sarah: If I lost friends or someone in the family, I'd think about it more. Leaving here today or leaving an assembly I would put it on because we'd just been talking about it. But it doesn't carry over time. There isn't any commercial that will, unless it's on like 500 times a day. If somebody was killed, máybe I would for a week later. But I get in a hurry...

Angela: The only thing that would change my mind is if I was in an accident myself.

Charlottesville Group II: Only one of the eight males recruited for the male focus group in Charlottesville came to the session. Therefore, an in-depth interview was conducted with this 15year old Black male named Brent. Brent was a beginning driver who had his learner's permit about eight months. He had not taken driver education. His views on the four subject areas are highlighted below.

Risk. Brent was a very cautious, beginning driver who was not prone to take risks. He did not ride with others who exhibited risky driving behavior. He rode with others only with permission from his mother and concluded that if his mother trusted them he could also. He believed other drivers were sometimes dangerous if they were immature or overly tired. Brent had never had occasion to drink and drive, had never ridden with anyone who had, and said he would not get into a car with anyone who had been drinking if there was any other alternative. He also did not speed while driving, and had never been given a citation.

Safety Belt Use. Brent said he always wore his safety belt in the front seat. He also wore his safety belt in the back seat if he was in the middle in a vehicle with a gap in the front seat or in a van in which he could move forward in a crash. However, if the front seat was tall and he was positioned behind it, he felt he would be protected by the seat back in a crash. The reason Brent gave for using his safety belt was, "in case someone else is not being as careful as me and makes a mistake, or if I make a mistake." He reported that he had been brought up to wear his safety belt, and that was his normal behavior in the front seat every time he got in the car.

Brent believed in the effectiveness of safety belts as life saving and injury reducing devices. However, he was more inclined to believe belts would be helpful in rear-end collisions than others, particularly frontal and roll-over collisions. In these cases, he expressed concern that the belt would jam and one could be trapped in the car. He also did not believe safety belts offered much protection in side collisions. Basically, he believed safety belts were a good safety device, but most helpful in fender benders.

Attitudes Toward the MUL. Brent was supportive of the Virginia safety belt law. He was aware of it from reading the driver manual in preparation for his learner's permit and from things he had seen on television. He was under the impression that Virginia's law was a primary one and that the fine was $\$ 50$. He thought $\$ 50$ was reasonable, but suggested the first offense should be a warning with progressively higher fines thereafter. 
Approaches. Brent was of the opinion that the Virginia law should be enforced more. He said he felt like it was treated like jaywalking by law enforcement and Virginia citizens. Other approaches he thought might have a positive effect included celebrity testimonials, billboards, and radio PSA's on the stations popular with teens. He very much believed that commercials and advertisements needed to be realistic and show results of what may happen if you don't wear safety belts. When asked if he could think of any current safety belt campaigns, he mentioned the crash test dummies. The moderator asked for his opinion of this campaign and Brent responded: "I think they're good commercials, but they sort of take away from the reality. They don't look real. They're like dolls with stuffing." He did not think this campaign was effective with teenagers.

Roanoke Group: The Roanoke group of 10 participants was a combination of 15 and 16 yearold males and females, all of whom were Anglo. Belt use was not recorded during recruiting efforts for this group. This was the only group to have been conducted away from a school campus. It was held in a reserved room of a restaurant.

Risk. These drivers were fairly confident in their own driving abilities, although they questioned the abilities of some of their friends. One participant had been in an accident in which another car crossed over into his lane, so he described himself as more nervous than before the accident. The group discussed drivers they considered so cautious as to be hazardous, and the differences between being cautious and skillful. This group projected images of fairly cautious drivers, indicating their risky behavior was primarily not paying attention when driving.

However, each participant said they speed on a regular basis, or ride with others who do. They indicated they felt more comfortable going about 10 miles over the speed limit, and that this was necessary to keep up with traffic.

The group was cognizant of the dangers of drinking and driving, and indicated they were not inclined to drive drunk. Yet, drinking and driving was described as fairly commonplace among their peers, and they admitted they rode with others who were intoxicated. This was explained by being unable to get home without accepting the ride. Several mentioned they would call someone else if they thought the driver was too drunk. Others said their drunk friends were better drivers because they were more careful when they were intoxicated.

Safety Belt Use. Restraint use among this group was mixed. Two participants said they did not wear safety belts. Two said they always wore safety belts, and felt uncomfortable backing out of the driveway without them. Three said they wore them most of the time. And three said their use was conditional.

Conditions of use included, first, the weather. In rainy or snowy weather, part-time users were most apt to wear their safety belts. Another condition was position in the car. Those who said they did not always buckle up said the times they did not were when they were in the back seat, or when they were a passenger in the front seat. They sometimes had doubts about the ability of the driver, and 
would opt to use their safety belt in those situations. Part-time users also reported the times they wore them were when the shoulder harnesses were automatic.

Non-users emphasized discomfort as the reason for non-use. The following dialogue occurred in Roanoke:

\author{
Moderator: What about you, Kirby? \\ Kirby: I just don't like the feel of it--it's uncomfortable. \\ Moderator: It's uncomfortable. Why is it uncomfortable? \\ Kirby: It's like all over my neck and stuff. I don't like it. \\ Moderator: Any other reasons? \\ Kirby: I don't know. I like to hang out the window sometimes. You take it off and \\ it gets hung up the middle.
}

Part-time and regular restraint users were required to wear safety belts as children by their parents more so than those who said they did not currently buckle up. Consistent users maintained that it was very much a habit with them.

The group was not overly convinced that safety belts save lives, because of the exceptions of being trapped. This group referred more often to running off the road than to vehicular collisions when they spoke of crashes. The following is an example of such a reference:

Moderator: $\mathrm{OK}$, so if the collision is violent, the seat belt might help. What about you Kirby, do you believe that?

Kirby: Yeah.

Moderator: Candy, what do you think?

Candy: Well, if I'm falling off a cliff I don't want the seat belt on because when the car lands it's going to blow up.

[All laugh.]

Rób: $\quad$ You are going to be dead anyway.

Candy: I know...

Kirby: At least you won't be all over the windshield. You'll be in the seat.

Most were of the opinion that safety belts could lessen the severity of injuries, and in general, it would be better to have them on in a crash.

AttitudesToward the MUL. The participants in this group were somewhat aware of the Virginia mandatory use law, but were not knowledgeable about the particulars. Most of the participants were not in favor of the law, stating that it should not be the State's business and should be a matter of personal choice. One individual said he thought if there wasn't a law, then nobody would wear their seat belts. 
A couple of members of the group had been in the car with someone (a parent) who had been given a safety belt citation in conjunction with a speeding ticket. No one in the group had been issued a safety belt citation. Positive and negative opinions were both expressed regarding increased enforcement.

Approaches. This group was the only group to suggest that positive reinforcement type approaches be used to encourage safety belt use. A suggestion was made that rewards be given to those who decide to wear their safety belts.

\section{Summary of Focus Group Results}

In the Spring of 1996 one in-depth interview and 10 focus groups were conducted. Discussions were held with 85 teens regarding their views, experiences, and behavior related to safety belts, safety belt laws, and other traffic safety related matters. Each focus group had a unique quality, though the subject matter was relatively consistent. These discussions produced first hand information about the insights of teenagers in four states. It was fairly obvious from the moderators' accounts, the videotaped demeanor of the participants, and the candor with which they spoke, that the teenage participants in this study were comfortable and expressed their views openly. There was no indication the participants felt in any way threatened, intimidated, or were less than forthright with their opinions.

One of the primary advantages of the focus group technique is that it allows researchers to gain insights into the motivations of people within the group context where sometimes it is easier to share information. In this way, the intensity and general tone of a group toward a subject can be ascertained. The focus group technique is not an effective statistical tool for testing hypotheses or making quantifiable statements. Yet, it can provide important information to give direction to the development of approaches for influencing behavior and shaping opinion. The results described above were detailed in such a way to provide a sense of the tone and intensity of the teen viewpoint that was elicited in this study. The following paragraphs are an attempt to synthesize the commonalities, consistent patterns and sentiments found among them.

The teenagers in this study were relatively confident in their own driving ability, but not as sure of the abilities of others. Many voiced the opinion that their friends or peers sometimes exhibited risky driving behavior, but they were good drivers and knew how to handle it. Teens in most of the groups were more wary of the driving ability of their parents and other older adults, whom they felt were either too cautious or too confident, but certainly of declining skill behind the wheel.

Focus group participants admitted to carelessness behind the wheel in what they described as dangerous acts. Inattention, and particularly distractions related to music and the radio were often mentioned. Speeding was also a commonly reported behavior for this age group. However, they 
rarely mentioned acts of aggression or acting out or showing off as a periodic behavior for them or their peers.

The taboo against drinking and driving was a fairly uniform consensus across all groups. This sentiment should not be too surprising, given that all the focus group participants were under the legal drinking age. However, the majority maintained they would not ride with others who had been drinking and driving if they had other alternatives. Other alternatives included taking the keys, encouraging someone else in the group to drive, or simply not getting into the vehicle.

Safety belt use varied within and across groups. In Houston, where observed belt use and self-reported belt use was high, focus group participants spoke of front seat safety belt wearing habits instilled by parents and schools since early childhood. Their experience with enforcement of the mandatory use law was notably different from teens of other states. Their part-time use was somewhat relegated to the back seat.

The factor mentioned most often for those who were not safety belt users was that safety belts are uncomfortable. If they said they did not like wearing safety belts, their statements were usually followed with comments of the opinion that they did not fit right, bothered them, or felt like they were choking them. Another comment often made was "I just don't think about it."

Other commonly given reasons for choosing not to wear safety belts included the fear of being trapped or not being able to escape from the vehicle. Teens often voiced a lack of confidence in the operation of the belt and buckle mechanism. Others felt that "if it's your time to go, it's your time" no matter what precautions you take. Therefore, they saw no need for a safety belt.

In every group there were doubts expressed regarding safety belt effectiveness. These doubts were often expressed with anecdotal accounts of instances where safety belts caused or failed to prevent injury or death. Further discussion revealed that teens are lacking in basic knowledge of how safety belts work, the physics of crashes, and have unrealistic notions of crash risk.

For most teens in the discussion groups, parental influence seemed to be a greater influence on belt wearing behavior than peer pressure. Parental influence was notably effective in establishing the belt wearing habit.

Conditional use was found to be associated with a heightened sense of danger. For example, teens reported tendencies for using safety belts when on the highway, on weekends, with people they did not trust, on prom night, and in bad weather. For some, conditional use was associated with reminders from parents, or with the presence of an automatic restraint.

In general, most of the group participants were not vocal against mandatory use laws. It is a bit more accurate to say they were basically supportive of the MULs in each of their states, although they were not very knowledgeable of their specifics. Some participants thought safety belt 
laws needed to be enforced more. A common suggestion was to implement progressive fines and warnings.

The discussions on approaches to encourage belt use among teens revealed that teens need to be affected at a personal level, with reality playing a strong role. Many said they would be convinced to wear safety belts on a full-time basis, only if they experienced the effects of non-use relatively first-hand. Repeatedly, and without prompting they indicated they did not like the dummy commercials because they were not serious or realistic. The development of educational approaches described in the next chapter focused on the need to be realistic, portray events with which teens can identify and personalize, and impart information on risk and belt effectiveness. 


\section{CHAPTER SIX}

\section{EVALUATION OF APPROACHES TO INCREASE BELT USE}

\section{Development of Approaches}

Observational surveys revealed that teen safety belt use generally reflects the general population's safety belt use in their local environment, although teens were belted somewhat less frequently. The surveys also indicated that a great deal of variation is not found by type of activity. There was a slightly greater belt usage when traveling to and from school than when traveling for recreational purposes. There was enough difference in belt use by age and gender to provide a rationale for discriminating among these groups when selecting focus group participants. However, focus group discussions did not reveal enough attitudinal differences to justify separate and distinctive campaign strategies targeting small age groupings or gender per se.

Interviews with teens revealed a strong tendency toward belt wearing behavior based on parental influence. If they had been taught by parents to wear safety belts, then they expressed a belt wearing habit that prevailed in most conditions. In general, safety belt use did not appear to be a result of a conscious, momentary decision influenced by their type of activity, who they were with, or peer behavioral influence. One exception was a decision against wearing their safety belt based on location in the vehicle. Very few teens reported wearing safety belts in the back seat.

Focus groups revealed that teens do not wear their safety belts for some of the same reasons studies have shown that adults choose not to wear them. These include discomfort, fear of being trapped, lack of trust they will work, and for the most part "just don't think about it." The teens did not make the "individualrights" argument, i.e., that the government should not be forcing them to take this precaution. In fact, they almost unanimously agreed that safety belt laws should be in effect, and many agreed they should be enforced.

During focus group sessions, the teens exhibited an obvious lack of knowledge regarding the physics of crashes and the benefits of safety belts in crashes. Many believed they could save themselves in minor crashes. Conversely, a common belief that surfaced was that it takes a crash of catastrophic proportions to kill someone, and in those cases the safety belt may or may not save the occupant, depending on luck. The researchers concluded that the decision making process regarding safety belt use for teens is hampered by misconception about how belts work and the dynamics of crashes, and has less association with the anticipated effects of peer pressure and resistance to safety belt use in general.

When asked about effective safety campaign messages, teens indicated that they don't relate well to "cute" messages such as those by Vince and Larry. They expressed the sentiment that "if it's a serious life or death subject, then treat it seriously." Many said the facts would be helpful, but to be really meaningful to them it had to come from someone they knew personally. They reported they 
are not overly affected by reports of accidents involving people they don't know (too commonplace), and although they admitted they realized they could be involved in an accident themselves, they were not particularly worried about it. The most effective campaigns mentioned in every focus group were anti-DWI campaigns that sadly portray the death of real people with lives with which they could identify.

Based on the findings that teens did not have a good understanding of the benefits of safety belts and the dangers of everyday crashes, and that messages need to be about people with whom they can identify, the following public education and information campaign themes directed at teens were developed for further focus group testing:

\section{It doesn't take much to lose (or wreck) a life. It doesn't take much to save one.}
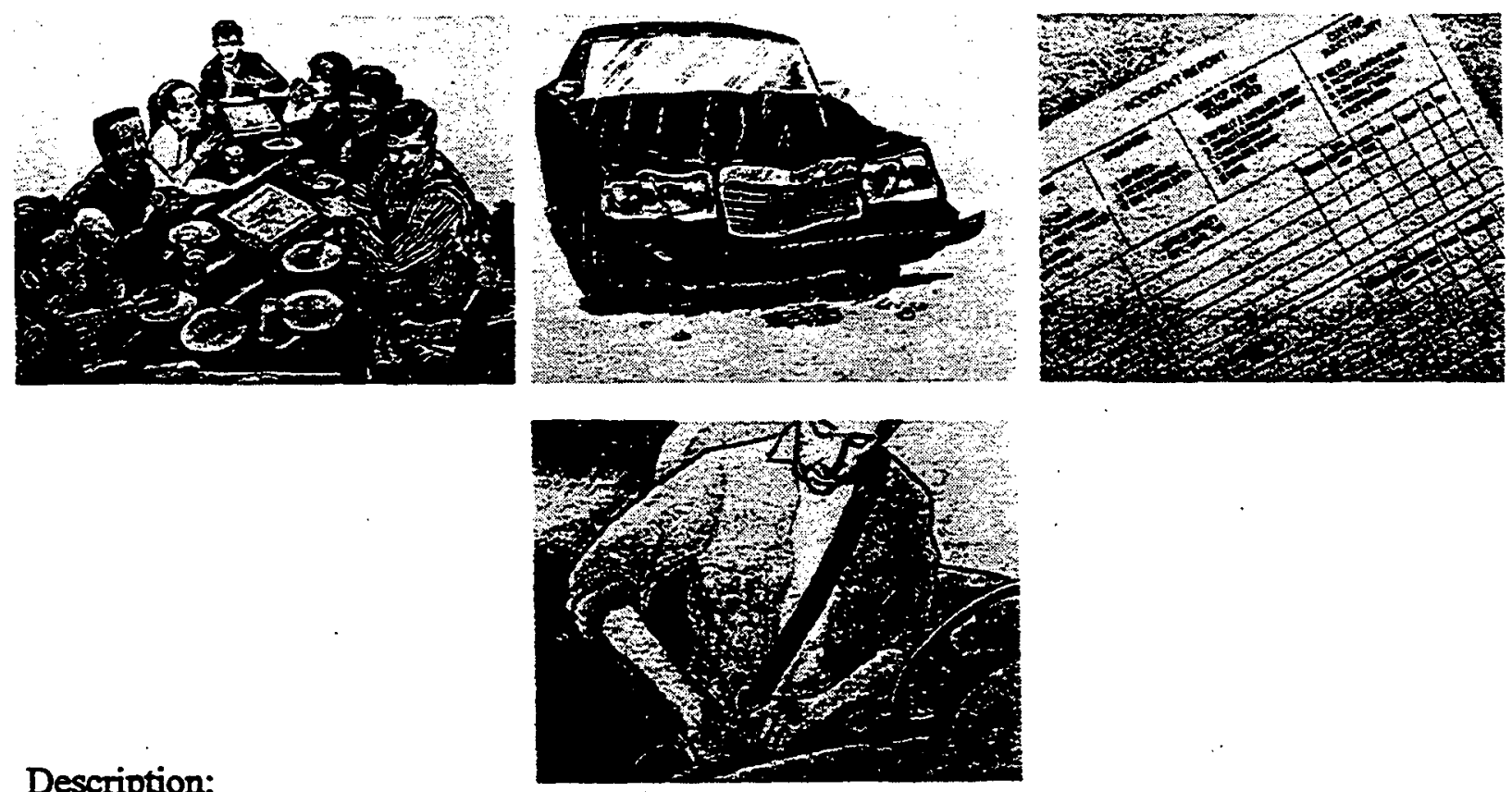

Description:

The message of this campaign targeted the misconception that it takes a catastrophic crash to kill, and that even though crashes are everyday occurrences, an everyday event like wearing a safety belt can save a life. The message has a serious and factual tone. An underlying message is that fatalities may appear to be merely statistics for someone, but loss of life is final and can be preventable.

A video PSA would show a close-up of the routine act of typing in an accident form. A fairly low speed $(35-45 \mathrm{mph})$ would be entered in a box. The next box entered would be Injury Code, indicating a fatality. And the last box entered would be Restraint Used, indicating none. Several might be completed, indicating this is "all in a day's work" for someone. Possible background shots include a car with frontal damage only; teens in an enjoyable setting; teens wearing safety belts. In the last series of accident reports, a higher speed is recorded, restraint use is yes, and injury is none: 


\section{Wear it now, or wear it later.}
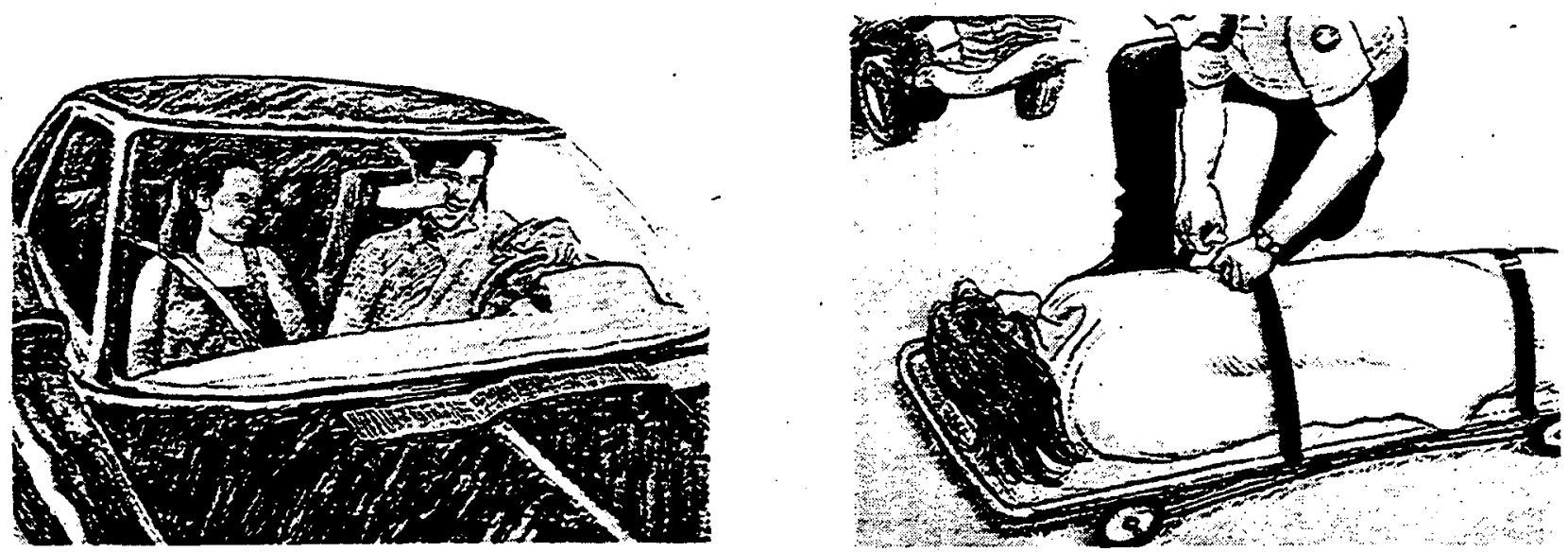

Description:

This message was intended to address the notion expressed by teens that the reality of the consequences of not wearing a safety belt would be given best by someone with whom they could relate who could speak from a stretcher. This campaign would rely heavily on the visual impact of the use (or non-use) of a safety belt in contrast with the belt used to secure a body to a gurney. The second visual for this campaign shows a female wearing a locket in a vehicle without a safety belt, followed by a locket displayed on a headstone, shown below.
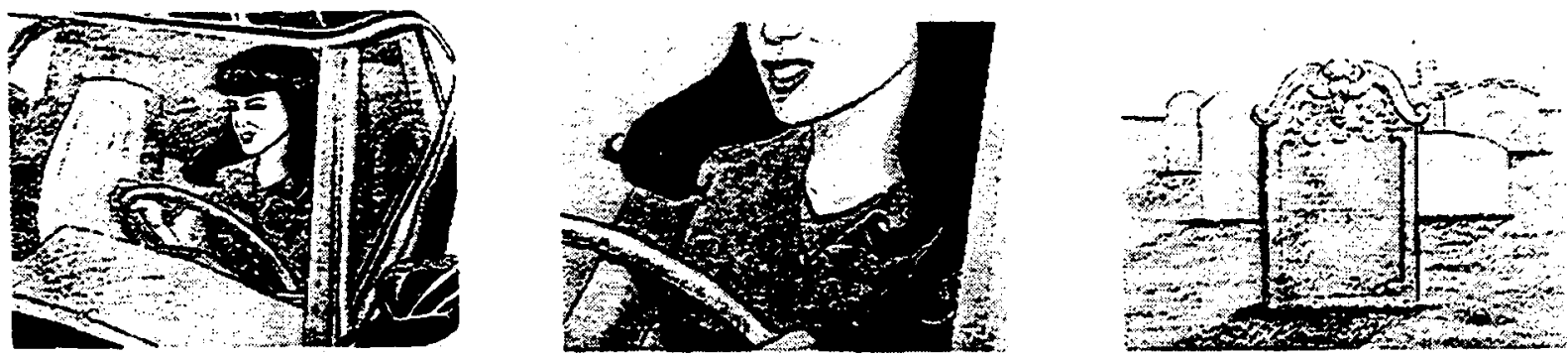

III. You wouldn't jump without a parachute. You wouldn't take on a linebacker without a helmet. You wouldn't walk a tightrope without a net. You wouldn't climb without a rope. Why would you cruise without a safety belt? 

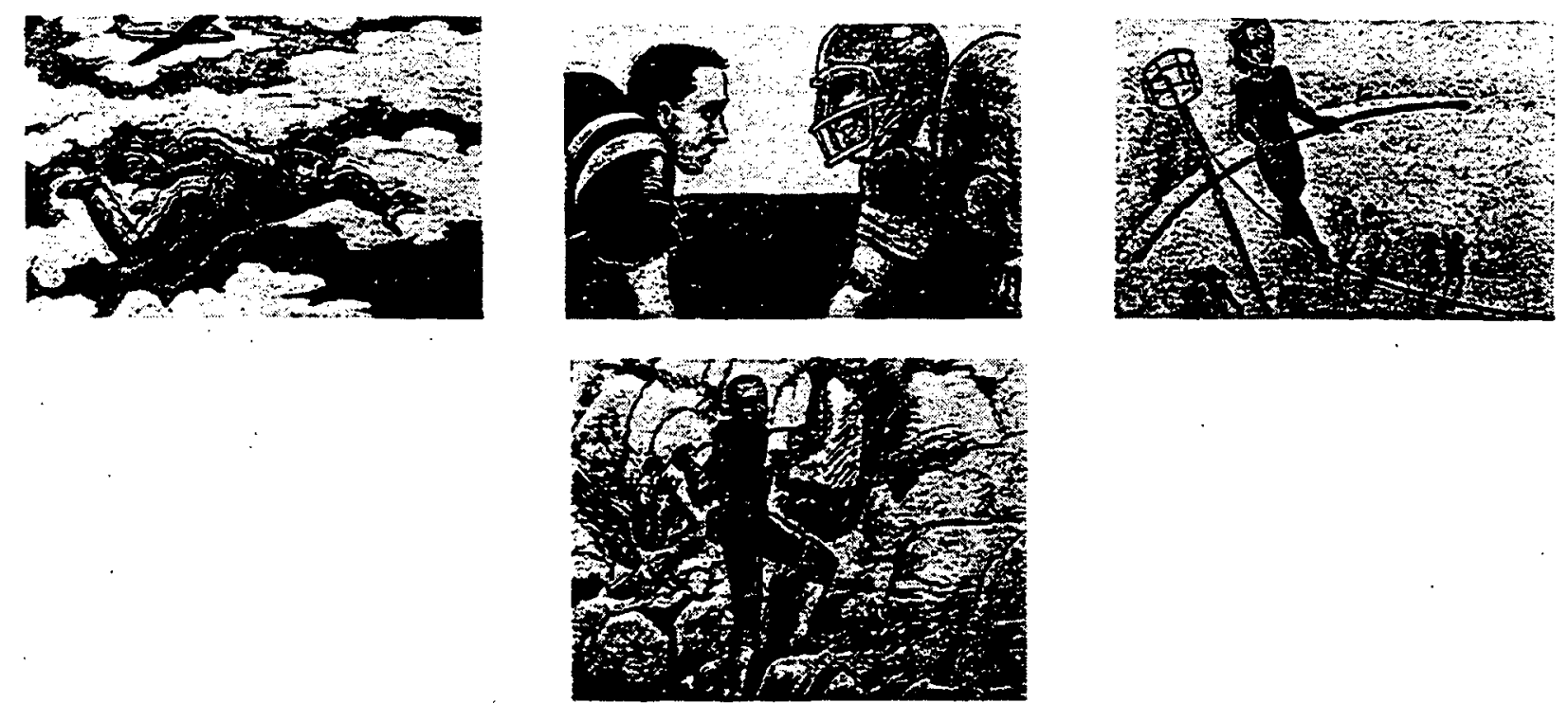

Description:

This message was intended to highlight the common sense safety benefit of a vehicular safety belt. It was important to discover during focus group testing if the driving and wearing belts analogy can be made with other more death defying activities.

\section{The Statistical Campaign}
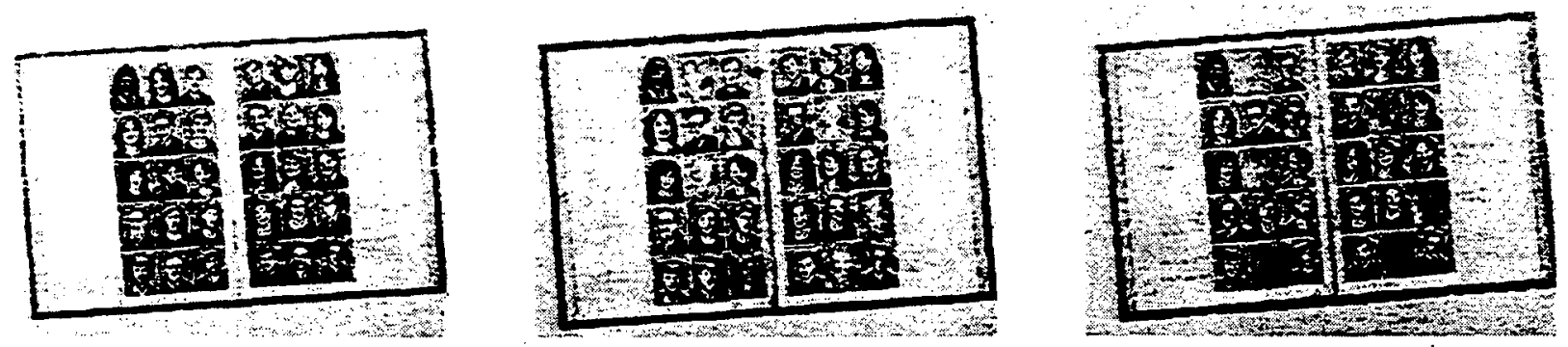

Description:

This campaign was intended to provide data for teens on the odds of: 1) being in a crash; 2) being in a serious injury crash; 3) being in a fatal crash; and 4) surviving a crash using occupant protection. Visuals included a school yearbook with statistics providing accident projections and fatalities for a graduating class. Students fade out or are X'd out, depicting the number of projected fatalities in a non-belted scenario over the lifetime of the class. Students fade back in, depicting the projected 
lives saved through $100 \%$ belt use. The message can be adapted in a variety of ways. For example, as shown below, a class at graduation can be depicted departing the stage in cap and gown, and the statistically appropriate number fade off in another direction. Additionally, the campaign has great potential for community level adaptation. The yearbook photographs can reflect the demographics of the local population. Teens can be depicted in a variety of activities that are popular in the area, and $X$ 'd out of the picture. This message also addresses the idea that teens are in a very active and fun stage in life with the promise of a future, and that this future can be radically changed or taken away. One rationale for this campaign comes from several focus group discussions where the effectiveness of similar campaigns near prom night or graduation with a focus on drinking and driving was mentioned.
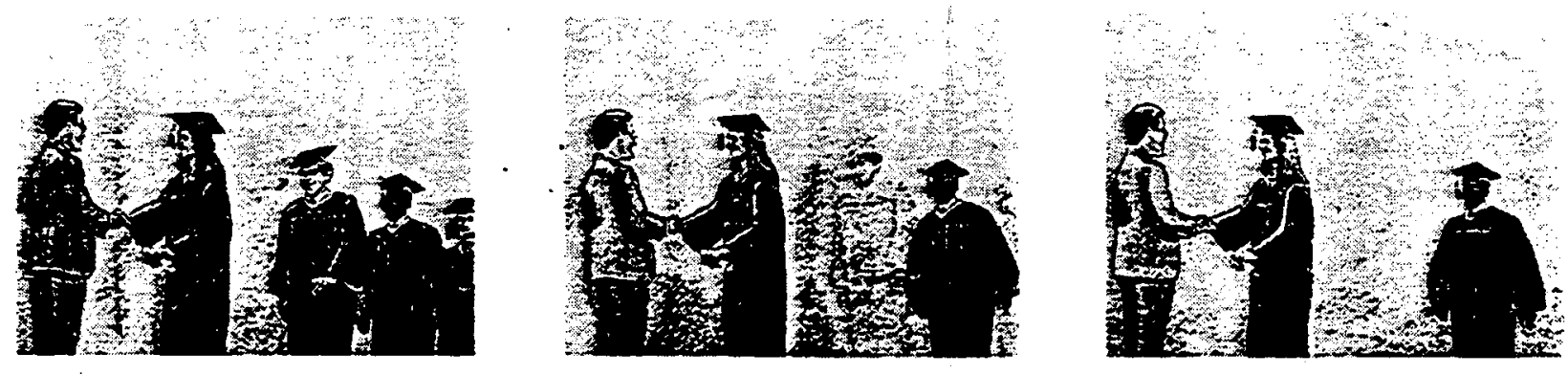

\section{Are you free tonight?}
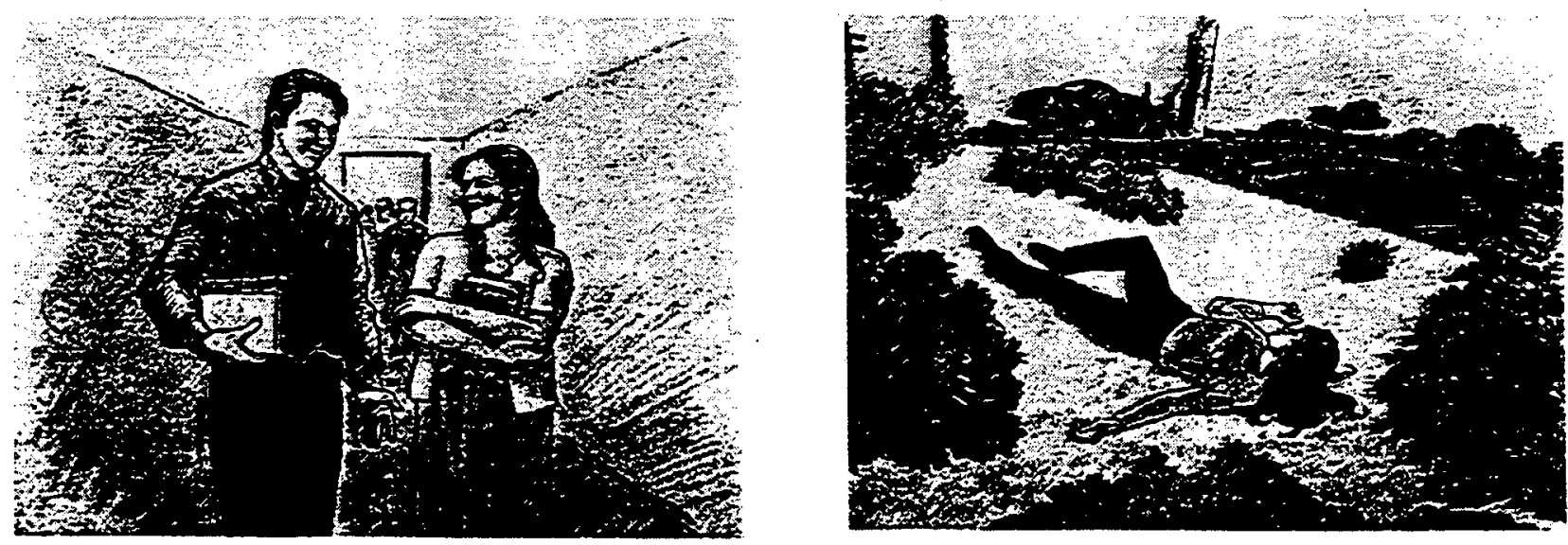


\section{Description:}

This play on words capitalized on one the most popular activities engaged in by teens--dating. During interviews with teen males, mention was made of the use of safety belts in dating situations as a sign of caring for or taking care of their date.

VI. What will it take to get you to wear one?
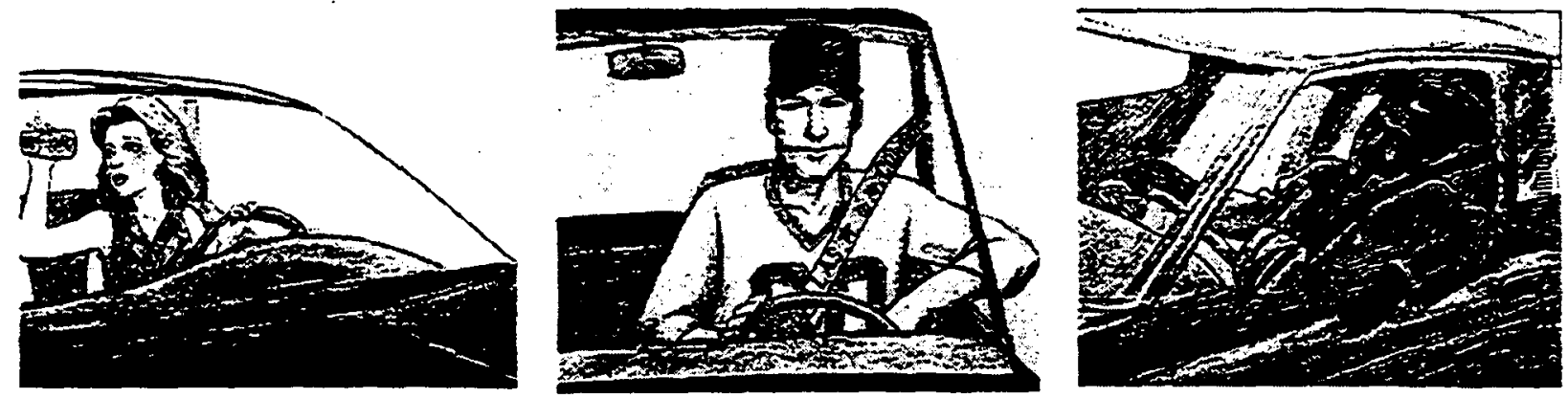

Description:

The strategy in this message was more lighthearted and fun, and capitalized on another area of interest for teens-fashion. Although many teens suggested that messages directed toward them should be serious and factual, there were a few who mentioned that the idea of making a fashion statement appealed to them. The approach should be so outlandish that it comes close to actually poking fun of the intense youthful regard for fads and appearances.

VII. One Size Fits All

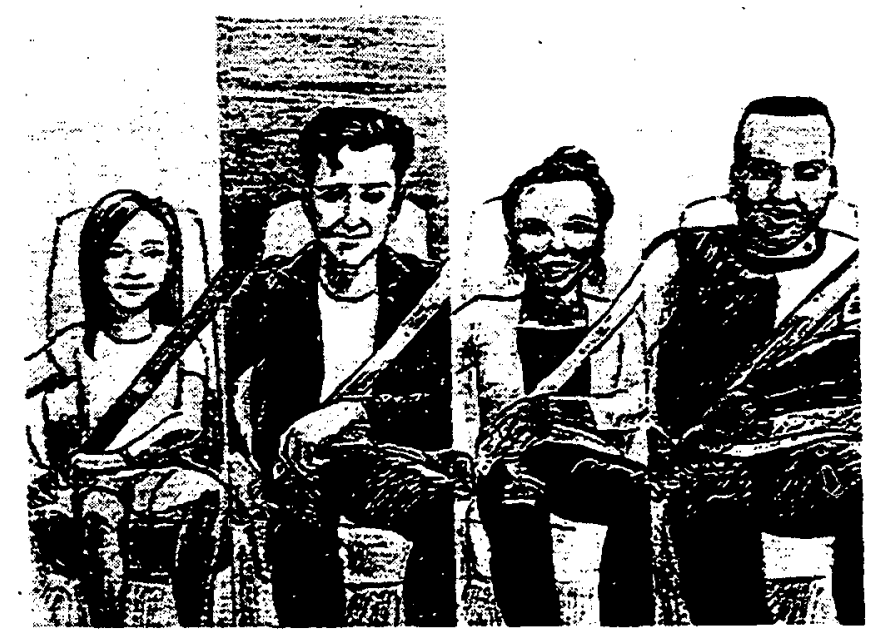


Description:

This is a series of visuals of teens of all types wearing safety belts. The intent of this message was to be able to show teens least likely to wear safety belts wearing them. The All-American teen would be juxtaposed with the spiked-haired, tattooed teen, and the athlete, and the cheerleader, and the studious-looking, etc., with the idea that there would be representation of types with which teens could identify. Additionally, a variety of seating positions could be illustrated to show teens belted in the back seat. Occupants could be pictured in a variety of vehicle types as well.

The seven approaches described above were presented in focus groups as media campaigns intended to convince teens to wear safety belts more often. They were developed with the assistance of TTI's Information and Technology Exchange Center, and the artwork was provided by Mr. Dick Westbrook of Houston, Texas. There were other approaches that were discussed in the focus group setting as methods of increasing belt use. These approaches included increasing enforcement, raising fines, changing laws, encouraging parents to use influence with teens, and other methods presenting the message, such as through stories, popular music or celebrity endorsements.

\section{Evaluation of Approaches}

The approaches were evaluated in focus groups of teens in the two states where teenage safety belt use was lowest and highest, Texas and Mississippi. Houston was chosen for testing because it represented the largest urban location in the study, and because teens in Houston were most likely to wear belts. Therefore, if non-belted teens could be recruited from amongst this population of majority users, they would be assumed to represent the group most difficult to convince to change their belt wearing behavior. Similarly, belt use among teens in Navasota was relatively low, considering the primary law in Texas, and there was interest in.determining if there was any difference in the appeal of the approaches for urban and small town youth. Jackson and Yazoo City were the two sites with the lowest safety belt use in the observational surveys. Again, both sites were included so that large and small city environments could be given consideration.

In Houston, Navasota, and Yazoo City, focus group participants were recruited from high schools where groups had previously been conducted. In Jackson, the group was recruited from Jackson State University freshmen dormitory areas. These areas were targeted to select 18 and 19 year-old males, the least frequent safety belt users. Tables 6.1 through 6.4 provide information on the composition of each group. 
Table 6.1. Characteristics of Houston Evaluation Focus Group

\begin{tabular}{|l|c|c|c|c|c|c|c|}
\hline \multicolumn{1}{|c|}{ Name } & Age & Race & Sex & $\begin{array}{c}\text { Driver } \\
\text { License }\end{array}$ & Drive & $\begin{array}{c}\text { Taken } \\
\text { DE }\end{array}$ & $\begin{array}{c}\text { Observed } \\
\text { SB Use }\end{array}$ \\
\hline Logan & 17 & $\mathrm{~W}$ & $\mathrm{M}$ & $\mathrm{Y}$ & $\mathrm{Y}$ & $\mathrm{Y}$ & $\mathrm{Y}$ \\
\hline Colette & 16 & $\mathrm{~W}$ & $\mathrm{~F}$ & $\mathrm{Y}$ & $\mathrm{Y}$ & $\mathrm{Y}$ & $\mathrm{Y}$ \\
\hline Evelyn & 15 & $\mathrm{~B}$ & $\mathrm{~F}$ & $\mathrm{~N}$ & ${ }^{*} \mathrm{Y}$ & $\mathrm{N}$ & $\mathrm{U}$ \\
\hline Ashley & 15 & $\mathrm{~W}$ & $\mathrm{~F}$ & $\mathrm{~N}$ & ${ }^{*} \mathrm{Y}$ & $\mathrm{N}$ & $\mathrm{U}$ \\
\hline Haley & 15 & $\mathrm{~W}$ & $\mathrm{~F}$ & $\mathrm{~N}$ & ${ }^{*} \mathrm{Y}$ & $\mathrm{Y}$ & $\mathrm{N}$ \\
\hline Andrea & 16 & $\mathrm{~W}$ & $\mathrm{~F}$ & $\mathrm{Y}$ & $\mathrm{Y}$ & $\mathrm{Y}$ & $\mathrm{Y}$ \\
\hline George & 16 & $\mathrm{H}$ & $\mathrm{M}$ & $\mathrm{N}$ & ${ }^{*} \mathrm{Y}$ & $\mathrm{N}$ & $\mathrm{N}$ \\
\hline Henry & 15 & $\mathrm{H}$ & $\mathrm{M}$ & $\mathrm{N}$ & ${ }^{*} \mathrm{Y}$ & $\mathrm{N}$ & $\mathrm{N}$ \\
\hline Rachel & 17 & $\mathrm{~W}$ & $\mathrm{~F}$ & $\mathrm{Y}$ & $\mathrm{Y}$ & $\mathrm{Y}$ & $\mathrm{U}$ \\
\hline
\end{tabular}

*drives occasionally or practices driving

Table 6.2. Characteristics of Navasota Evaluation Focus Group

\begin{tabular}{|l|c|c|c|c|c|c|c|c|}
\hline \multicolumn{1}{|c|}{ Name } & Age & Race & Sex & Class & $\begin{array}{c}\text { Driver } \\
\text { License }\end{array}$ & Drive & $\begin{array}{c}\text { Taken } \\
\text { DE }\end{array}$ & $\begin{array}{c}\text { Observed } \\
\text { SB Usage }\end{array}$ \\
\hline Carolyn & 15 & W & F & Freshman & N & N & N & N \\
\hline Matthew & 15 & W & M & Freshman & N & Y & Y & N \\
\hline Serena & 15 & H & F & Freshman & N & N & N & N \\
\hline Antwan & 16 & B & M & Junior & Y & Y & Y & N \\
\hline Shawn & 17 & B & M & Junior & ${ }^{*}$ N & Y & Y & U \\
\hline Josh & 16 & W & M & Junior & Y & Y & Y & U \\
\hline
\end{tabular}

*will receive his driver license at the end of the week of the focus group 
Table 6.3. Characteristics of Jackson Evaluation Focus Group

\begin{tabular}{|l|c|c|c|c|c|c|c|}
\hline \multicolumn{1}{|c|}{ Name } & Age & Race & Sex & Class & $\begin{array}{c}\text { Driver } \\
\text { License }\end{array}$ & $\begin{array}{c}\text { Observed } \\
\text { SB Use }\end{array}$ & $\begin{array}{c}\text { Years } \\
\text { Driving }\end{array}$ \\
\hline Ron & 18 & B & M & Freshman & Y & - & 2 \\
\hline Chris & 19 & B & M & Freshman & Y & N & 5 \\
\hline Antony & 19 & B & M & Sophomore & Y & N & 5 \\
\hline Alfred & 19 & B & M & - & Y & N & 4 \\
\hline Jamiri & 19 & B & M & - & Y & - & 1 \\
\hline Damon & 19 & B & M & Sophomore & Y & - & 4 \\
\hline Frank & 19 & B & M & - & Y & - & 4 \\
\hline James & 19 & B & M & - & Y & N & 4 \\
\hline
\end{tabular}

Table 6.4. Characteristics of Yazoo City Evaluation Focus Group

\begin{tabular}{|l|c|c|c|c|c|c|c|}
\hline \multicolumn{1}{|c|}{ Name } & Age & Race & Sex & Class & DL'S & $\begin{array}{c}\text { Observed } \\
\text { SB Usage }\end{array}$ & Auto/Make \\
\hline Ashondria & 17 & B & F & 12 th & N & NA & NA \\
\hline Nikki & 18 & B & F & 12 th & Y & NA & NA \\
\hline Lakita & 18 & B & F & 12 th & N & NA & NA \\
\hline Cliffon & 18 & B & F & 12 th & Y & NA & NA \\
\hline Stacy & 18 & W & F & 12 th & Y & NA & NA \\
\hline Jason & 17 & W & M & 12 th & Y & NA & NA \\
\hline Tangela & 17 & B & F & 12 th & Y & NA & NA \\
\hline Dwan & 17 & B & $M$ & 12 th & Y & NA & NA \\
\hline
\end{tabular}


Several topics were discussed in the focus groups (see Appendix ?) to establish a frame of reference for the evaluation topic. The first topic was safety belt use and reasons for use or non-use. The second topic was influences on safety belt use; i.e., by parents, laws, penalties, driver education, and peers. The third topic was a discussion of motivations, fears, and decision-making while driving or riding. Topics four, five, and six dealt with the evaluation of approaches for increasing belt use among teens. The first three topics yielded results similar to those described in chapter 5. As these first three topics were essentially setup topics for the last three, a discussion of each is not included in detail in this report, except as they relate to countermeasure or campaign development.

\section{Results of Safety Belt Campaigns Assessment}

\section{Campaign I: It Doesn't Take Much to Wreck a Life. It Doesn't Take Much to Save One}

This educational approach did not receive overwhelming support from any of the focus groups. The groups in Texas tended to believe the message. The group in Yazoo City held to their beliefs that accident depictions needed to be serious to be effective, and they did not think it likely they would be in a serious accident. The concept's point was made with many of the participants. However, it was not a favorite or influential message to anyone.

\section{Campaign II: Wear It Now-Wear It Later}

This theme had great appeal to many of the focus group participants because of its focus on death. The first set of visuals was considered to the point, simple, and thought provoking. The second set of visuals was more abstract, but also considered thought provoking, and several mentioned they liked the "surprise ending." This campaign was ranked as favorite in all of the groups. Non-belt users said they would be influenced by the ad, and many said it would make them think about belt use.

Campaign III: You wouldn't jump without a parachute, you wouldn't take on a linebacker without a helmet, you wouldn't walk a tightrope without a net...

In discussions of this campaign, the teens tended to want to challenge the premise. Some said they would take those risks. One participant said it lacked blood and guts and seemed cartoonlike. Another remarked that if you were smart enough not to do those things, you should be smart enough to wear your safety belt. Some liked the emphasis on common sense. However, a few teens pointed out that "you automatically know you could get hurt or killed by the things illustrated in the ad, but you do not automatically think you can get killed or hurt in a car accident." This campaign was no one's favorite. 


\section{Campaign IV: The Statistical Campaign}

This campaign seemed to have a thought-provoking effect on group members. The appeal was greater for the high school student groups. They mentioned that it was a good ad campaign because it used facts and data to get the message across, and used friends and classmates with whom they could associate. Several comments were made such as: "it made me think it could be my graduating class-it could be my friends." The ad was not appealing, however, to the university age group. They indicated such an ad might work for a younger audience but was too late for them, since their age group had either been in crashes themselves or knew others who had, and their mind would not be changed by the facts presented. The only group in which this campaign was ranked as a favorite by any of its participants was in Houston.

\section{Campaign V: Are you free tonight?}

This campaign was fairly popular in each of the focus groups, and it also generated the most discussion. There was some confusion about what happens from the first frame to the second. The teens had many suggestions for what could be added to fill in the information gaps. A major area of agreement was that the guy from the first frame should be shown somewhere in the second frame, either beside the girl, in or near the car. The participants also frequently mentioned that the crash should be shown, and more information should be shown regarding the safety belt. Individual differences surfaced in terms of the degree of appropriate gore. That is, some wanted more blood, some wanted to see her halfway ejected through the windshield, some wanted a white sheet over her, etc.. No one indicated they thought the message was too grim. This campaign was second in popularity for most groups.

\section{Campaign VI: What will it take to get you to wear one?}

A clear divergence of opinion arose in response to this campaign. The ad was received with a somewhat lukewarm response in Navasota. They were amused, did not feel insulted, and several said they would like to be able to wear a Nike belt. The entire group said they just looked better, which would make them better to wear. The Houston group did not like the ad at all. Furthermore, they did not think the ad would influence anyone to wear their safety belt. They responded as if they were insulted and found it incredulous that the ad would appeal to anyone.

The reaction in Mississippi was the opposite. In Yazoo City they all agreed that a fashion statement would work better than a safety statement. The entire group like the designer belts, and felt their peers would wear them. The consensus was the bigger, the brighter, the better. In the Jackson group, no one reported they wore safety belts. and they considered themselves "lost causes". in this regard. However, they did respond positively to this presentation. One participant stated he thought if anything could make them wear a safety belt, a designer belt just might. They all concurred that if belts were designed to be more comfortable they would wear them more. 


\section{Campaign VII: $\quad$ One Size Fits All}

This campaign was not very well received. One of its major shortcomings for this audience was that many did not believe it. As described in the preceding chapter, the most common complaint regarding safety belts was that they are uncomfortable. The people drawn in each frame did not represent the target audience well enough or convincingly enough. Although a few could see a benefit to this campaign as a reminder, almost all agreed the ad would not persuade them to wear their safety belt.

\section{Message Delivery}

In each group the issue of how best to deliver safety belt messages was discussed. Television was by far the most highly recommended venue by this age group for this age group. The consensus in every group was that they could relate best to someone in their own age group who had been through an accident, someone with whom they could identify. Other types of messages and message delivery may serve as reminders or techniques of keeping the issue in front of them. But these approaches were viewed as easier to ignore and not likely to change opinion or behavior. The messages that seemed to have the most impact were those that were highly visual with the messenger being "one of their own." Experts, law enforcement personnel, teachers, and celebrities were viewed as uninteresting, ineffective, or insincere. However, given the number of comments in this vein, apparently teens would do almost anything Michael Jordan told them to do.

\section{Results of Assessment of Other Approaches}

Other approaches to influence full-time safety belt use were presented in addition to the seven educational campaigns described above. One approach was the presentation of several vignettes wherein a personal account of losing a loved one was written. The moderator read major parts of a letter called "Dead at 17" (see Appendix D) and asked for reactions. The letter did not really hit home with any of the groups. Some said it might have a temporary effect of raising awareness, but the overriding response was that "it happened to someone else somewhere else." It was also considered sad, and something they would tune out.

The teens were asked about the effect of greater enforcement of the safety belt law on their behavior. In general, teens in the focus groups asserted that the law was not a causal factor in their decision. For those in the secondary law state of Mississippi, there was some agreement that if the law was primary they would be more inclined to use their belts. However, when this topic was discussed in Jackson, the 19-year old participants thought it highly unlikely that Mississippi police would enforce a primary law. They considered Mississippi police much too heavily involved in fighting more serious crimes to spend time on something they considered so insignificant. In addition, they stated that most of the police did not wear safety belts. If the secondary law was 
enforced more, they claimed their reaction would be to react faster to put their belt on when they saw an officer, or to make sure they did not commit other offenses.

Two individuals in the Jackson focus group said they had been given a ticket for not wearing their safety belt. The fine was $\$ 27$. They reported they did not wear safety belts afterwards. Raising the fine was not seen as an influential method for encouraging belt use among this group. The high school group in Yazoo City thought doubling the fine would have an effect. In both groups in Texas, their evaluation of the effect of raising the fine was diluted by the fact that about half of these teens said their parents would pay the fine for them.

The approach of parental involvement in teen decision-making with regard to belt behavior was discussed. According to teens, parents telling them to wear their safety belts or teaching them at this age is a highly ineffective approach. They may think about it sometimes, but basically, once they're in the car independent of their parents, they make their own decision. Parents in the car have a more direct effect. Prior focus groups indicated that parents as models of belt wearing behavior and as enforcers of belt use with younger children seemed to have a lasting effect through teen years.

According to the focus group participants, driver education had a positive but not a lasting effect on their use of safety belts. All said safety belts were required during driver education and that they dealt with the issue briefly in class. After completing the course, those who did not wear them before quit wearing them. No one in these sets of focus groups said the course changed their mind to wear them.

The effect of peer pressure was discussed in these evaluation focus groups as well as in the focus groups in the four states. In Texas, Virginia, and Idaho, mixed safety belt use within vehicles by teens was not uncommon. An attitude of consideration for individual choice was prevalent, i.e., "if they want to [don't want to] wear their seatbelt that's fine with me. It's up to them." Furthermore, in these states teen safety belt users said they would have no problem asking other teens in their car to buckle up. Everyone who was asked said they would put their seatbelt on and not think anything of it, if someone in the vehicle requested it. They maintained there was no stigma or stereotype associated with individual belt use. Many reported that seeing friends put their safety belts on served as a reminder to them to do likewise.

In Mississippi, however, the consensus among the evaluation focus groups was that it is not necessarily considered cool to wear a safety belt. Belt use by one teen in the car was viewed with. suspicion by others. For example, one participant said if he noticed his driver friend putting on a safety belt, he would put his on also because the driver must think something is going to happen. One female said she wondered if her friend thought she was a bad driver when the friend put her seatbelt on. A Jackson participant said, "if you said to your date, hey baby put your seatbelt on for safety reasons, she would laugh." 


\section{Summary of Evaluation of Approaches to Increase Safety Belt Use}

Four focus groups were convened in Texas and Mississippi with a total of 31 participants to evaluate approaches to increase safety belt use among teen non-users and part-time users. The key findings from this effort are summarized below:

- Teens expressed a preference for reality in educational campaigns.

- Grim and bloody were considered more effective in influencing their thinking than humorous and catchy.

- Ads featuring other teens were preferred.

- Teens said they were more likely to pay attention to television or radio commercials than anything in print.

- Teens in focus groups did not think greater enforcement of secondary laws would influence them or other teens to buckle up more often. However, they thought greater consistency of use would result from the enforcement of a primary law.

- Increasing the fine for a safety belt violation may not have the desired effect for this age group because they do not think they will be ticketed, and if ticketed they may not be responsible for paying the fine themselves. 


\section{CHAPTER SEVEN}

\section{CONCLUSIONS AND RECOMMENDATIONS}

\section{Summary of Findings}

The purpose of this study was to identify conditions of safety belt use among teenage youth, and to develop and evaluate approaches to increase belt use for the 15 to 19 year-old age segment. Four states were selected for study in which various types of mandatory safety belt use laws, previously measured levels of compliance, and licensing requirements were in effect. Observational surveys, individual discussions with teens, and focus groups were the three techniques employed to collect data.

Observational Surveys. During the observational phase, 17,411 vehicles were observed, and restraint data were recorded for 28,326 occupants, 7,384 of whom were estimated as $15-19$ years old. In addition, ages and other pertinent information was obtained from 2,330 teen occupants in 1,453 vehicles.

Patterns of safety belt use for teens were found to be similar to those of the adult population at large, although the teenage usage rate was lower than the general usage rate in each area. Usage rates in each state were found to be comparable to reported rates from previous surveys for the areas in the study. The difference was mitigated by position in the vehicle. No statistically significant differences in driver restraint use between teens and older adults were found in Houston, Charlottesville, and. Boise, while statistically significant lower use rates for teen drivers were observed in Navasota, Roanoke, Mountaint Home, Jackson, and Yazoo City.

Teen drivers were more likely than teen passengers to wear safety belts. Females were more likely than males to wear them. Passenger car occupants were more likely to be belted than pickup and other utility type vehicle occupants. Younger and less experienced drivers were more prone toward belt use. Additionally, those who had taken driver education were more apt to be belted. These findings were supportive of the indications of belt use among teens discussed in the literature review.

Almost 60 percent of the teens interviewed said there were times or conditions in which they did not always wear their safety belt. Very few said they wear them in the back seat. Teens were more apt to buckle up when driving on the highway, and less apt to buckle up for short trips in the city and when involved in recreational activities. Passengers were more likely than drivers to use safety belts on a conditional basis, depending on who was driving and where they were riding in the vehicle.

Focus Groups. Ten focus groups and one in-depth interview were held in the four study states. The content of the discussion included assessment of the risks associated with driving, 
attitudes and behavior regarding safety belt use, attitudes toward the mandatory use law, and approaches for influencing belt use behavior and attitudes.

A degree of confidence in their own driving ability was expressed by teens in the focus group setting. This confidence carried over in their assessment of their peer's abilities as well. Descriptions of risky driving behavior by their teenage counterparts were given by the focus group participants, but did not lead to much concern because of their assessment of the skill levels of youth. Some acknowledgment was occasionally given to the experience factor among older adult drivers, but in general, teens viewed older drivers (e.g., their parents and adults who had been driving many years) as complacent about driving and more dangerous than themselves.

The degree of perceived risk for crashes was very much an individual characteristic, and could not be generalized to this age group or any particular location. The fatalistic viewpoint surfaced in several groups. Furthermore, most teens did not express the belief that increased skill resulted in invulnerability on the road.

The most often cited reason for restraint non-use was that they are uncomfortable. Teens also frequently reported they "just don't think about" wearing safety belts. The necessity for safety belts was not recognized by many participants in the focus groups. Very often statements were made that belts can do more harm than good. Teens voiced a lack of confidence in the reliability of safety belts to work when needed. They were not knowledgeable of the effectiveness of belts in various crash types, nor of the physics of crashes.

The decision for use was often associated with a heightened sense of danger as exemplified by use on highways, on weekends, on prom night, and in bad weather, or with a lack of trust in the driver. For some, such conditional use was associated with reminders from parents, or with the presence of an automatic restraint. Conditional use was not overly sensitive to peer pressure (except in Mississippi) or to fear of being given a citation (especially in Mississippi).

Teens who wore safety belts on a regular basis did so primarily because it was their habit. Although most of the full-time users believed in the safety benefit of wearing safety belts, they were not motivated entirely by an accurate perception of accident risk, or of crash characteristics. More commonly, they had been "raised wearing them," had begun wearing them in conjunction with learning to drive, or had been convinced by a first-hand accident experience or the experience of someone close to them.

Evaluation of Approaches for Improvement. Four additional focus groups were convened in Texas and Mississippi to evaluate approaches for improving belt use among teens. These groups confirmed the appeal of realism, visual consequences and peer involved presentations for this age group. Widespread endorsement of greater enforcement, higher fines, or parental steps to influence use was not found during the discussion groups, although some of these factors did appear to be at work in the establishment of the belt wearing habit. An enforced, primary law was considered a 
highly effective approach for increasing consistent restraint use, according to the focus group participants.

\section{Conclusions and Recommendations}

A key conclusion that can be drawn from this research is the perhaps obvious one that the best means to increase conditional use is tó reinforce habitual use. Observational data and focus group discussions indicated that situational decisions are not made that override usual practices with great frequency. It is more likely that occasional use results from perceived risky situations.

- A second key conclusion is that this segment of the motor vehicle population is severely lacking in knowledge regarding safety belt effectiveness and crash dynamics. Efforts should be directed toward educating this group that belts are effective. The study supported recommendations by Loo (1984) for the need to focus on two types of non-users: those who disagree with mandatory use and never use belts (i.e., attitude and behavior are consistent); and those who agree with mandatory belt use but never use belts (i.e., attitude and behavior are inconsistent.) Most of the teens encountered in this research fit the second category-they were actually supportive of safety belt laws but were not consistent with their own belt wearing behavior.

Recommendations for Short Term Approaches for Influencing Youth Safety Belt Use. Converting teens who are safety belt non-users to users would be enhanced by the use of hardhitting, factual, realistic demonstrations and enactments to illustrate the results of non-use. These approaches would also benefit efforts to keep the issue before teens who are part-time users. Additional attention-getting campaigns may supplement the more direct approach to serve as reminders for conditional users.

Recommendations for Long Term Approaches for Influencing Youth Safety Belt Use. Observational survey results support the case for primary mandatory use laws. In the primary law state in this study, safety belt use was much more a social norm for the teenage group. This approach appears most likely to instill and reinforce the safety belt wearing habit. 


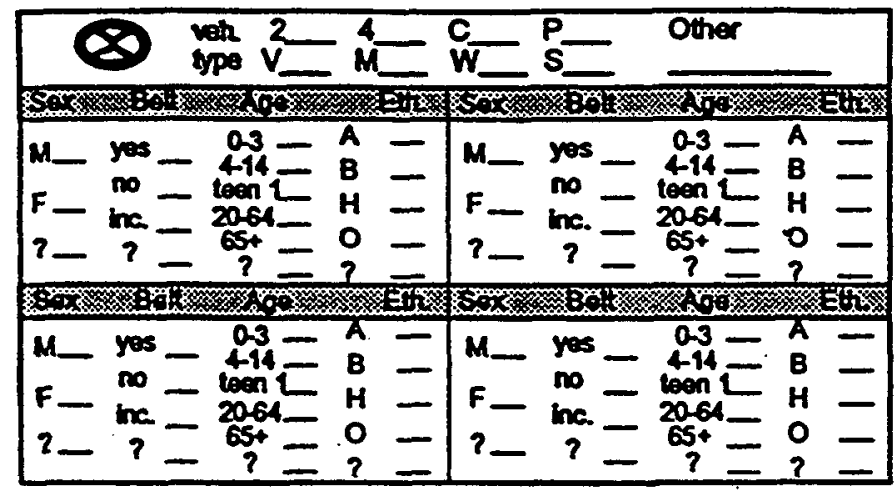

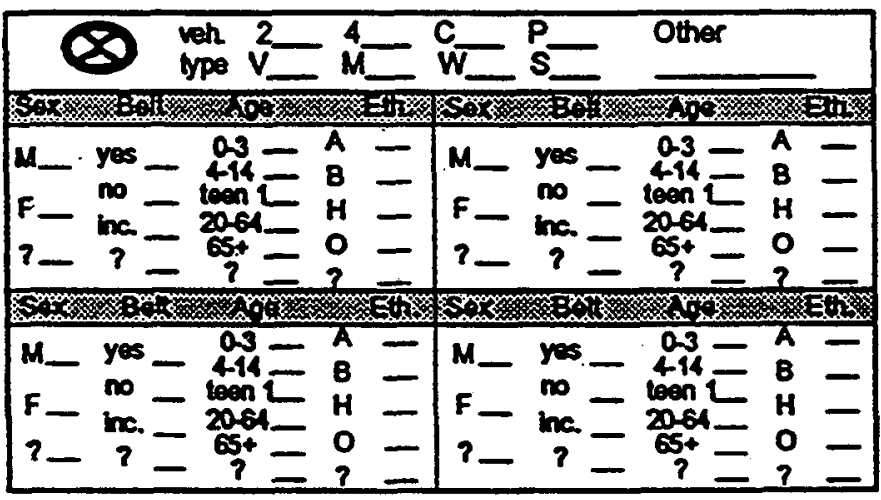

\begin{tabular}{|c|c|c|c|c|c|c|c|c|c|}
\hline & & $v^{2}$ & -4 & 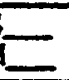 & $\mathbf{c}_{-}$ & $\mathrm{P}$ & Other & & \\
\hline & & & & & & & & & $\operatorname{seth}$ \\
\hline ?- & $\begin{array}{l}\text { yes - } \\
\text { no - } \\
\text { inc. - } \\
? \text { - }\end{array}$ & $\begin{array}{c}\operatorname{sen} 2 \\
2064= \\
65+= \\
?=\end{array}$ & $\begin{array}{l}\text { A } \\
\mathbf{B} \\
H \\
0 \\
?\end{array}$ & $\begin{array}{l}- \\
z\end{array}$ & $\begin{array}{l}\mathrm{M}_{-} \\
\mathrm{F}-\end{array}$ & $\begin{array}{l}\text { yos - } \\
\text { no - } \\
\text { nc. - } \\
?-\end{array}$ & $\begin{array}{c}03= \\
414= \\
\tan 2- \\
204= \\
65=\end{array}$ & $\begin{array}{l}A \\
B \\
H \\
0 \\
?\end{array}$ & I \\
\hline $59 x$ & 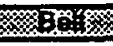 & s. & & Entro & $\operatorname{sen}$ & 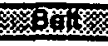 & $10 \%$ & & Etry \\
\hline$=$ & $\begin{array}{l}\text { yes } \\
\text { no - } \\
\text { inc - } \\
?\end{array}$ & $\begin{array}{c}03= \\
414= \\
6002= \\
2064= \\
65+= \\
?=\end{array}$ & $\begin{array}{l}A \\
B \\
H \\
0 \\
7\end{array}$ & - & $\begin{array}{l}M_{-} \\
F_{-}\end{array}$ & $\begin{array}{l}\text { yes } \\
\text { no - } \\
\text { me. - } \\
?+\end{array}$ & $\begin{array}{c}03- \\
4-14= \\
\log 2- \\
2064= \\
65+= \\
7=\end{array}$ & $\begin{array}{l}A \\
B \\
H \\
0 \\
?\end{array}$ & - \\
\hline
\end{tabular}

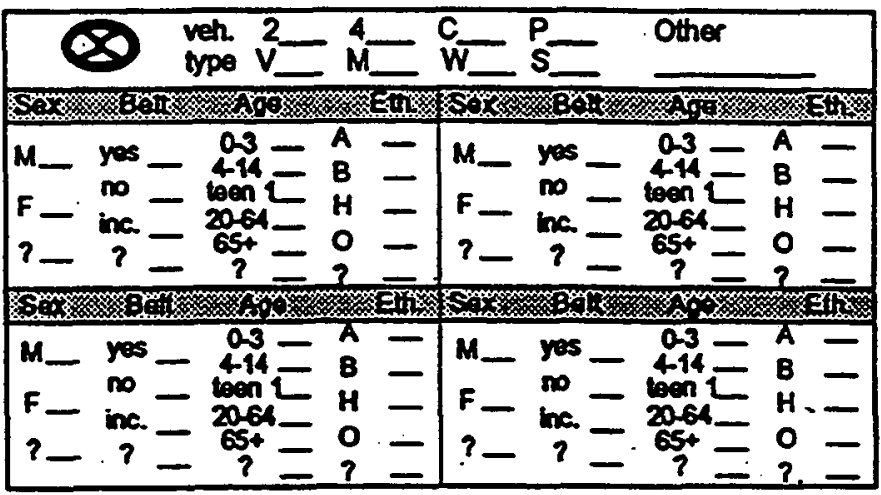

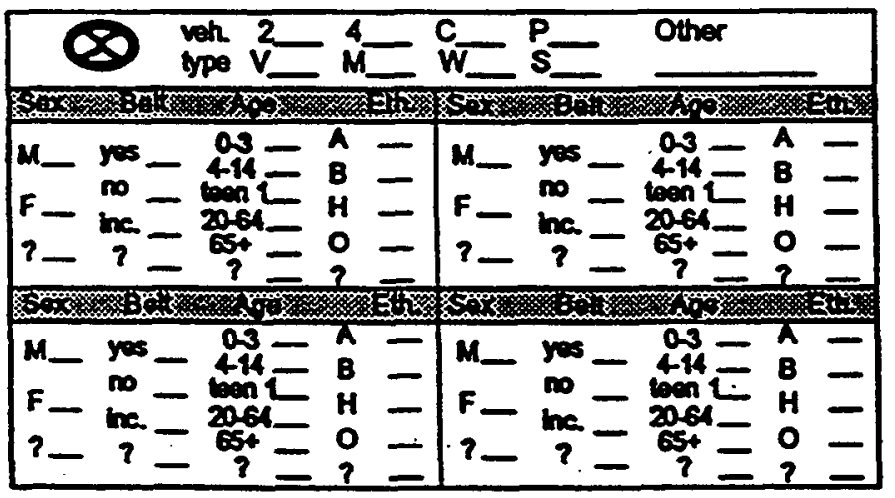

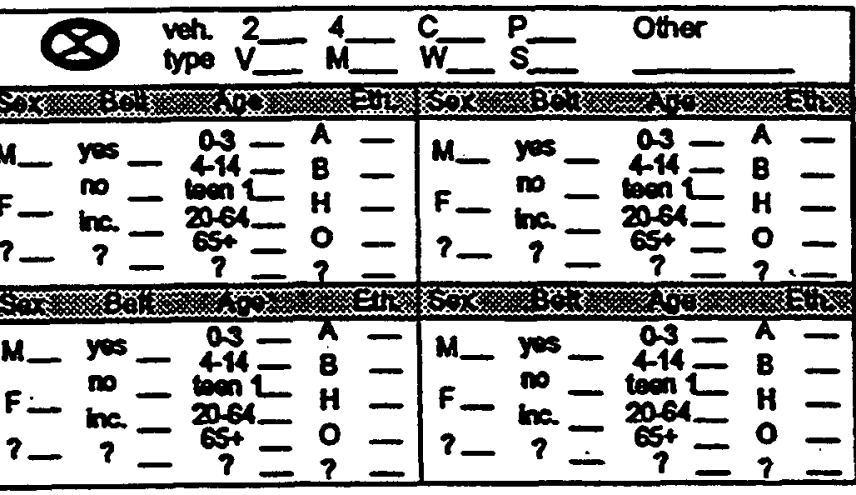

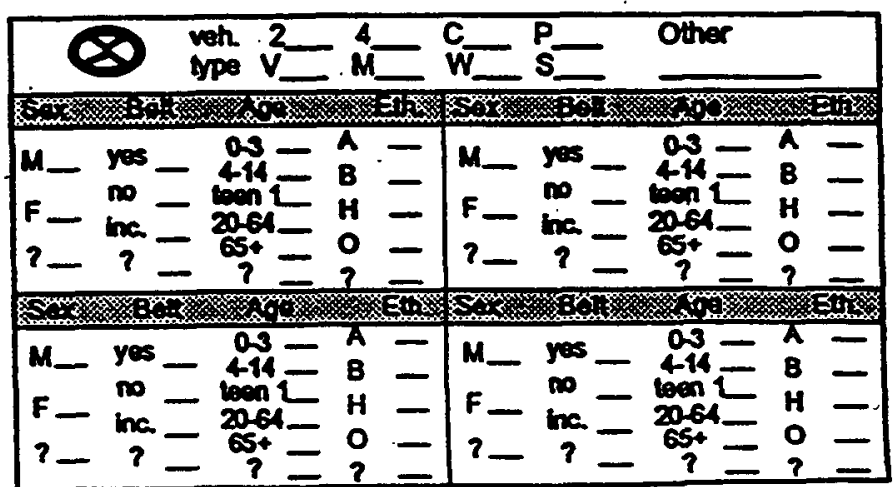




\section{Occupant Information}

Driver Middle

Outboard

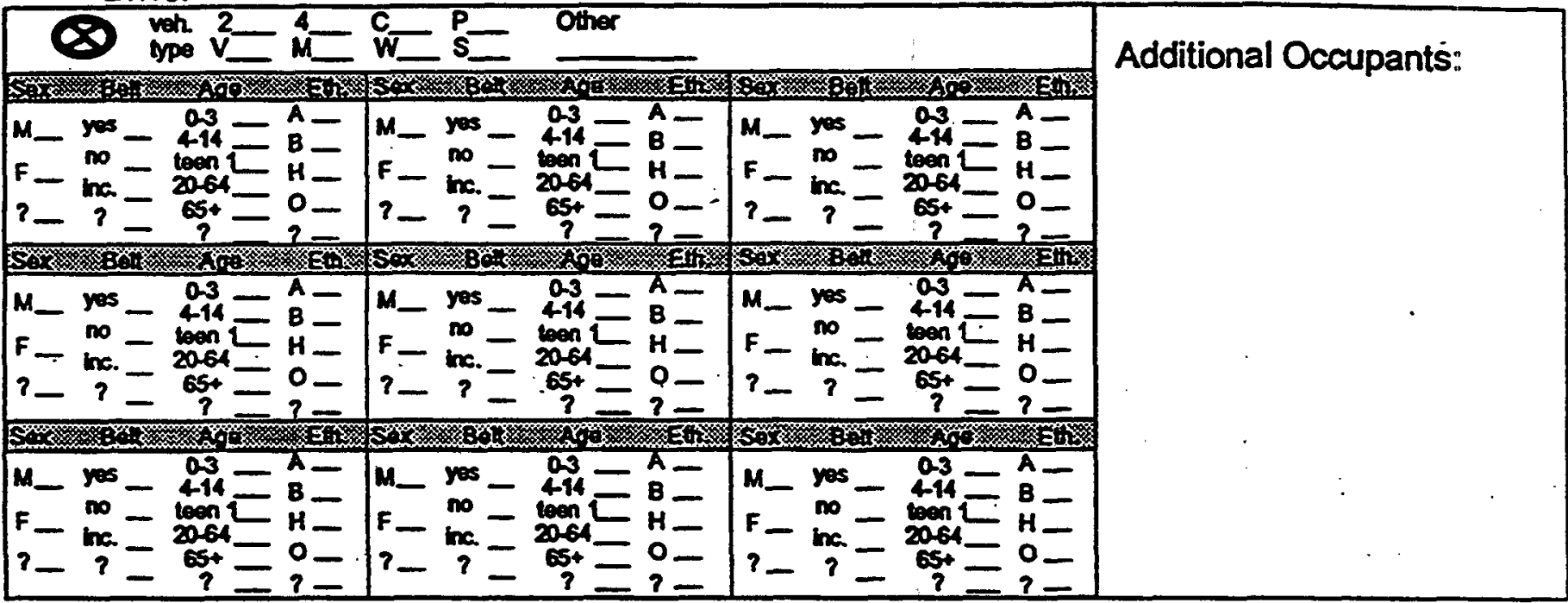

HOW OFTEN DO YOU USE BELTS?

Most About Some- Very Never not
Aways of the $1 / 2$ the Soes
time time times rarely (if mentioned) or why not (if less than $1 / 2$
apply
1. As a
driver
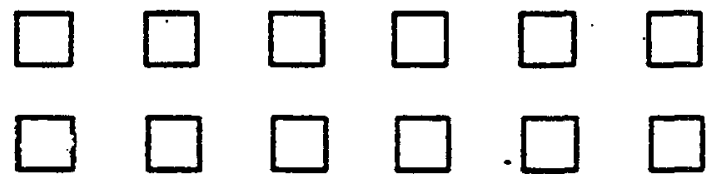
2 As a passenger
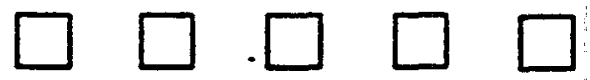
3. Highnay
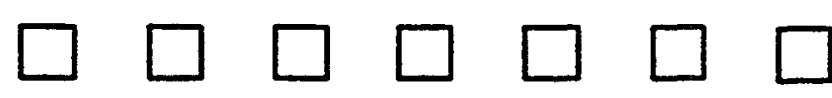
4. Cityrtown
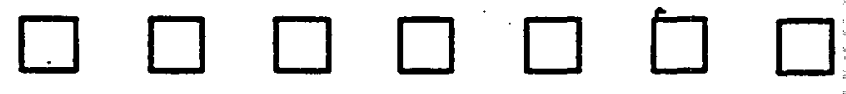
5. To School
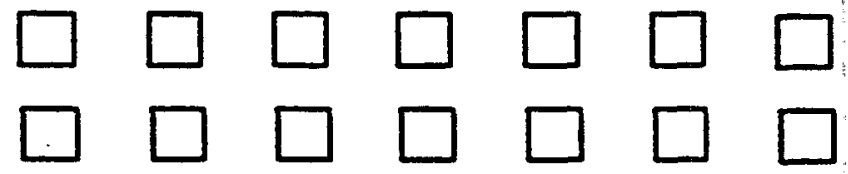
6. To Work
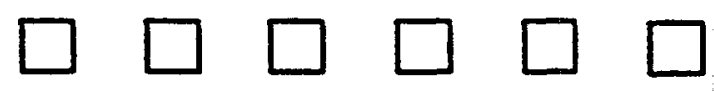
7. Recreational
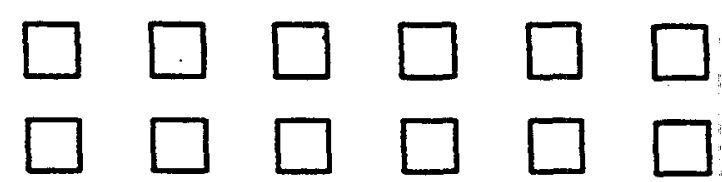

\section{Other}

10. Have you ever taken driver education?

11. What type of driver license do you have?
$\square$ coanditional license
Operator/regular Ecense
None
$\square$ Commercial toense

Motorcycle

license yes

$\square$ no

$\square$ taking now

12. Relationship of the Occupants:

$\square$ Friends $\quad \square$ Family members

$\square$ Dates $\quad \square$ Co-workers

Other 


\section{MINOR ASSENT FORM}

The Texas Transportation Institute (TTI) will be leading a discussion session to talk with teenagers about traffic safety issues. These discussion sessions will last about 2 hours and will be held in [month] at [school, church, or public meeting room name]. About 8 teenagers will take part in the group. You will be asked to share your opinions on several traffic safety subjects. Your full name will never be used in the study.

As a discussion group member, I agree to:

Take part in the discussion with the understanding that there are no right or wrong answers. I may choose not to talk about any of the subjects that make me uncomfortable.

Be given $\$ 10$ in cash at the end of the session for being a part of the group.

Share my opinions to help the researchers understand the views of teenagers. I understand that I may quit after $11 / 2$ hours and still be given $\$ 10$.

This research study has been reviewed and approved by the Institutional Review Board at Texas A\&M University. If you have questions, you may contact the board at (409) 845-1811.

I have read and understand this form, and agree to be a part of the discussion group.

Name of group member

Date

Name of researcher

Date

Researcher: Katie Womack, Human Factors Program, Texas Transportation Institute, College Station, Texas, 77843-3135, (409)845-2736. 


\section{GUARDIAN CONSENT FORM}

The Texas Transportation Institute (TTI) will be leading a discussion session to talk with teenagers about traffic safety issues. These discussion sessions will last about 2 hours and will be held in [month] at [school, church, or public meeting room name]. About 8 teenagers will take part in the group. Your teenager will be asked to share their opinions on several traffic safety subjects. All identities will be confidential.

As a discussion group member, each teenager agrees to:

Take part in the discussion with the understanding that there are no right or wrong answers. They may choose not to talk about any of the subjects that make them uncomfortable.

Be given $\$ 10$ in cash at the end of the session for being a part of the group.

Share opinions to help the researchers understand the views of teenagers. They may withdraw after $11 / 2$ hours and still be given $\$ 10$.

This research study has been reviewed and approved by the Institutional Review Board at Texas A\&M University. If you have questions, you may contact the board at (409) 845-1811.

- I have read and understand this form, and voluntarily give my consent for [name of minor] to participate in the discussion group.

Guardian Signature

Date

Researcher Signature

Date

Researcher: Katie Womack, Human Factors Program, Texas Transportation Institute, College Station, Texas, 77843-3135, (409)845-2736. 
Dead at Seventeen

by: John Berrio

Agony claws my mind. I am a statistic. When I first got here, I felt very much alone. I was overwhelmed by grief, and I expected to find sympathy.

I found no sympathy. I saw only thousands of others whose bodies were as mangled as mine. I was given a number and placed in a category. That category was called "Traffic Fatalities."

The day I died was an ordinary school day. How I wish I had taken the bus! But I was too cool for the bus. I remember how I wheedled the car out of Mom. "Special Favor," I pleaded. "All the kids drive." When the 2:50 p.m. bell rang, I threw my books in the locker... free until tomorrow morning! I ran to the parking lot, excited at the thought of driving a car and being my own boss.

It doesn't matter how the accident happened. I was goofing off- going too fast, taking crazy chances. But I was enjoying my freedom and having fun. The last thing I remember was passing an old lady who seemed to be going awfully slow. I heard a crash and felt a terrific jolt. Glass and steel flew everywhere. My whole body seemed to be turning inside out. I heard myself scream.

Suddenly, I awakened. It was very quiet. A police officer was standing over me. I saw a doctor. My body was mangled. I was saturated with blood. Pieces of jagged glass were sticking out all over. Strange that I couldn't feel anything.

Hey, don't pull that sheet over my head. I can't be dead. I'm only 17. I've got a date tonight. I'm supposed to have a wonderful life ahead of me. I haven't lived yet. I can't be dead.

Later, I was placed in a drawer. My folks came to identify me. Why did they have to see me like this? Why did I have to look at Mom's eyes when she faced the most terrible ordeal of her life? Dad suddenly looked very old. He told the man in charge, "Yes, he's our son."

The funeral was weird. I saw all of my relatives and friends walk toward the casket. They looked at me with the saddest eyes I've ever seen. Some of my buddies were crying. A few of the girls touched my hand and sobbed as they walked by.

Please somebody- wake me up! Get me out of here. I can't bear to see Mom and Dad in such pain. My grandparents are so weak from grief they can barely walk.

$\mathrm{My}$ brother and sister are like zombies. They move like robots. In a daze. Everybody. No one can believe this. I can't believe it, either.

Please, don't bury me! I'm not dead! I have a lot of living to do! I want to laugh and run again. I want to sing and dance. Please don't put me in the ground! I promise if you give me just one more chance, God, I'll be the most careful driver in the whole world. All I want is one more chance. Please God, I'm only 17. 


\section{REFERENCES}

Arnett, J. (1990). Drunk driving, sensation seeking, and egocentrism among adolescents. Personality and Individual Differences, 11 (6), 541-546.

Basch, C.E. (1987). Focus group interview: an underutilized research technique for improving theory and practice in health education. Health Education Quarterly, 14(4), 411-448.

Basch, C.E., DeCicco, I.M., and Malfetti, J.L. (1989). Health Education Quarterly, 16(3), 389-396.

Boyle, J.M. (1995). Motor Vehicle Occupant Safety Survey. U. S. Department of Transportation, Washington, DC. DOT-HS-808-334.

Brick, M., and Lago, J. (1988). The design and implementation of an observational safety belt use survey. Journal of Safety Research, 19, 87-98.

Budd, R.J., North, D., and Spencer, C. (1984). Understanding seat-belt use: a test of Bentler and Speckart's extension of the 'theory of reasoned action.' European Journal of Social Psychology, 14, 69-78.

Calder, B.J. (1977). Focus groups and the nature of qualitative marketing research. Journal of Marketing Research, 14, 353-364.

Carey, M.A., and Smith, M.W. (1994). Capturing the group effect in focus groups: a special concern in analysis. Qualitative Health Research, 4(1), 123-127.

Cope, J.G., Johnson, A.W., and Grossnickle, W.F. (1990). Behavior engineering proposals: effects on drivers and passengers of a mandatory use law for safety belts. Perceptual and Motor Skills, 71, 291-298.

Desai, A., and You, M.B. (1992). Policy implications from an evaluation of seat belt use regulation. Evaluation Review, 16(3), 247-265.

Deutsch, D., Sameth, S., \& Akinyemi, J. (1980). Seat belt usage and risk-taking behavior at two major traffic intersections. Proceedings of the 24th Conference of the American Association. for Automotive Medicine, Rochester, NY.

Dolcini, M.M., Cohn, L.D., Adler, N.E., Millstein, S.G., Irwin, C.E., Kegeles, S.M., and Stone, G.C. (1980). Adolescent egocentrism and feelings of invulnerability: are they related? Journal of Early Adolescence, $2(4), 409-418$.

Eiser, J.R., and Harding, C.M. (1983). Smoking, seat-belt use and perception of health risks. Addictive Behaviors, $\underline{8}, 75-78$. 
Eiser, J.R., Sutton, S.R., and Wober, M. (1979). Smoking, seat-belts, and beliefs about health. Addictive Behaviors, 4, 331-338.

Elman, D., and Killebrew, T.J. (1978). Incentives and seat belts: changing a resistant behavior through extrinsic motivation. Journal of Applied Social Psychology, $\underline{8},(1), 72-83$.

Emery, E.M., Ritter-Randolph, G.P., Strozier, A.L., and McDermott, R.J. (1993). Using focus group interviews to identify salient issues concerning college students' alcohol abuse. Journal of American College Health, 41(5), 195-198.

Enright, R.D., Lapsley, D.K., and Shukla, D.G. (1979). Adolescent egocentrism in early and late adolescence. Adolescence, 14(56), 687-695.

Enright, R.D., Shukla, D.G., and Lapsley, D.K. (1980). Adolescent egocentrism-sociocentrism and self-consciousness. Journal of Youth and Adolescence, 2(2), 101-116.

Eriksen, M.P., and Gielsen, A.C. (1983). The application of health education principles to automobile child restraint programs. Health Education Quarterly, 10(1), 30-55.

Evans, L., Wasielewski, P., and vonBuseck, C.R. (1982). Compulsory seat belt usage and driver risk-taking behavior. Human Factors, 24(1), 41-48.

Fern E.F. (1982). The use of focus groups for idea generation: tool for qualitative research. Qualitative Sociology, $7(3), 253-270$.

Ferrari, J. R., and Carter, A.L. (1987). Compliance by young and older drivers to the New York mandatory seat belt law: does wisdom come with age? Psychological Reports, 61, 697-698.

Fhaner, G., and Hane, M. (1973a). Seat belts: factors influencing their use. A literature survey. Accident Analysis and Prevention, $5,27-43$.

Fhaner, G., and Hane; M. (1973b). Seat belts: the importance of situational factors. Accident Analysis and Prevention, 5, 267-285.

Fhaner, G., and Hane, M. (1974a). Seat belts: contextual factors and bias of reported use. Journal of Safety Research, 6(4), 166-170.

Fhaner, G., and Hane, M. (1974b). Seat belts: relations between beliefs, attitude, and use. Journal of Applied Psychology, 59(4), 472-482.

Fhaner, G., and Hane, M. (1979). Seat belts: opinion effects of law-induced use. Joumal of Applied Psychology, 64(2), 205-212. 
Finn, P., and Bragg, B.W.E. (1986). Perception of the risk of an accident by young and older drivers. Accident Analysis and Prevention, 18(4), 289-298.

Fockler, S.K.F., and Cooper, P.J. (1990). Situational characteristics of safety belt use. Accident Analysis and Prevention, 22(22), 109-118.

Geller, E.S. (1984). A delayed reward strategy for large-scale motivation of safety belt use: a test of long-term impact. Accident Analysis and Prevention, 16(5/6), 457-463.

Geller, E..S., Johnson, R.P., and Pelton, S.L. (1982). Community-based interventions for encouraging safety belt use. American Journal of Community Psychology, 10(2), 183-195.

Geller, E.S., Paterson, L., and Talbott, E. (1982). A behavioral analysis of incentive prompts for motivating seat belt use. Journal of Applied Behavior Analysis, 15, 403-415.

Hawkins, W.E. (1992). Problem behaviors and health-enhancing practices of adolescents: a multivariate analysis. Health Values, 16(4), 46-54.

Helsing, K.J., and Comstock. G.W. (1977). What kinds of people do not use seat belts? American Journal of Public Health, 67(11), 1043-1050.

Hunter, W.W., Campbell, B.J., Gemming, M.G., and Stewart, J.R. (1984). Seat belts pay off: the evaluation of a community wide incentive program. 28th Annual Proceedings, American Association for Automotive Medicine, Denver, $\mathrm{CO}$.

Hunter, W.W., and Stutts, J.C., (1982). Use of economic incentives to modify safety belt use behavior. 26th Annual Proceedings, American Association for Automotive Medicine, Ottawa, Ontario, Canada.

Hunter, W.W., Stutts, J.C., Stewart, J.R., and Rodgman, E.A. (1988). Over-representation of seat belt non-users in traffic crashes. Report No. HSRC-TR74, Chapel Hill, NC: University of North Carolina Highway Safety Research Center.

Johnson, J.J., Hendricks, S.A., and Fike, J.M. (1994). Effectiveness of behavioral safety belt interventions. Accident Analysis and Prevention, 26(3), 315-323.

Jonah, B.A. (1984). Legislation and the prediction of reported seat belt use. Journal of Applied Psychology, 69(3), 401-407.

Jonah, B.A. (1986). Accident risk and risk-taking behavior among young drivers. Accident Analysis and Prevention, 18(4), 255:271. 
Jonah, B.A., and Dawson, N.E. (1982). Predicting reported seat belt use from attitudinal and normative factors. Accident Analysis and Prevention, 14(4), 305-309.

Jonah, B.A., Dawson, N.E., MacGregor, C.G., and Wilde, G.J.S. (1982). Promoting seat belt use: a comparison of three approaches. 26th Annual Proceedings. American Association for Automotive Medicine, Ottawa, Ontario, Canada.

Knapper, C.K., Cropley, A.J., and Moore, R.J. (1976). Attitudinal factors in the non-use of seat belts. Accident Analysis and Prevention, 8 , 241-246.

Langer, E.M., and Roth, J. (1975). Heads I win, tails it's chance: the illusion of control as function of the sequence of outcomes in a purely chance task. Joumal of Personality and Social Psychology, 32(6), 951-955.

Lau, R.R., Quadrel, M.J., and Hartman,K.A. (1990). Development and change of young adults' preventive health beliefs and behavior: influence from parents and peers. Journal of Health and Social Behavior, 31, 240-259.

Lederman, L.C. (1990). Assessing educational effectiveness: the focus group interview as a technique for data collection. Communication Education, 38, 117-127.

Lichtenstein, S., Slovic, P., Fischhoff, B., Layman, M., and Combs, B. (1978). Judged frequency of lethal events. Journal of Experimental Psychology: Human Learning and Memory, 4(6), 551-578.

Loo, R. (1984). Correlates of reported attitude towards and use of seat belts. Accident Analysis and Prevention, 16(5/6), 417-421.

Manheimer, D.I., and Mellinger, G.D. (1964). A survey of seat belt ownership in six California communities. Traffic Safety Research Review, 8(1), 3-9.

Matthews, M.L., and Moran, A.R. (1986). Age differences in male drivers' perception of accident risk: the role of perceived driving ability. Accident Analysis and Prevention, 18(4), 299-313.

Mortimer, R.G., Goldstein, K., Armstrong, R.W., and Macrina, D. (1990). Effects of incentives and enforcement on the use of seat belts by drivers. Joumal of Safety Research, 21, 25-37.

National Highway Traffic Safety Administration (1994). Request for Proposal: Identify Conditions of Safety Belt Use for Youth. RFP\# DTNH22-94-R-05010.

Nelson, G.D., and Moffit, P.B. (1988). Safety belt promotion: theory and practice. Accident Analysis and Prevention, 20(1), 27-38. 
Nordentoft, E.L., Kruse, T., Nielsen, H.V., and Weeth, R. (1978). The effect of mandatory seat belt legislation on mortality and morbidity in Denmark. Proceedings of the 22nd Conference of the American Association for Automotive Medicine and Traffic Medicine, Ann Arbor, MI.

O'Neill, B. (1977). A decision-theory model of danger compensation. Accident Analysis and Prevention, 2, 157-165.

Peltzman, S. (1975). The effects of automobile safety regulation. Joumal of Political Economy, $\underline{83}, 677-725$.

Preusser, D.F., Blomberg, R.D., and Edwards, J. M. (1989). Increasing safety belt use among high risk drivers. Interim report. Washington, DC: U.S. Department of Transportation.

Preusser, D.G., Williams, A.F., and Lund, A.K. (1985). Parental role in teenage driving. Journal of Youth and Adolescence, 14(2), 73-84.

Preusser, D.G., Williams, A.F., and Lund, A.K. (1987). The effect of New York's seat belt use law on teenage drivers. Accident Analysis and Prevention, 19(2), 73-80.

Robertson, L.S., O'Neill, B., and Wixom, C.W. (1972). Factors associated with observed safety belt use. Journal of Health and Social Behavior, 13, 18-24.

Ross, L., Greene, D., and House, P. (1977). The 'false consensus effect': an egocentric bias in social perception and attribution processes. Journal of Experimental Social Psychology, 13 , 279-301.

Rudd, J.R., and Geller, E.S. (1985). A university-based incentive program to increase safety belt use: toward cost-effective institutionalization. Joumal of Applied Behavior Analysis, 18(3), 215-226.

Schootman, M., Fuortes, L.J., Zwerling, C., Albanese, M.A., and Watson, C.A. (1993). Safety behavior among Iowa junior high and high school students. American Journal of Public Health, 83(11), 1628-1630.

Shanteau, J. (1978). When does a response error become a judgmental bias? Commentary on 'Judged frequency of lethal events'. Journal of Experimental Psychology: Human Learning and Memory, 4(6), 579-581.

Shinar, D. (1993). Demographic and socioeconomic correlates of safety belt use. Accident Analysis and Prevention, 25(6), 745-755.

Sleet, D.A. (1987). Motor vehicle trauma and safety belt use in the context of public health priorities. The Journal of Trauma, 27(7), 695-702. 
Sleet, D.A., and Geller, E.S. (1986). Do incentive programs for safety belt use work? Focal Points, 3, 1-2.

Slovic, P., Fischhoff, B., and Lichtenstein, S. (1978). Accident probabilities and seat belt usage: a psychological perspective. Accident Analysis and Prevention, 10, 281-285.

Smith, V.K., Desvousges, W.J., Johnson, F.R., and Fisher, A. (1990). Can public information programs affect risk perceptions? Journal of Policy Analysis and Management, 2(1), 41-59.

Stevenson, T., and Lennie, J. (1992). Empowering school students in developing strategies to increase bicycle helmet wearing. Health Education Research, 7(4), 555-566.

Streff, F.M., and Geller, E.S. (1986). Strategies for motivating safety belt use: the application of applied behavior analysis. Health Education Research, 1(1), 47-59.

Streff, F.M., Molnar, L.J., and Christoff, C. (1992). Increasing safety belt use in a secondary enforcement state: evaluation of a three-county special enforcement program. Accident Analysis and Prevention, 24(4), 369-383.

Streff, F.M., and Wagenaar, A.C. (1989). Are there really shortcuts? Estimating seat belt use with self-report measures. Accident Analysis and Prevention, 21(6), 509-516.

Svenson, L., Fischhoff, B., and MacGregor, D. (1985). Perceived driving safety and seat belt usage. Accident Analysis and Prevention, 17(2), 119-133.

Thuen, F., and Rise, J. (1994). Young adolescents' intention to use seat belts: the role of attitudinal and normative beliefs. Health Education Research, 2(2), 215-223.

Transportation Research Board (1981). Study of Methods for Increasing Safety Belt Use: Comments on the Study by the U.S. Department of Transportation. Washington, DC. DOT-HS-805556.

Underwood, G., Jiang, C., and Howarth, C.I. (1993). Modeling of safety measure effects and risk compensation. Accident Analysis and Prevention, 25(3), 277-288.

U.S. Department of Transportation. (1992): $70 \%$ by 92 : safety belt promotion idea sampler. Washington, DC. DOT-HS-807-801.

U.S. Department of Transportation. (1996). Traffic Safety Facts 1995: A Compilation of Motor Vehicle Crash Data from the Fatal Accident Reporting System and the General Estimates System. Washington, DC. 
Wagenaar, A.C., Streff, F.M., Molnar, L.J., Businski, K.L., and Schultz;R.J. (1987). Factors related to non-use of seat belts in Michigan. Report No. UMTRI-87-36. Ann Arbor, MI: University of Michigan Transportation Research Institute.

Wagner, H.R. (1970). Alfred Schutz on Phenomenology and Social Relations: Selected Writings. Chicago: The University of Chicago Press.

Waller, P.F., and Barry, P.Z. (1969). Seá Belts: A Comparison of Observed and Reported Use. Highway Safety Research Center, University of North Carolina, Chapel Hill, NC.

Ward, V.M., Bertand, J.T., and Brown, L.F. (1991). The comparability of focus group and survey results: three case studies. Evaluation Review, 15(2), 266-283.

Weinstein, N.D. (1980). Unrealistic optimism about future life events. Journal of Personality and Social Psychology, 39(5), 806-820.

Williams, A.F. (1972). Factors associated with seat belt use in families. Journal of Safety Research, 4(3), 133-138.

Williams, A.F., and Karpf, R.S. (1983). Deaths of teenagers as passengers in motor vehicles. Accident Analysis and Prevention, 15(1), 49-54.

Williams, A.F., Preusser, D.F., and Lund, A.K. (1984). High school students' views of laws restricting teenage driving. Joumal of Public Health Policy, 5(3), 387-395.

Williams, A.F., Wells, J.K. and Lund, A.K. (1983). Voluntary seat belt use among high school students. Accident Analysis and Prevention, 15(2), 161-165.

Winnicki, J. (1995). Safety belt use laws: evaluation of primary enforcement and other provisions. Final report. Washington, DC: National Highway Traffic Safety Administration.

Wittenbaker, J., Gibbs, B.L., and Kahle, L.R. (1983). Seat belt attitudes, habits, and behaviors: an adaptive amendment to the Fischbein model. Journal of Applied Social Psychology, 13(5), 406-421.

Womack, K.N., and Schiflett, K. (1988) Public Attitudes Toward the Texas Mandatory Safety Belt Use Law. College Station, TX: Texas Transportation Institute.

Womack, K.N. (1994). Statewide Public Opinion Survey of Occupant Restraint in Texas. College Station, TX: Texas Transportation Institute.

Womack, K.N. (1996). 1996 Survev of Front Seat Occupant Restraint Use in Eighteen Texas Cities. College Station, TX: Texas Transportation Institute. 
Yaksich, S. (1982). Teenagers under attack. Journal of Traffic Safety Education, 29(2), 7. 
